\title{
آطر معالجة الصحافة البحرينية لقضايا المؤسسات الصحية وانعكاساتها على اتجاهات الجمهور
}

\author{
فاطمة خليل أسيري \\ تحت اشر اف
}

د| دالكا عبدالوهاب

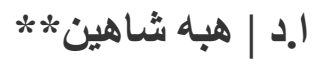

المستخلص : n (ال

تمثل الصحافة المكتوبة من أهم الوسائل الإعلامية التي يعتمد عليها الجمهور في الحصول على في

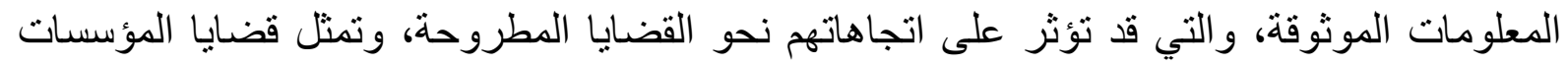
الصحية إحدى أهم القضايا المطروحة في الصحافة بصفتها مؤسسات تقدم خدمات مرتبطة بحياة الإنسان بشكل مباثر ، وقد تتأثز اتجاهات الجمهور بأطر المعالجة الاعلامية للقضايا المتعلقة بالمؤسسات الصحية في وسائل الاعلام، وبالتالي قد يؤثر على سلوكه.

لذا يمكن بلورة مشكلة الدراسة في التساؤل الآتي: ما أطر المعالجة الاعلامية للموضوعات والقضايا

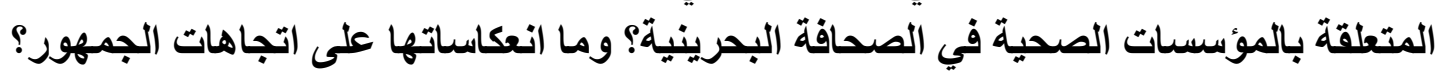

وللإجابة على التساؤل السابق اعتمدت الدراسة على منهج المسح الإعلامي، واستخدمت أداة تحليل

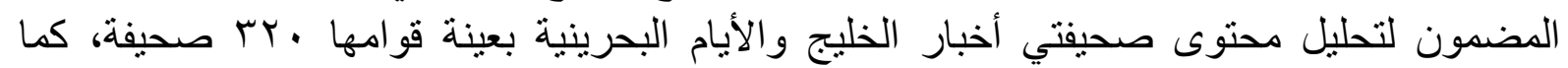
استخدمت أداة الاستبيان على عينة عشو ائية قو امها ـ . . م مبحوثًا فئة البالغين المقيمين في مملكة البحرين. توصلت أهم نتائج الدراسة التحليلية إلى عدم وجود فروق واضحة بين الصحيفتين من حيث المعالجة

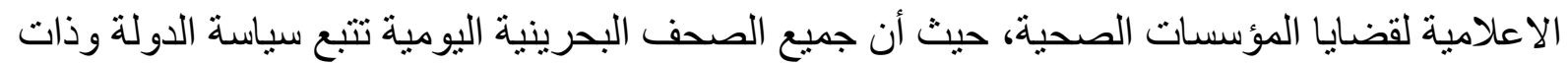
اتجاه سياسي واحد، وأن اتجاه التغطية السلبية لقضايا المؤسسات الصحية مقتصرة على المؤسسات الصحية الحكومية فقط، بينما ساهمت صحف الدار استة في ترسيخ صورة إيجابية تامة عن المؤسسات

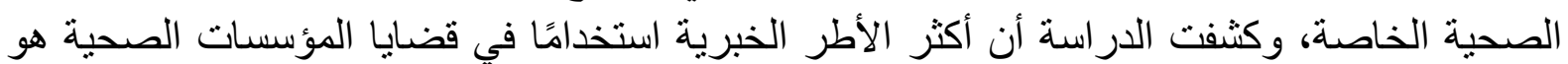
(إطار المسؤولية)، أما أقل القضايا التي تهتم بإبراز ها الصحافة البحرينية هي قضايا (الأخطاء الطبية و الإهمال الطبي) (بؤه)

$$
\begin{aligned}
& \text { *احثة دكثور اهـ قسم علوم الاتصال و الاعلام- كلية الآداب - جامعة عين شمس } \\
& \text { fatima.aseeri@gmail.com } \\
& \text { ***استاذ ورئيس قسم الاتصال و الاعلام_ كلية الآداب- جامعة عين شمس الآنس }
\end{aligned}
$$

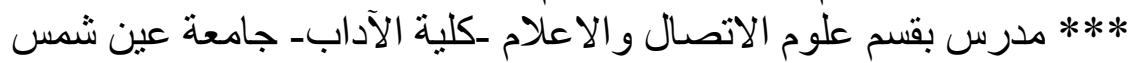




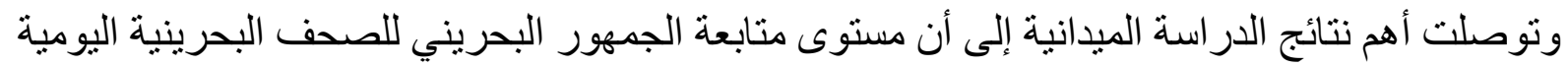

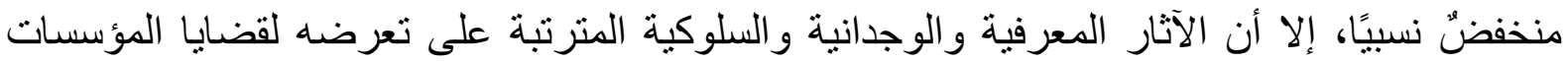

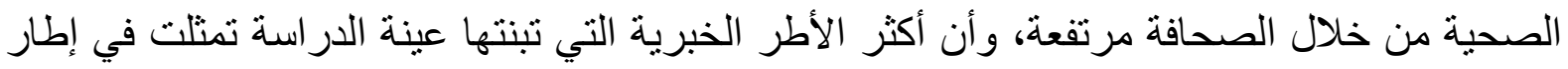

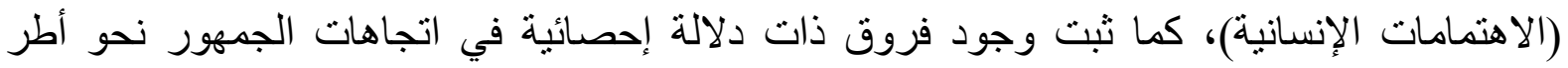
معالجة الصحافة البحرينية لقضايا المؤسسات الصحية تعزى للمتغير دات دلات الديمو غر افية.

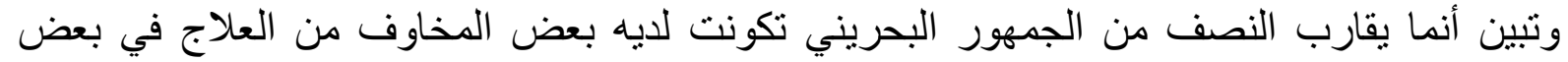

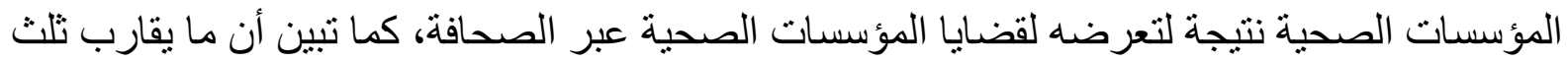

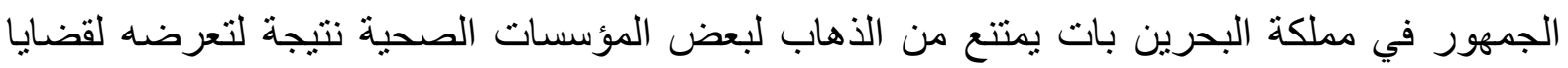
المؤسسات الصحية عبر الصحافة.

الكلمات الدالة: أطر المعالجة، الصحافة، المؤسسات الصحية، اتجاهات، الجمهور

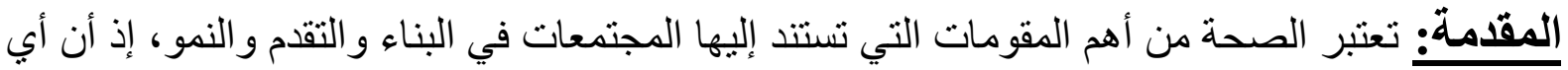

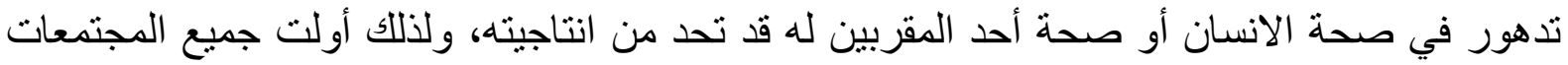
المتقدمة اهتمامًا بالخدمات الصحية، باعتبار ها من أهم الخدمات الاساسية التي يحتاجها جميع الأفر اد. التها.

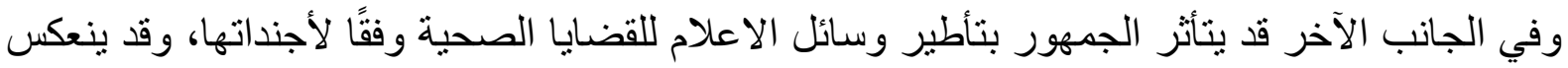

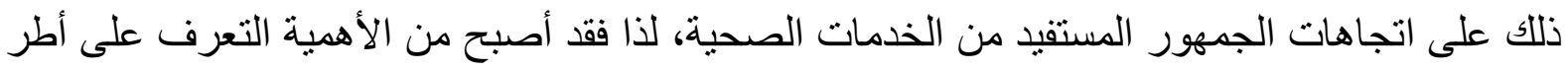

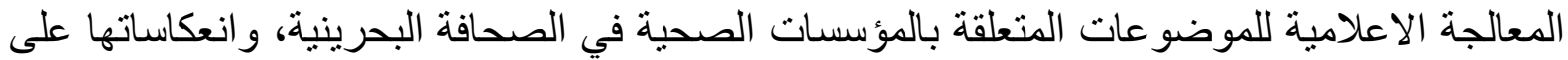

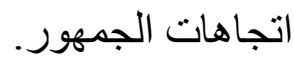

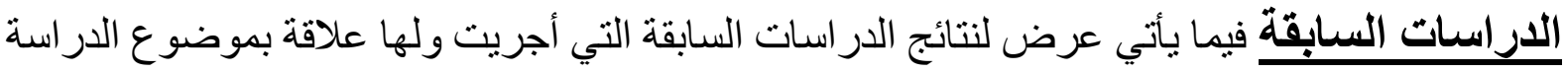

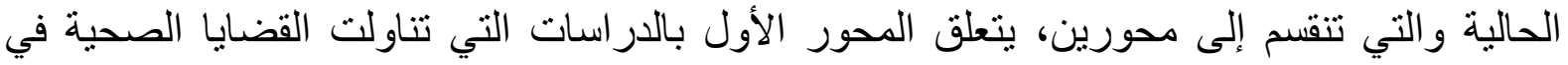

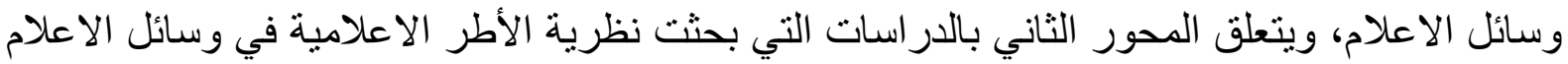

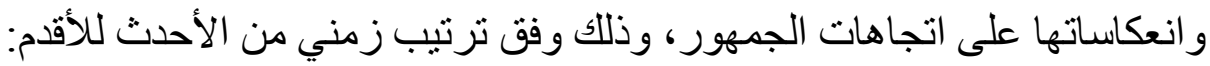

\section{المحور الأول: الدراسات التى تناولت القضايا الصحية في وسائل الاعلام}

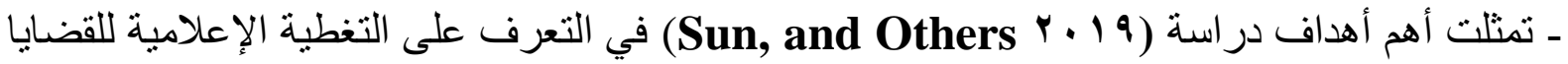

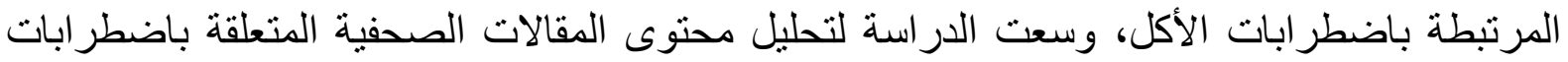

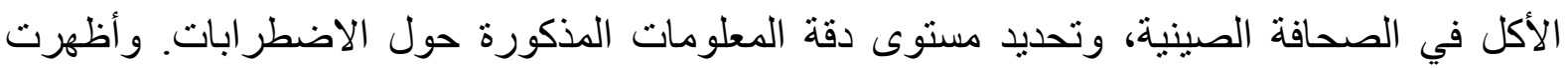
النتائج أن الجزء الأكبر من التقارير الإخبارية عن اضطر ابات الاكل متعلقة حول اضطر الاضطراب (فقدان 


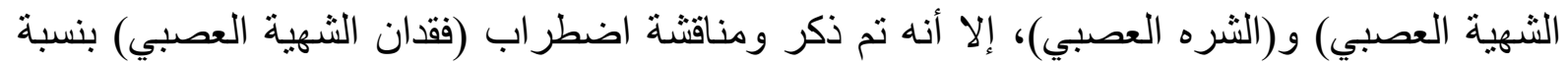

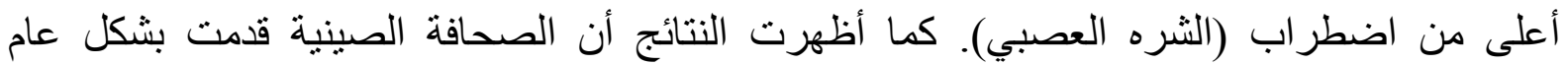

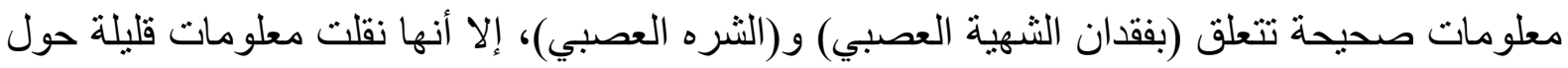

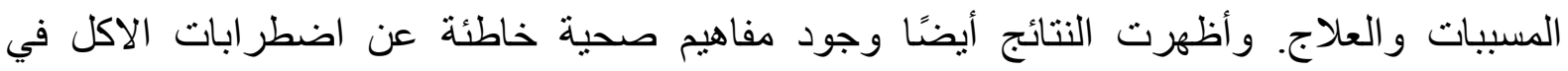

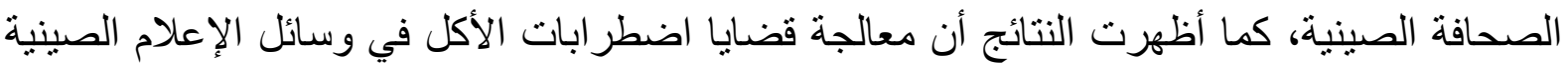

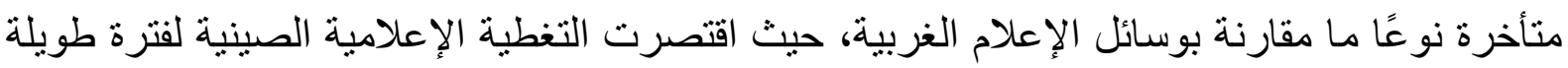

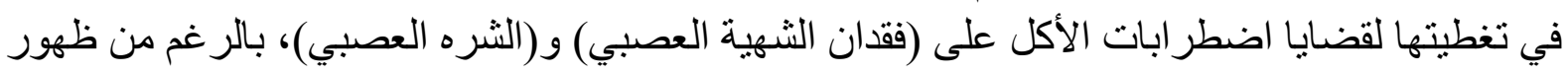

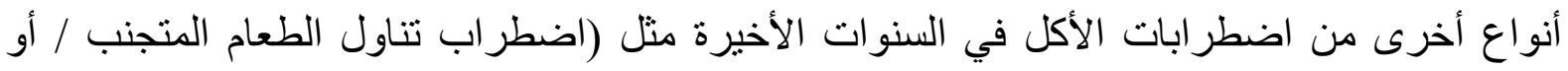

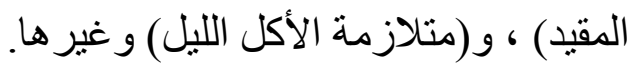

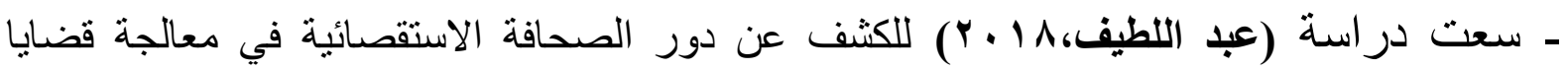

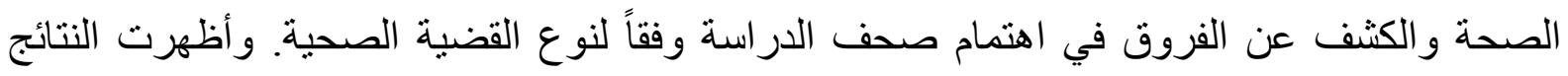

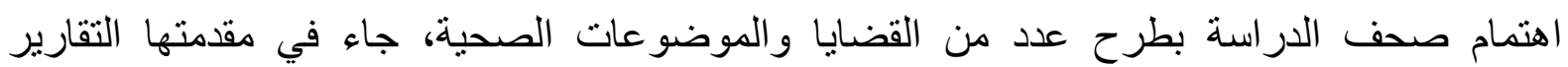

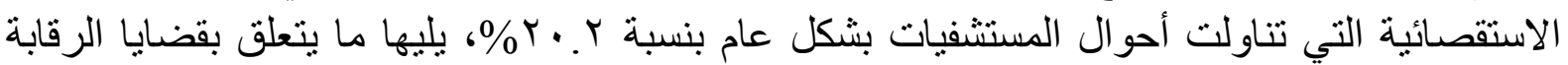

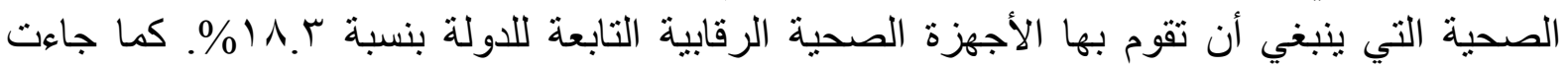

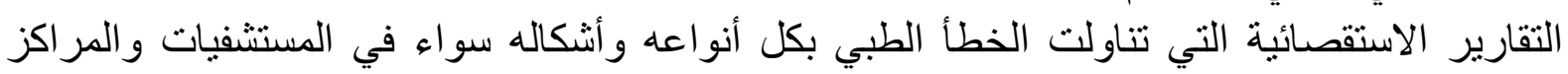

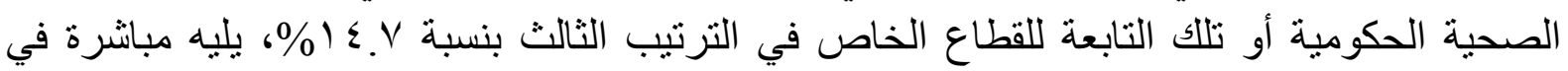

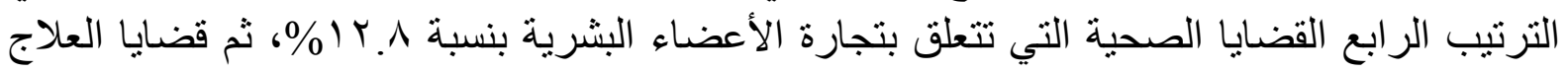

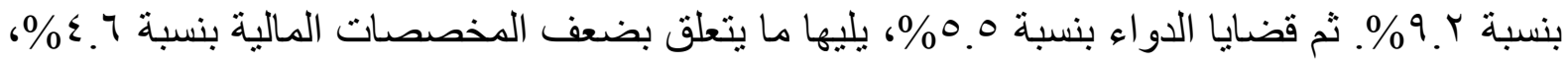

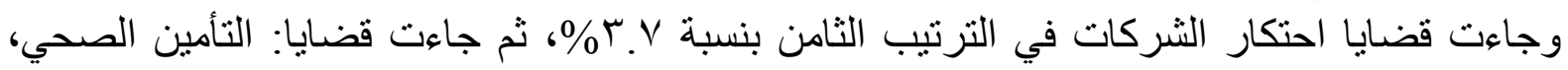

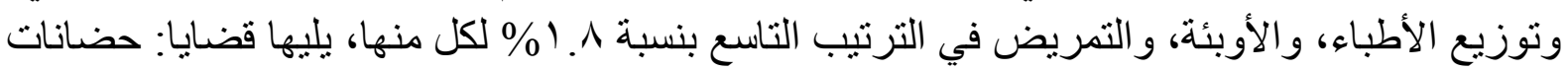

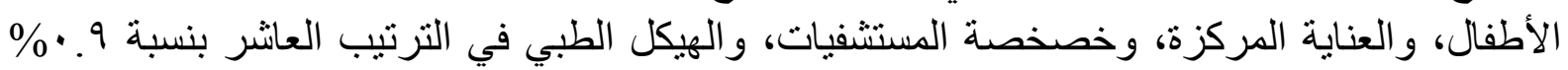

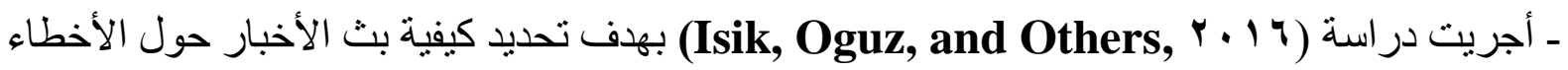

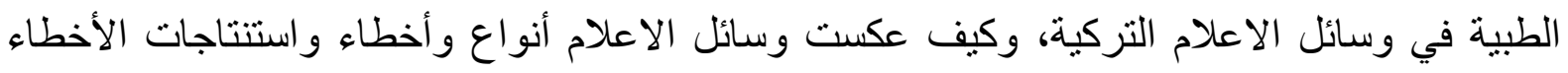

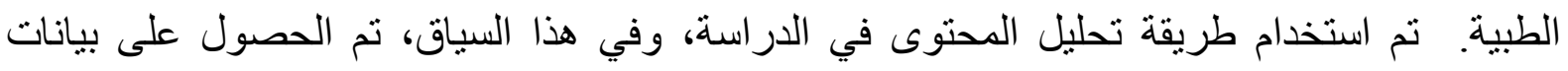

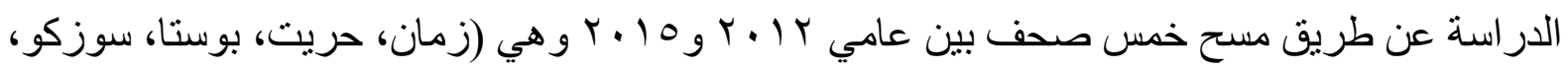

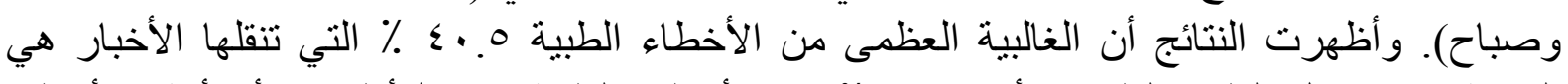

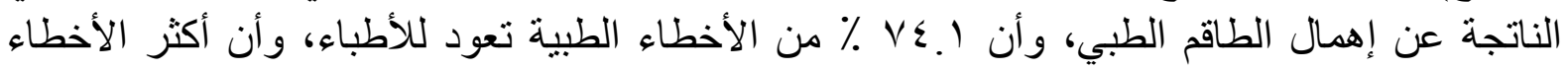

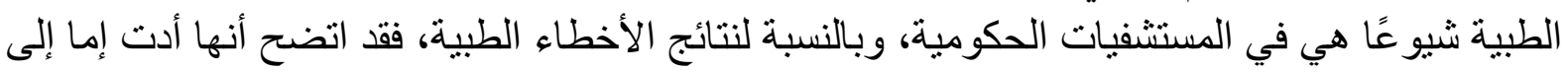

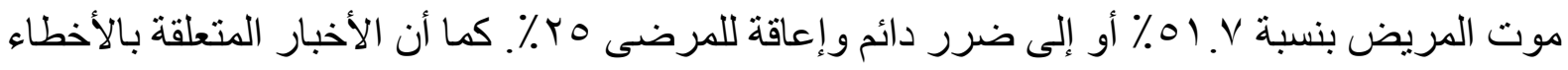

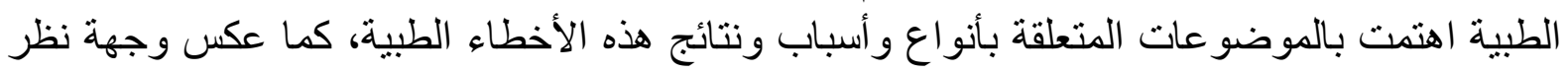

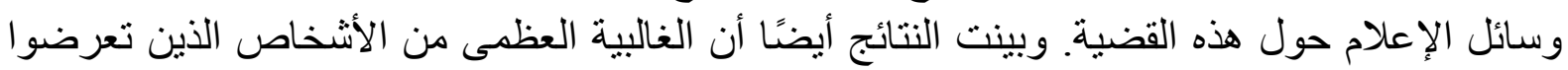

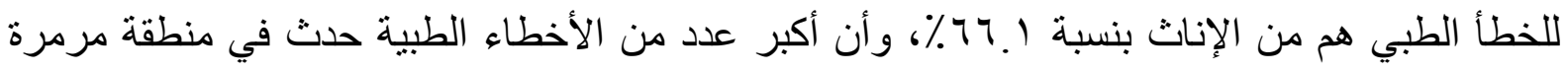




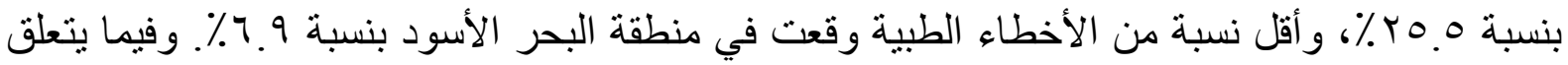

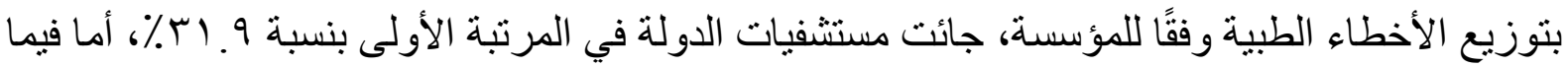

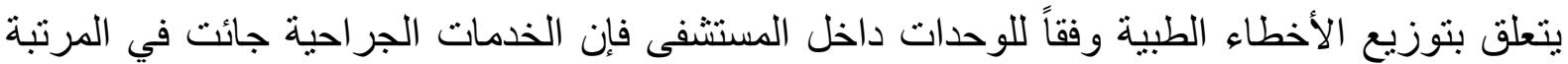

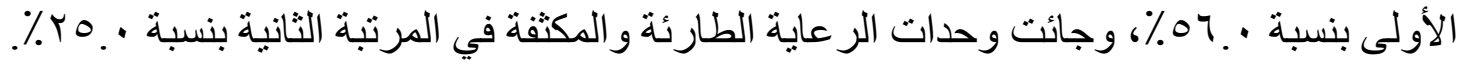

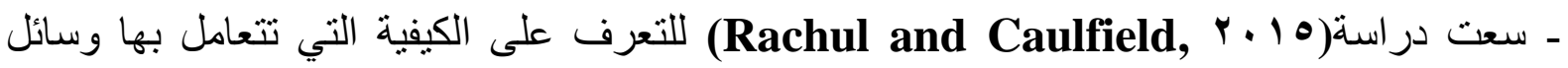

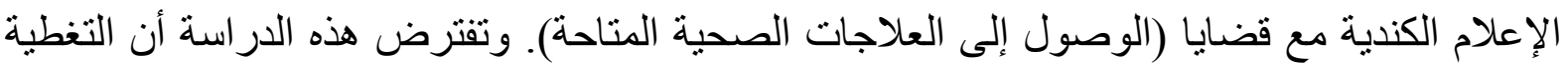

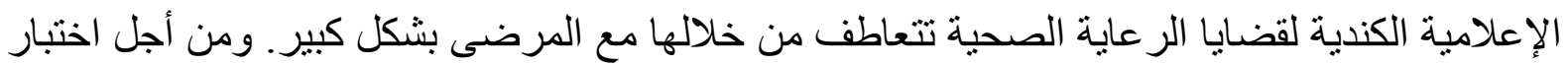

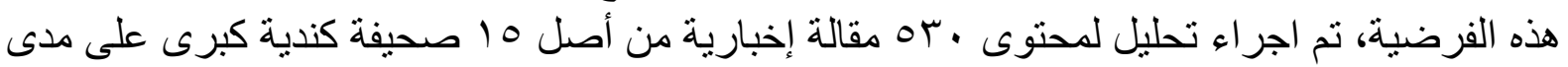

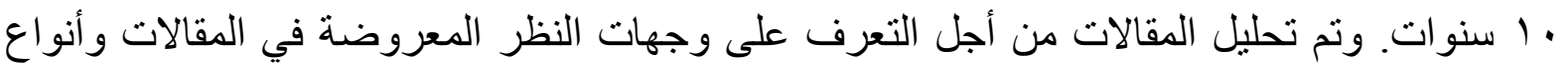

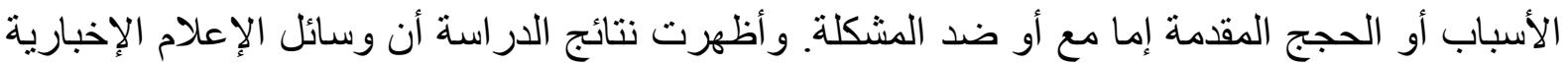

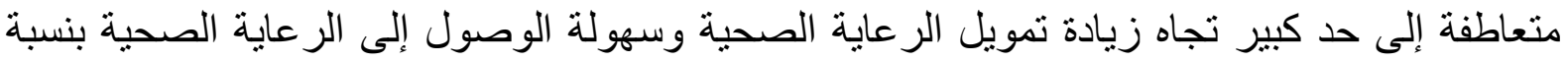

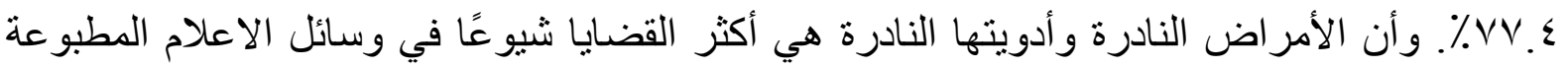

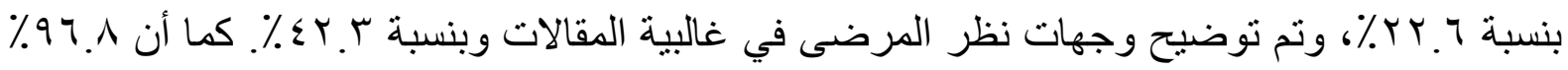

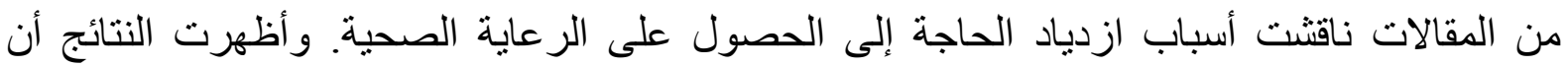

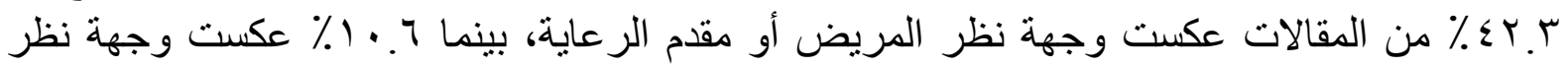

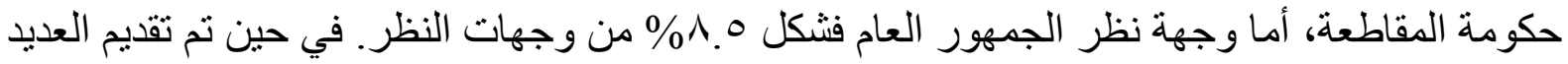

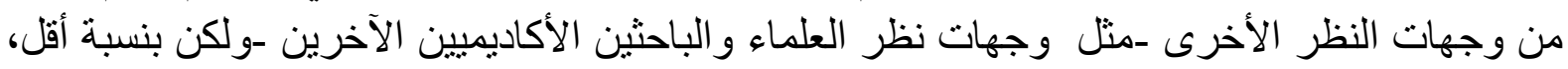

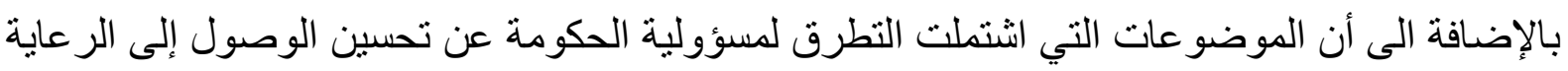

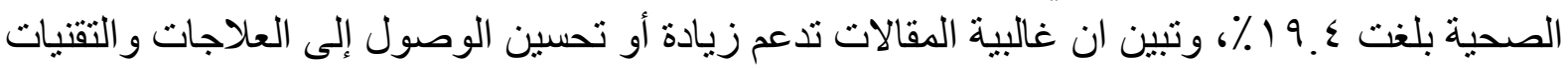

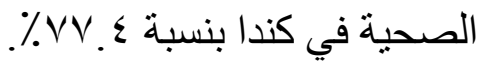

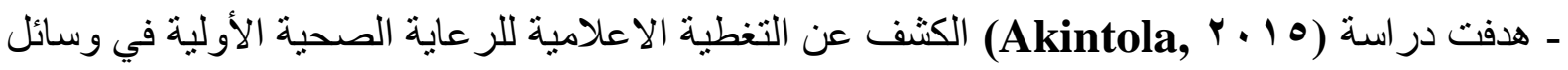

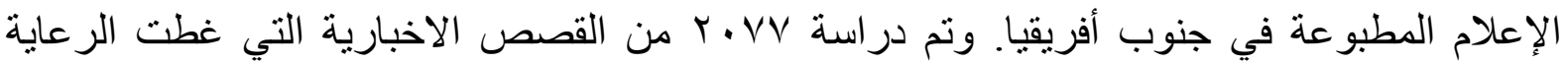

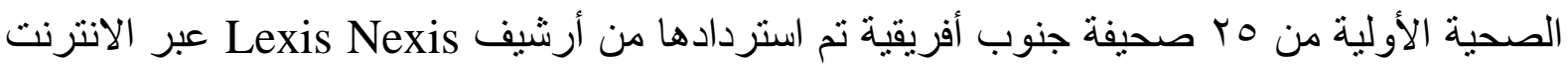

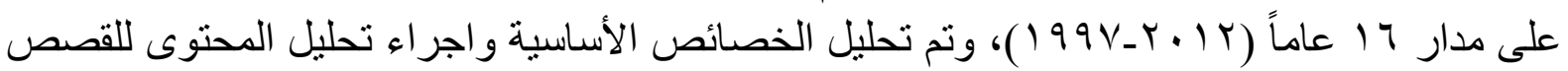

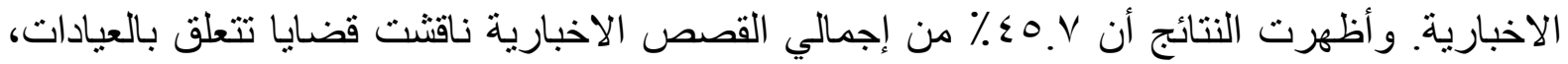

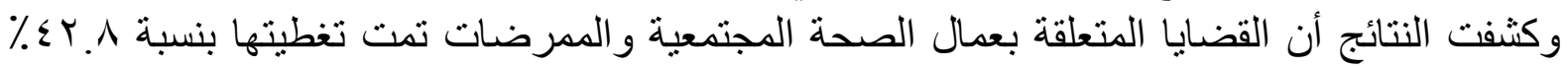

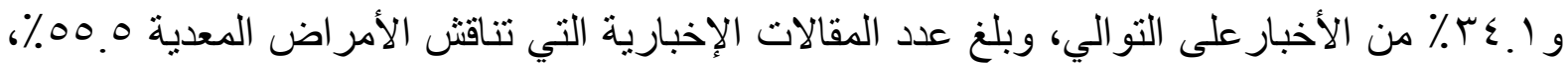

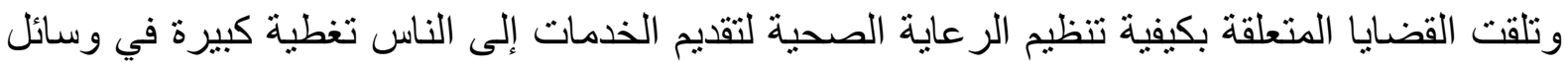

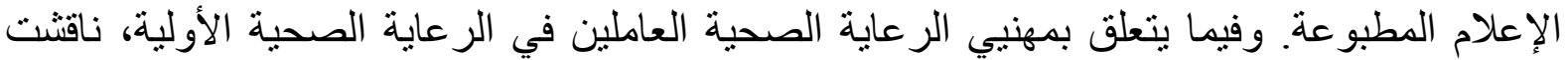

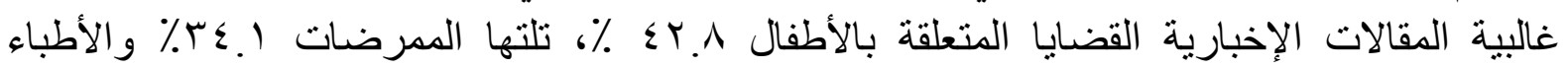

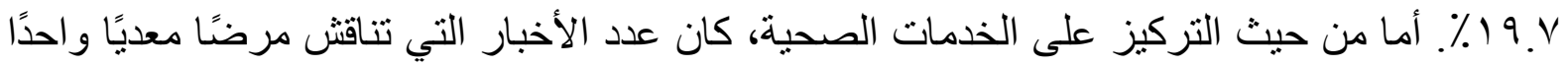

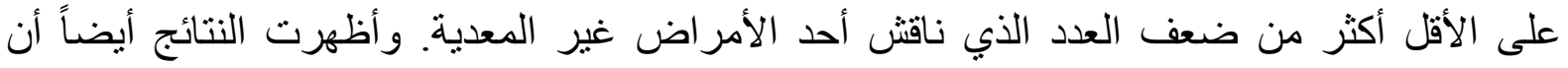

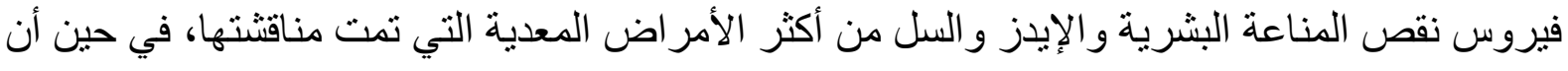


أكثر الأمر اض غير المعدية التي نوقتت هي أمراض (الصحة العقلية). كما أظهرت النتائج أن القضايا

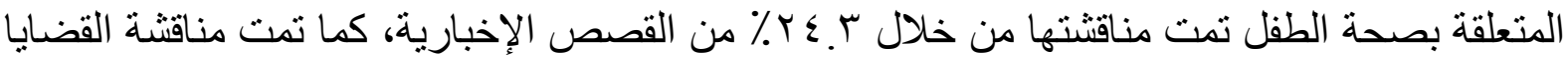

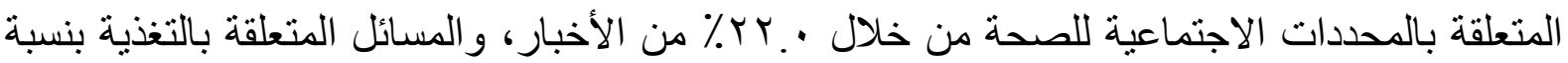

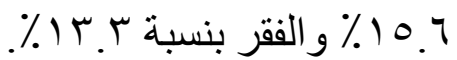

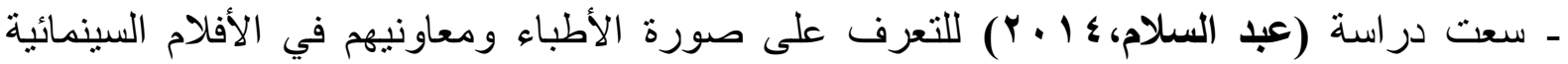

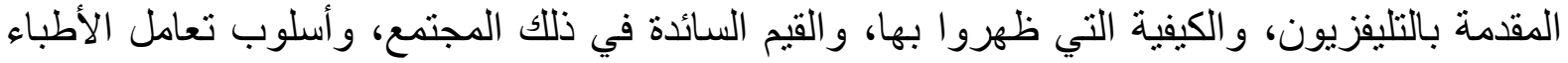

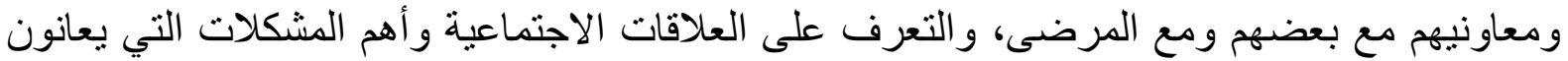

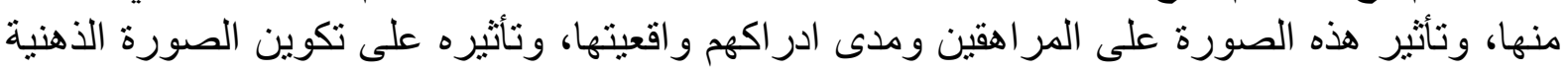

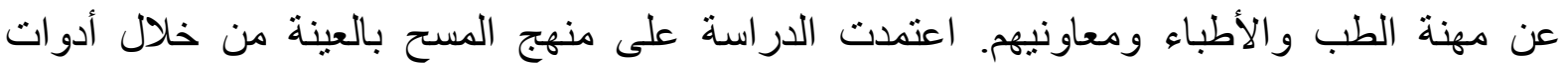

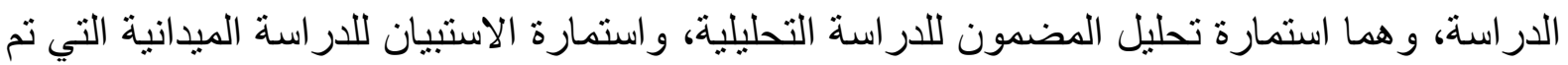

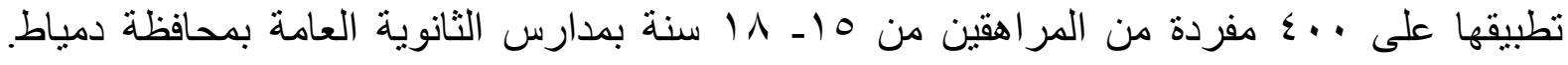

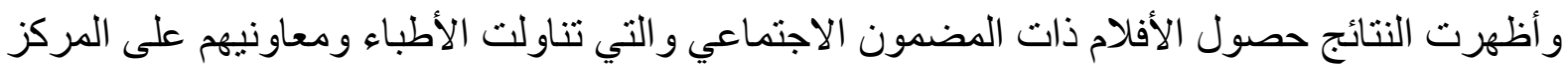

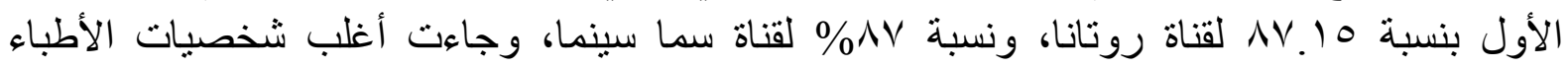

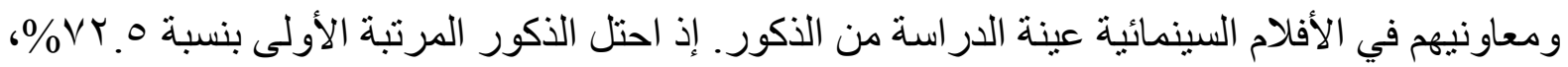

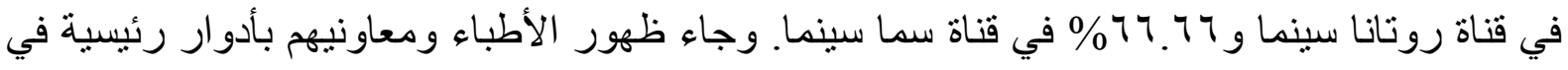

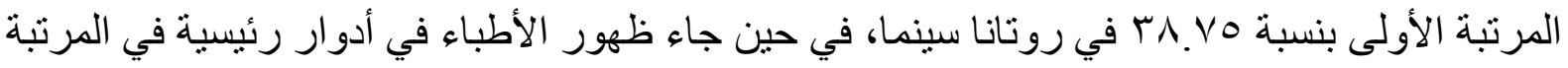

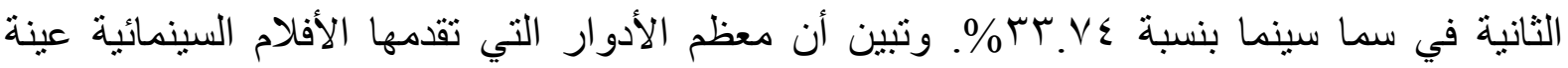

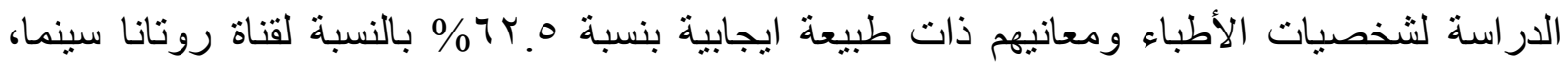
وبنسبة 709 \% \% بالنسبة لقناة سما.

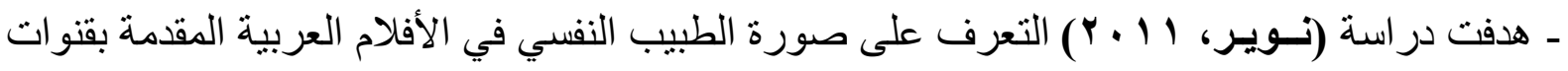

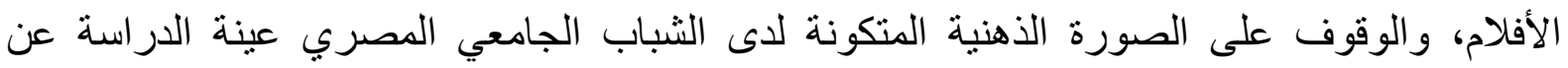

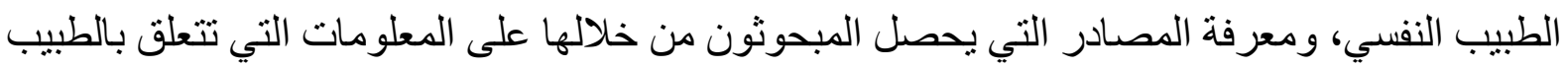

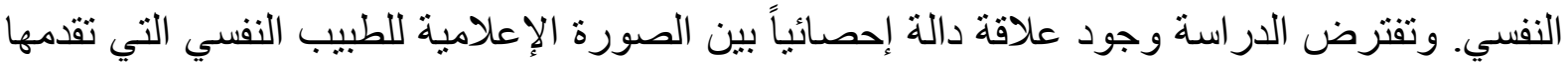

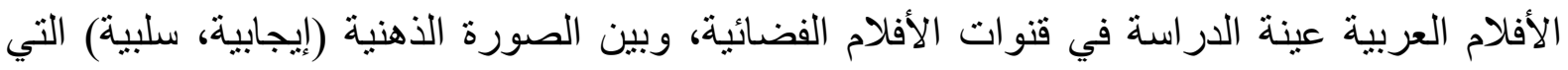

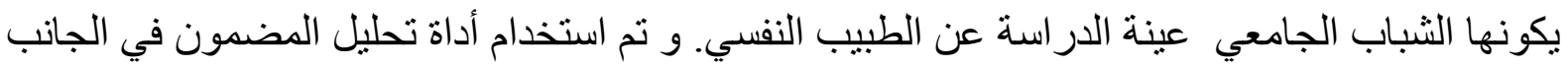

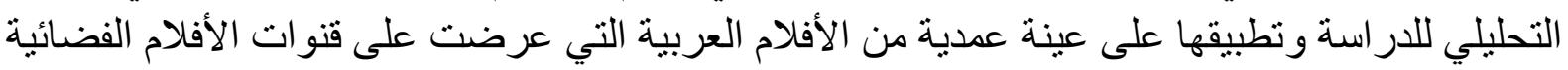

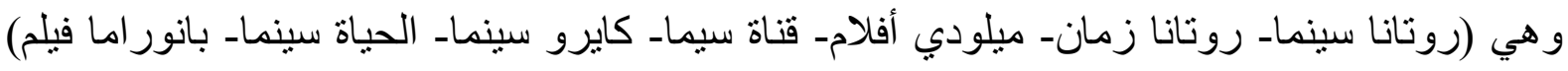

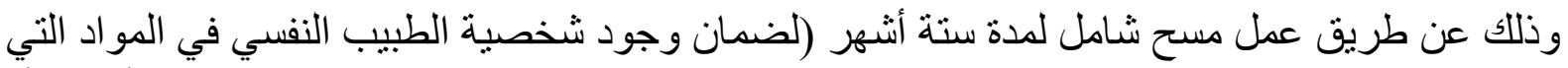

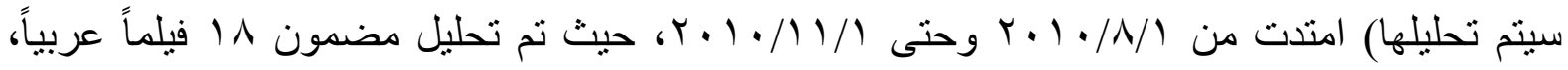

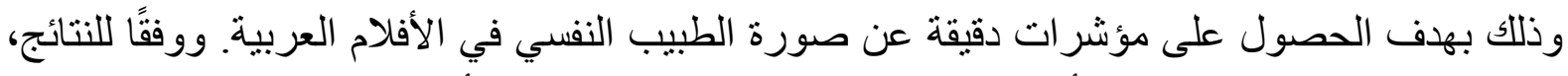

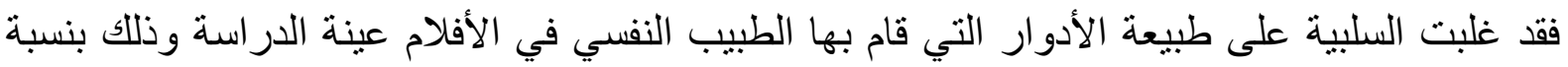

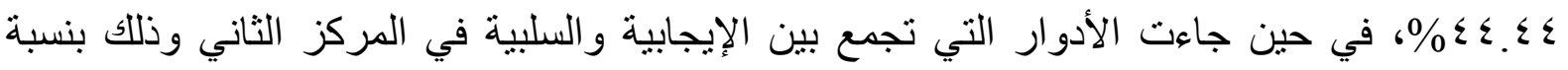

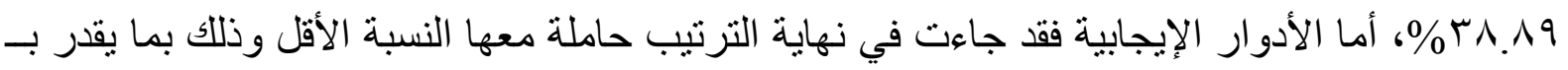




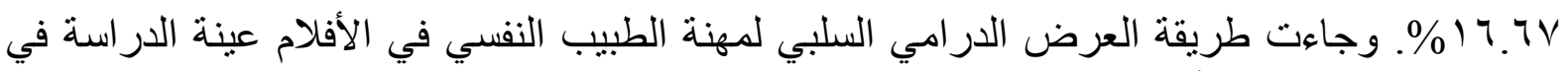

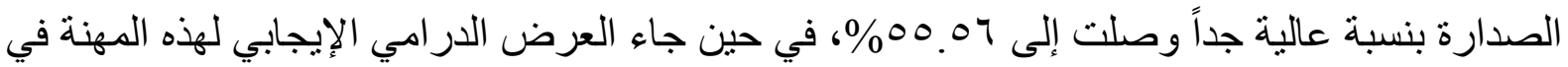

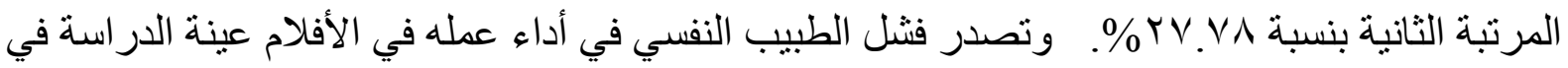

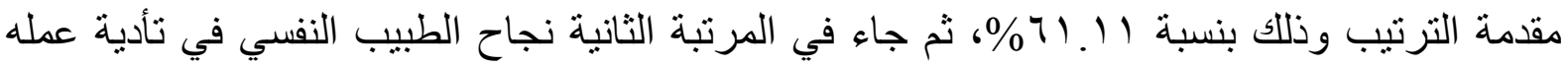

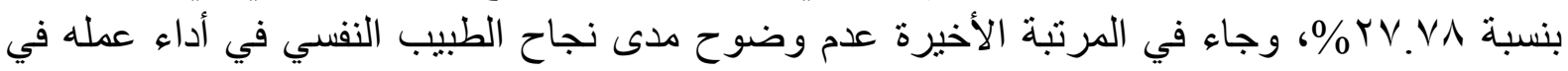

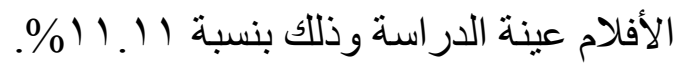

المحور الثاني: الدراسات التي تناولت نظرية الأطر الخبرية وانعكاساتها على اتجاهات الجمهور.

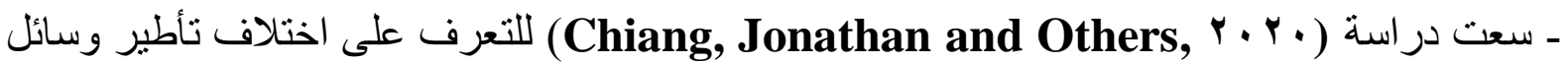

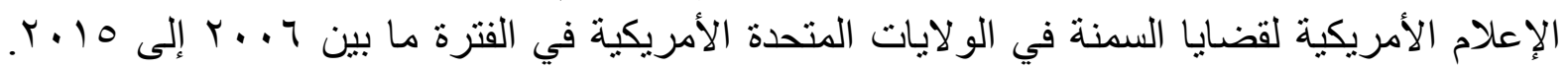

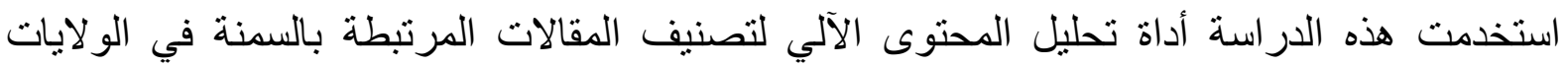

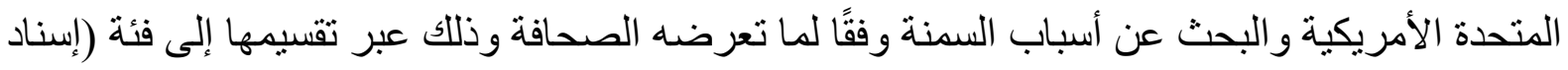

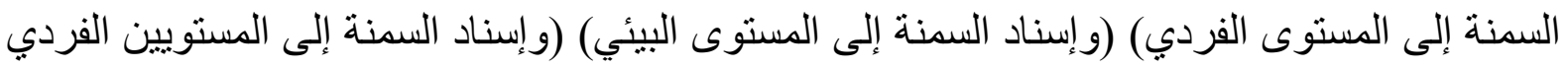
و البيئي معًا).

ـ أظهرت نتائج الدراسة التحليلية أن مصادر الاعلام الأمريكية تركز بشكل كبير على التأطير الفردي

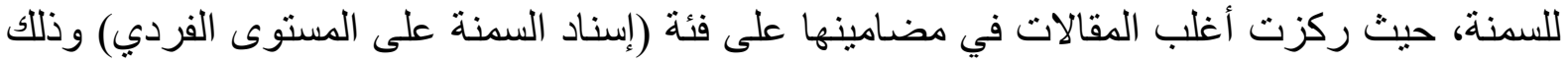

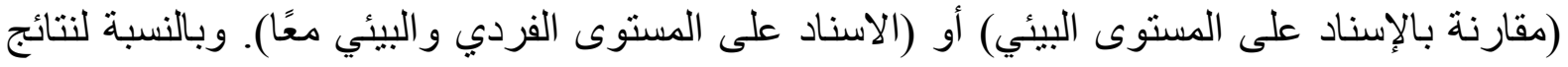

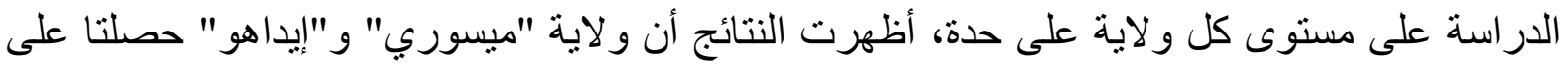

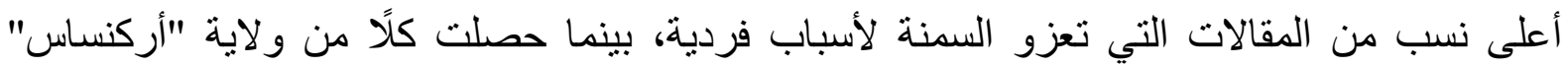
و "ويسكونسن" و "نيفادا" على أعلى نسب من المقالات التي تعزو السمنة لأسباب بيئية.

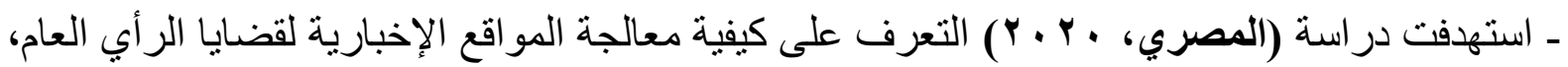

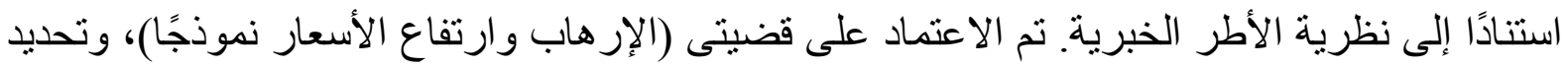

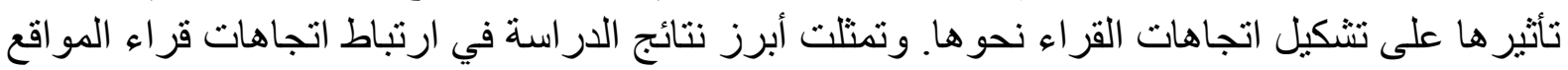

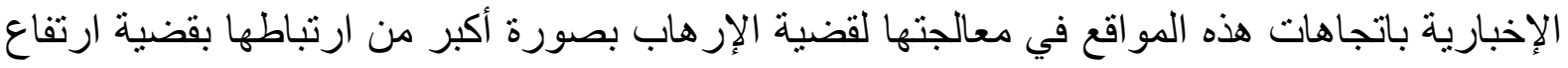

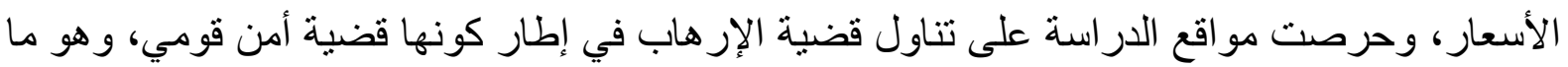

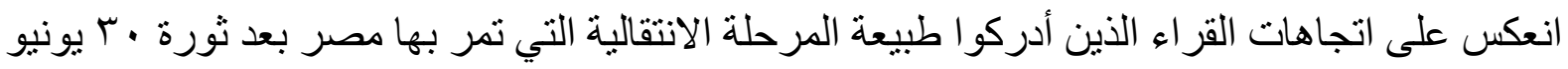

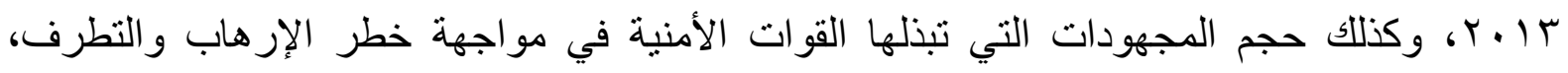




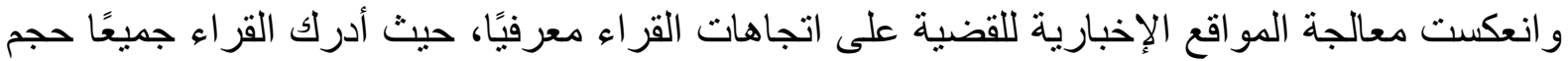

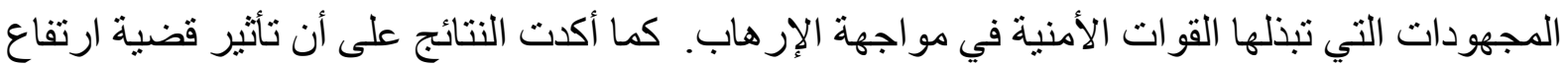

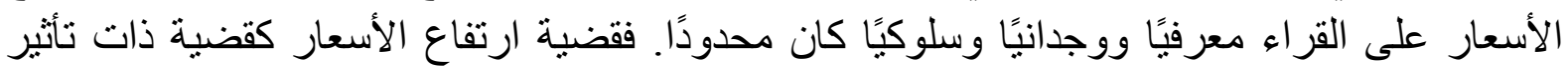

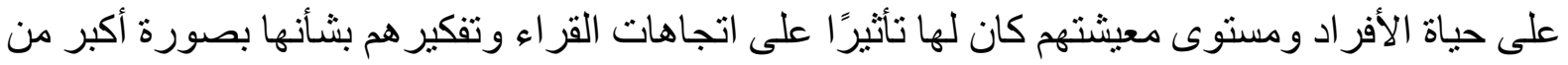

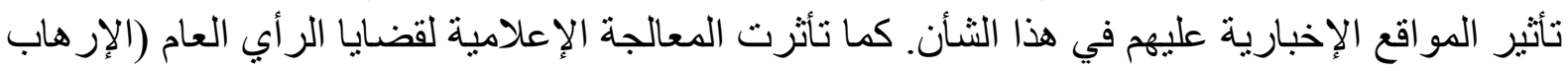

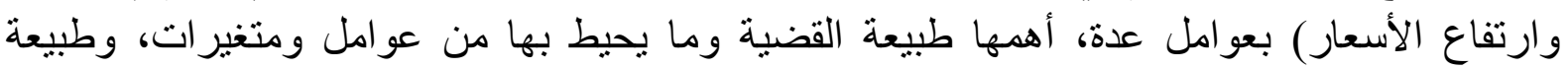

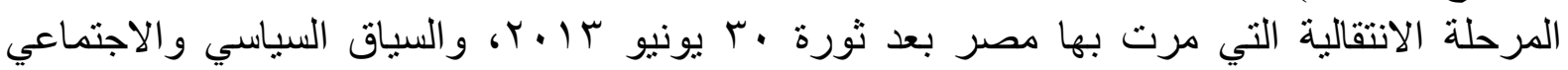

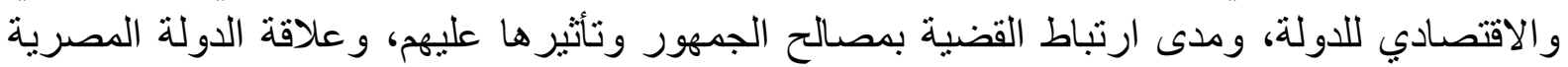

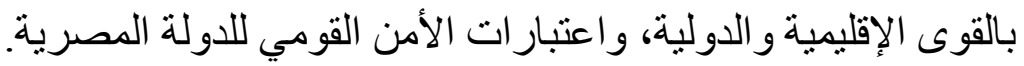

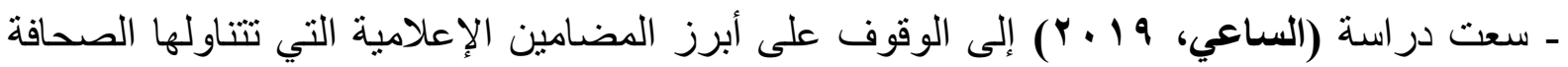

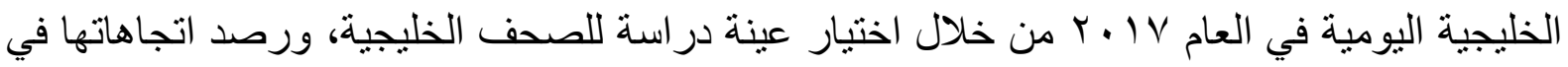

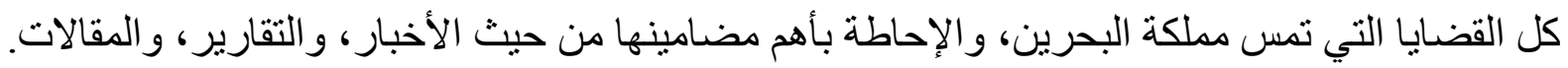

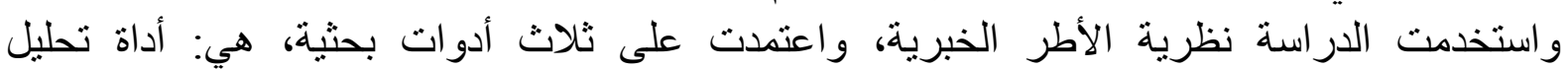

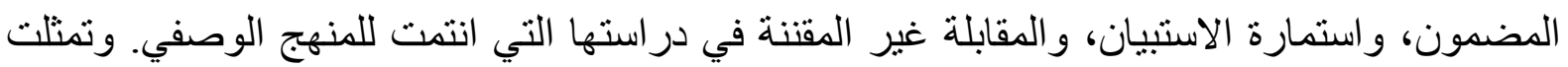

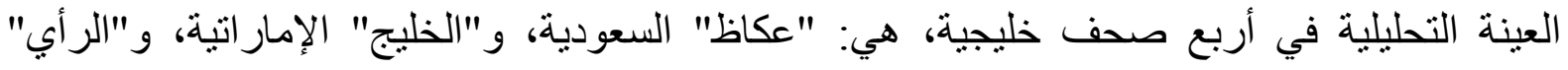

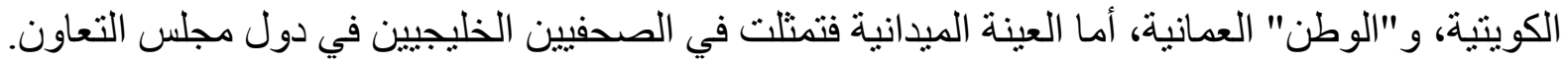

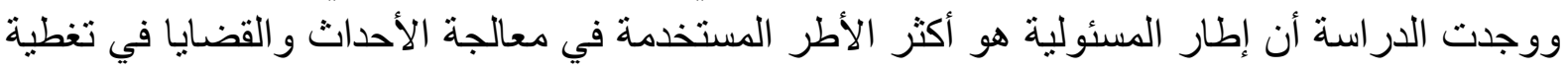

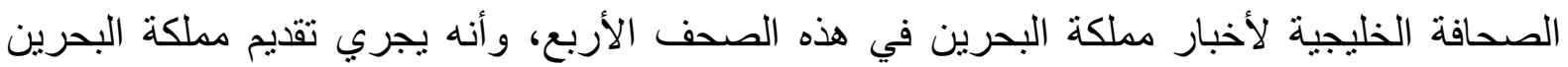

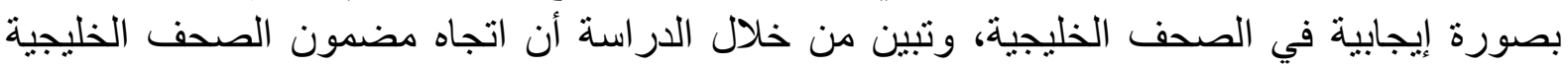

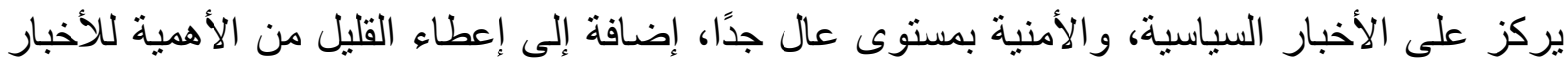

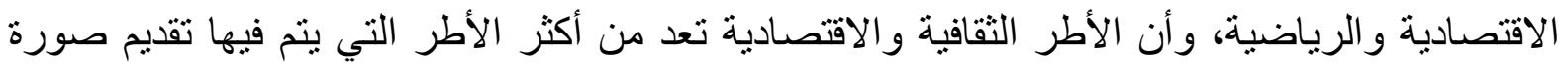

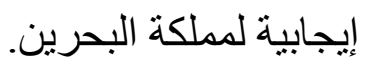

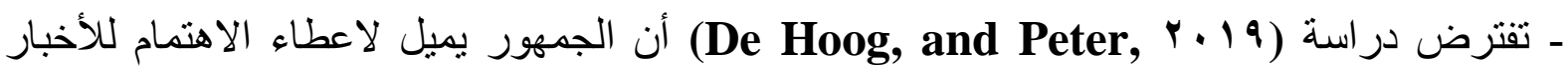

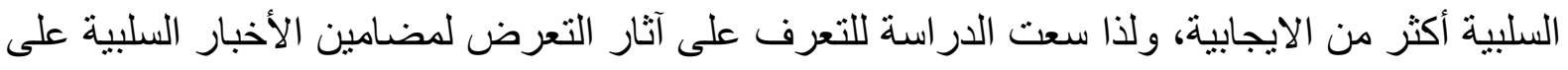

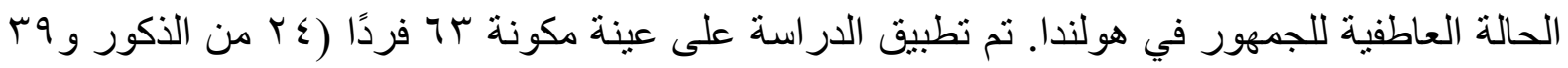

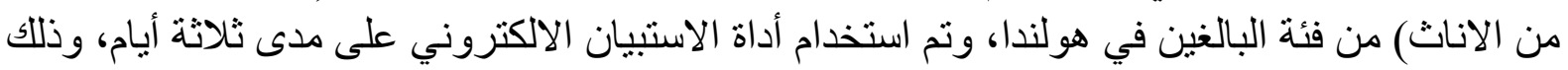

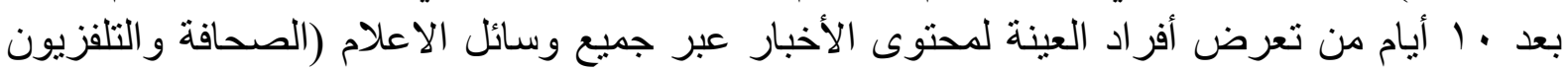

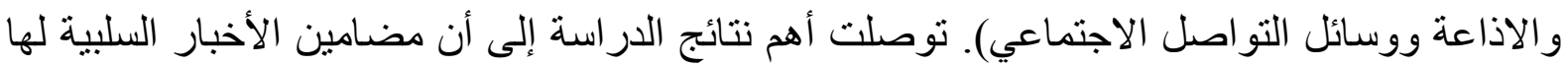

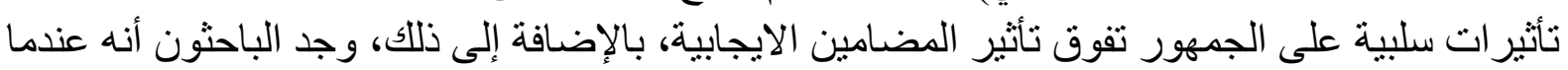

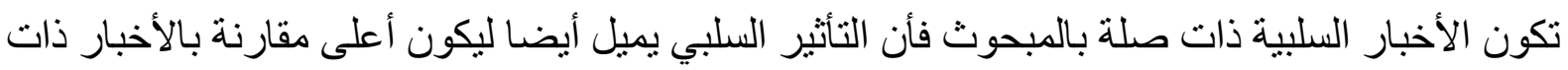

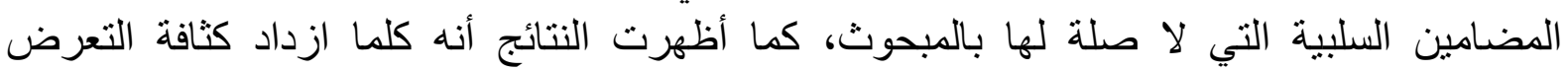

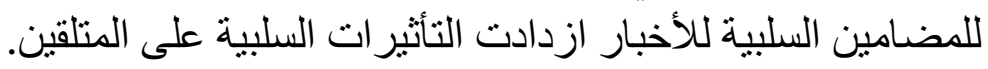


ـ تحددت مشكلة در اسة (عطية، 9 ( ب Y) في سعيها لرصد أطر تقديم قضايا العشو ائيات في الصحافة

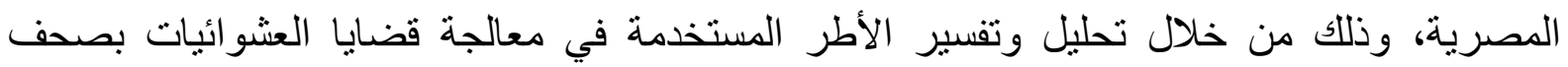
الدراسة، وتحليل اتجاهات الجمهور نحوها. وسعت الدراسة التحليلية للتعرف على التى الإطار الخبري

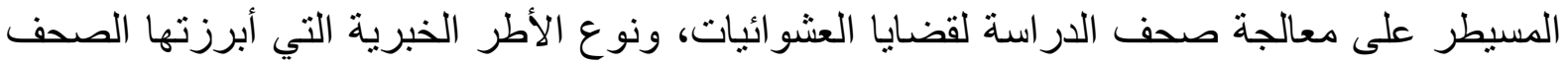

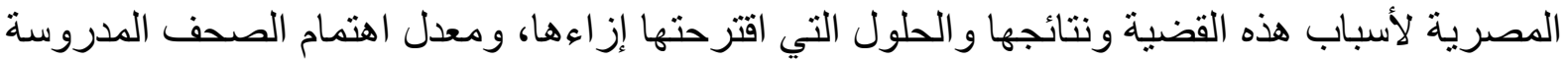
بظاهرة العشو ائيات وأسباب ذللك، و التعرف على اتجاهات الجمهور نحو أطر تقديم قضايا العشو ائيات في الصحافة المصرية، أما الدر اسة الميدانية، فسعت للتعرف على التى اتجاهات الجمهور نحو أطرات ألقر تقديم قضايا العثوائيات في الصحافة المصرية. وتفترض الدراسة وجود فروق ذات دلالة إحصائية في اتجاهات المبحوثين حول الأطر التي توظفها الصحف في معالجة قضايا العثو ائيات تعزى لخصائهم الديمو غر افية

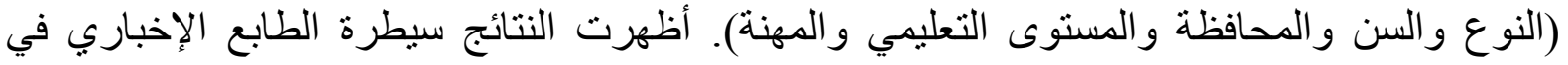
معالجة قضايا العشوائيات، كما كثفت وجود تقارب أو اتفاق عرفي بين القائمين بالاتصال على تبنى تبادل

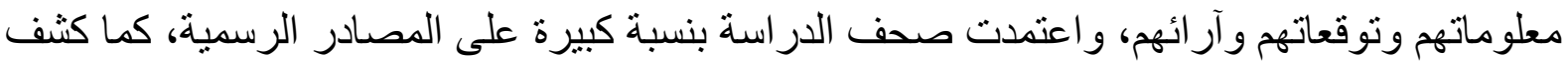

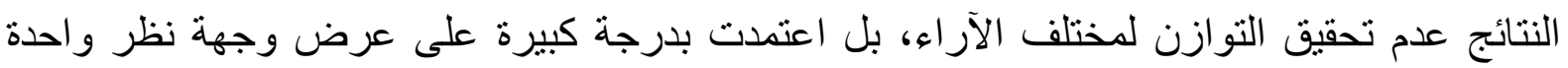

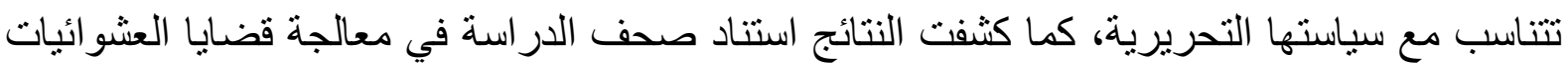
إلى أطر مرجعية توجه طبيعة ممارستها الصحفية وتتتوع هذه الأطر التي تعد بمثابة المتغير ات المستقلة

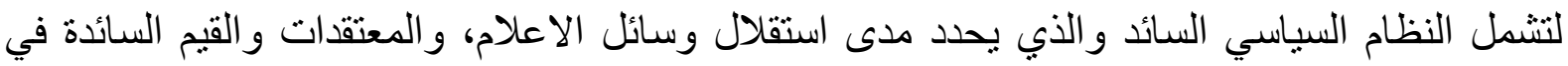

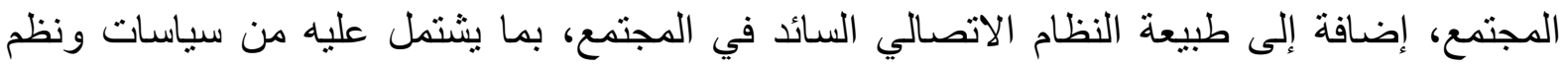

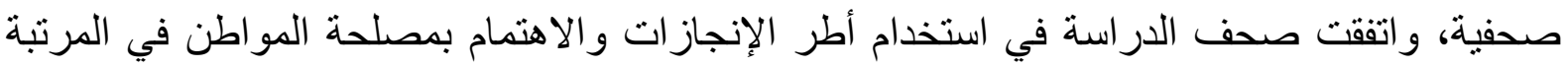

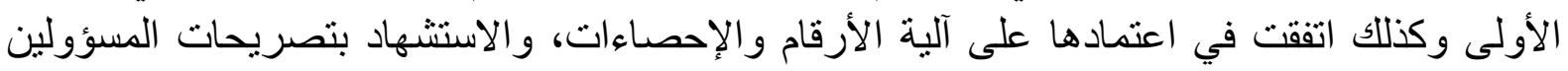

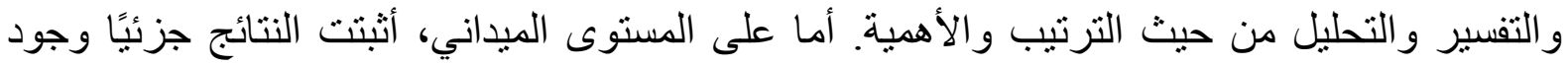
اختلاف في اتجاهات المبحوثين حول الأطر التي توظفها الصحف في معالجة قضايا العشوائيات وفقًا لاختلاف خصائهم الديمو غر افية (النوع و السن و المحافظة و المستوى التعليمي و المهنة).

ـ هدفت در اسة (المطيري، 9 ( ـ ب ) إلى التعرف على أطر المعالجة الإعلامية للقضايا السياسية المحلية

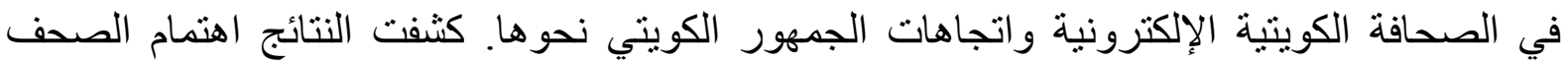

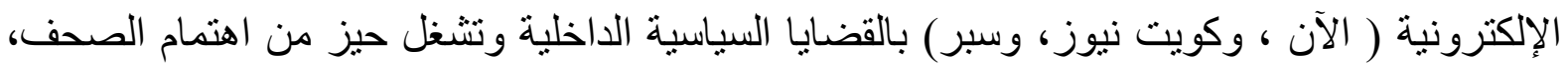

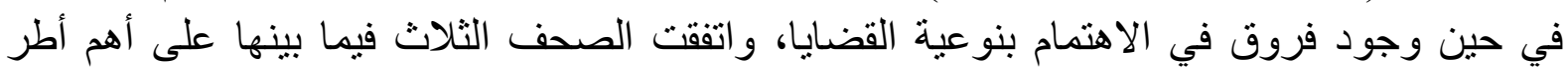

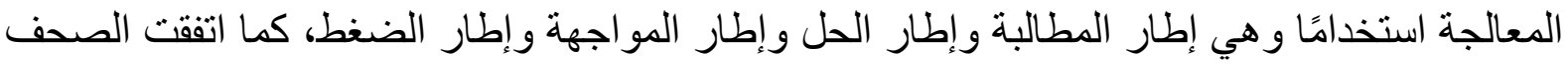

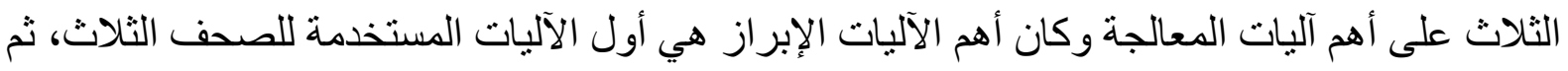
آلية الحثد ثم آلية التأكيد والتأييد، في حين اختلفت التهات الصحف الثنلاث فيما بينها في استخدام الفنون

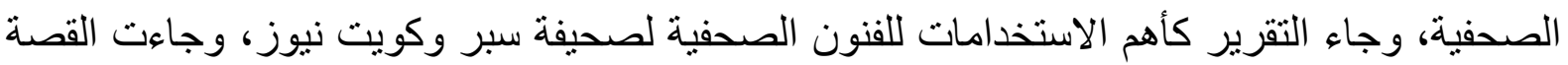

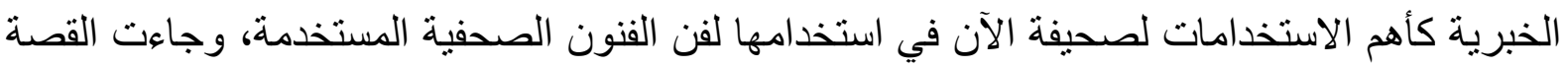
الإخبارية في المرتبة الثانية كأهم الاستخدامات للفنون الصحفية لصحيفة سبر وكويت نيوز ، في حين جاء الخبر الصحفي في المرتبة الثانية كأهم الاستخدامات لصحيفة الآن في استخدامها لفن الفنون الصحفية 
المستخدمة وأظهرت النتائج أن أهم وظائف أطر المعالجة في القضايا السياسية للصحف الثناث هي مقترح حل ثم الوظيفة التقييمية ثم الوظيفة التنبؤية، وجاء اتجاه المضمون الخبري في المرتبة الأولى الإيجابي ثم المحايد ثم السلبي لصحيفة سبر والآن، ولكن اختلفت معهم صحيفة كويت نيوز حيث جاء اتجاه المضمون الخبري محايد ثم إيجابي ثم سلبي.

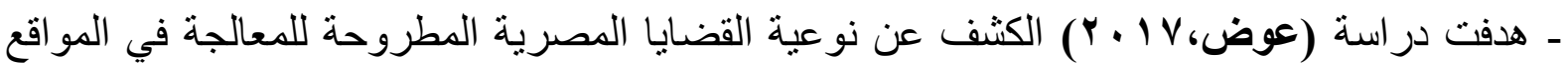
الصحفية الغربية، والكثف عن المصادر الإعلامية للقضايا المصرية في المواقع الصحفية الغربية، ومعرفة الأطر المرجعية في عرض القضايا المصرية بالمواقع عينة الدراسة، والتعرف على على اتجاه

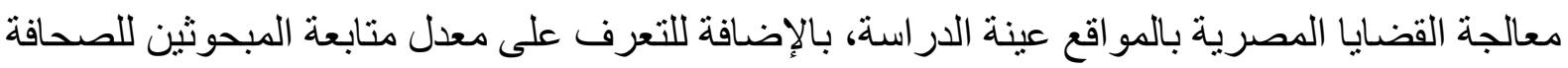
الغربية الإلكترونية. وأظهرت النتائج تغلب الثكل الصحفي القائم على التقارير الإخبارية عن باقي

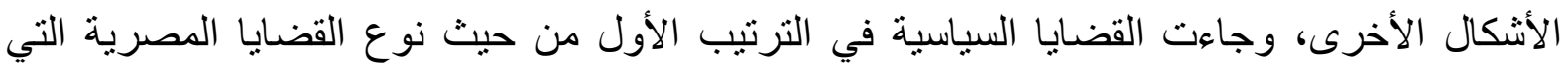
عالجتها المواقع الالكترونية محل الدراسة ثم القضايا العسكرية ثم الاقتصادية فالسياحية يليها الحقوقية وأخيراً القضايا الاجتماعية، وجاءت صحيفة الواشنطن بوست في الترتيب التئ الأول كأول الصحف

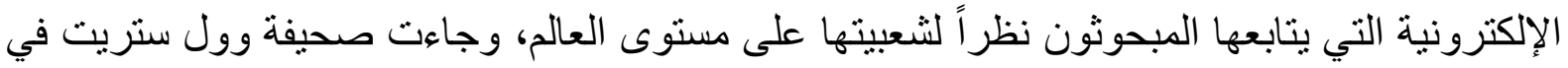

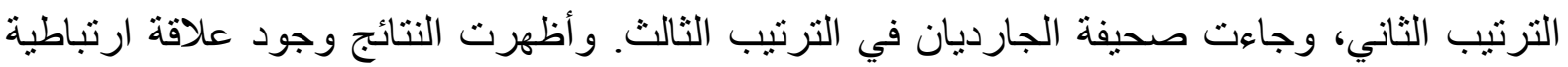

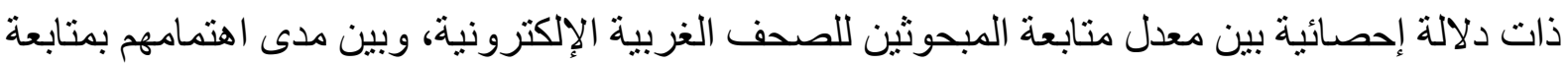

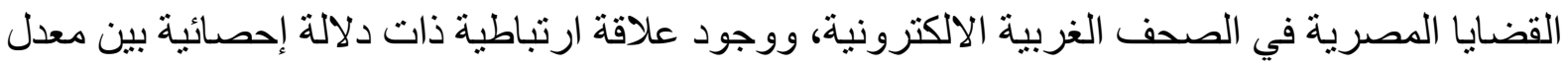
متابعة المبحوثين للصحف الغربية الإلكترونية وبين مدى وجود تفاعل بين هذه الصحف الغربية و المستخدمين لها.

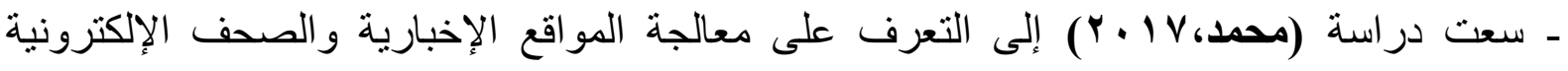

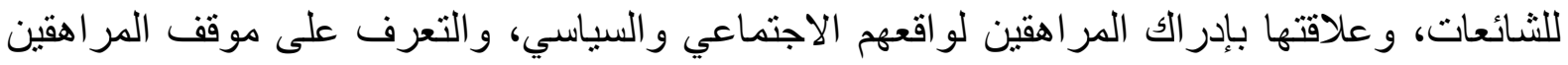

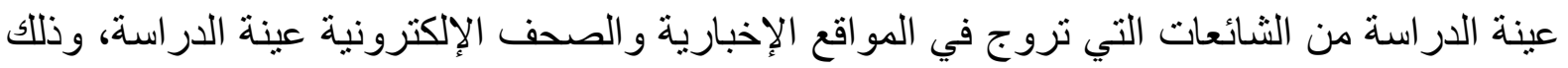
حسب اختلاف المستوى الاجتماعي والاقتصادي ونوع التعليم و غير ها من المتغيرات الديموغر افية.

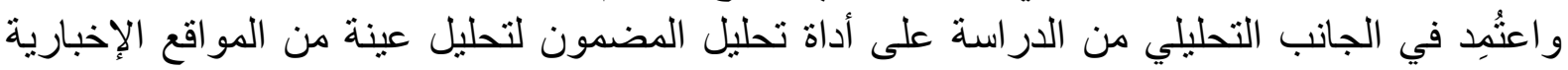
منمثلة في موقع "فيتو "، وعينة من الصحف الإلكترونية متمنلة في "اليوم السابع"، في الفترة

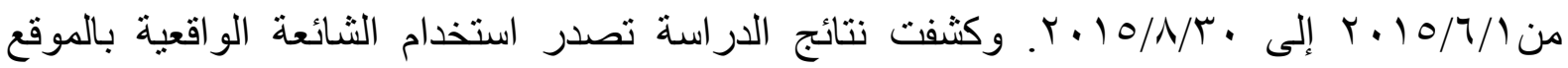
الإخباري و الصحيفة الإلكترونية الثائعات المرصودة، و غلب الاتجاه السلبى كإطار للمعالجة في تناول

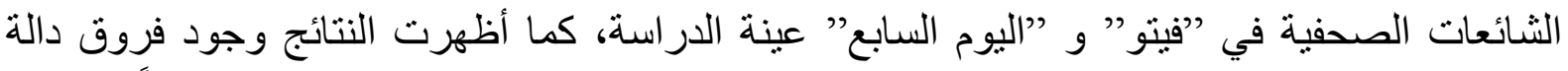
إحصائيًا بين متوسطات درجات المبحوثين على مقياس إدر الك الواقع السياسي والاجتماعي تبعاً لدرجات خطورة الشائعات السياسية و الاجتماعية.

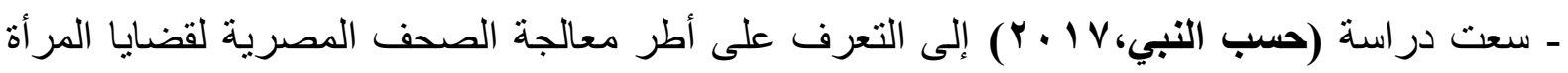

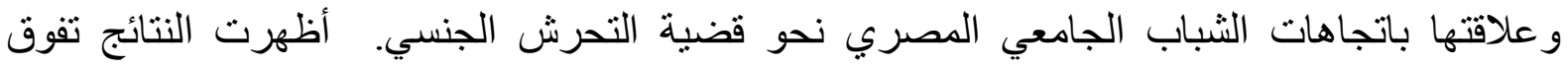

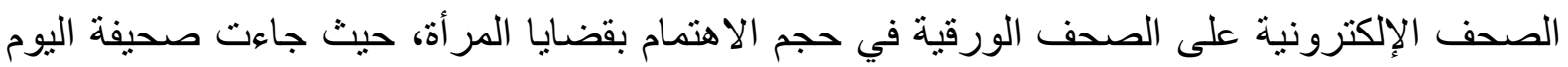

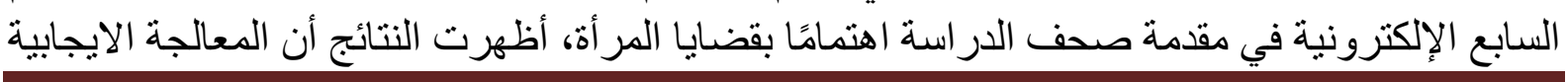


لقضايا المر أة جاءت بالترتيب الأول بمعظم صحف الدراسة، وجاءت المعالجة المحايدة بالترتيب الثاني،

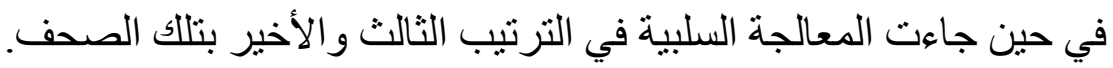

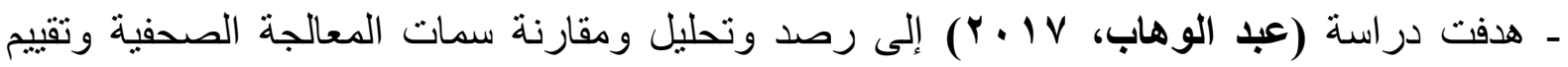

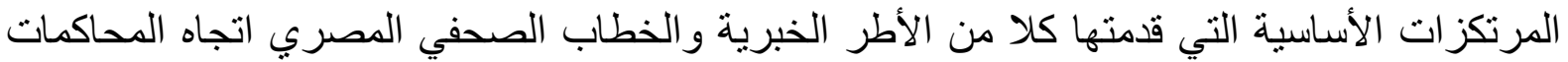

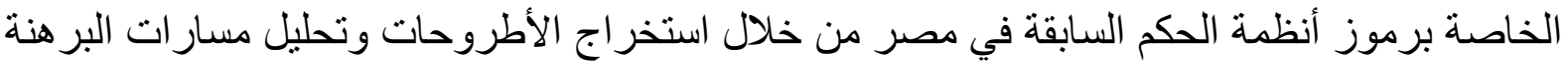

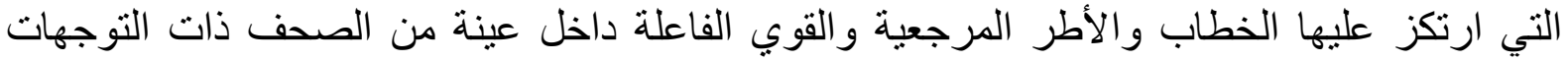

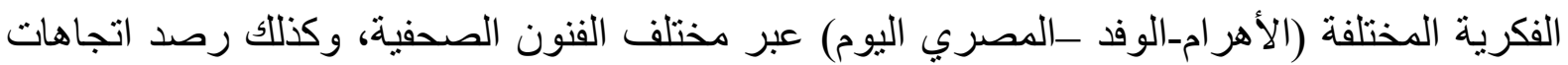

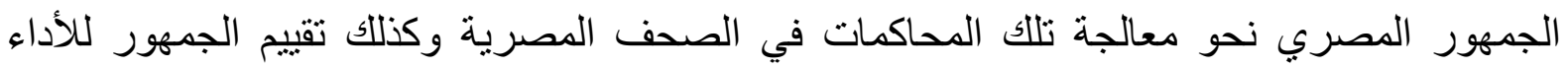

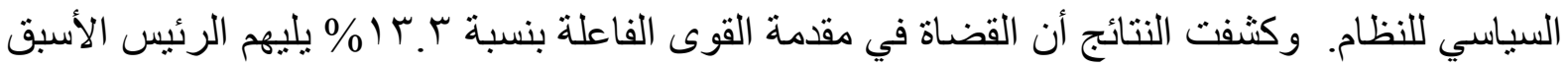

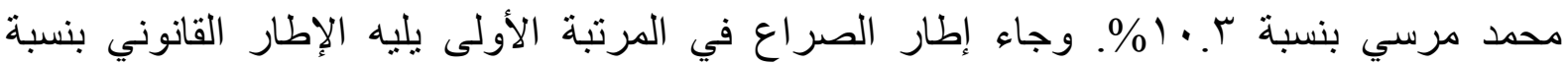

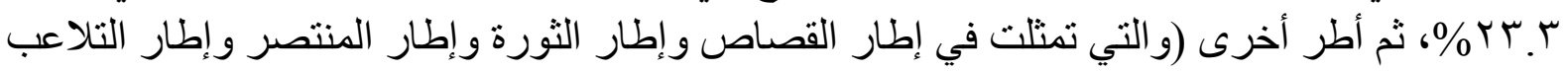

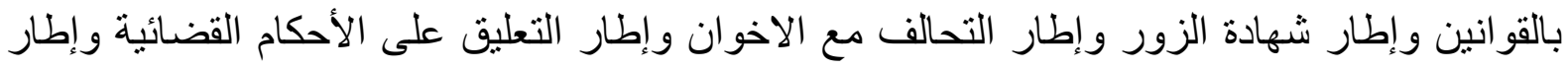

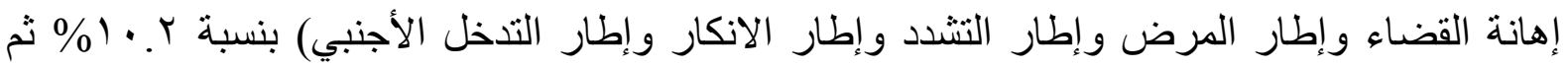

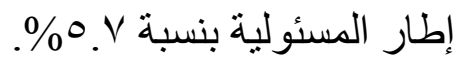

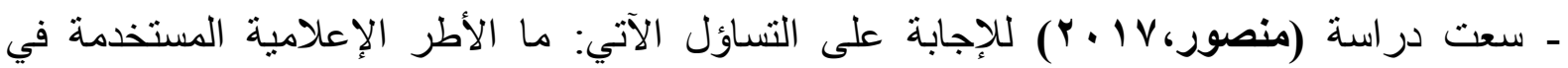

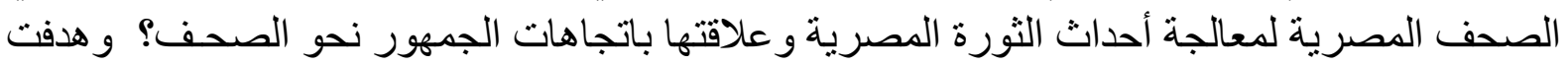

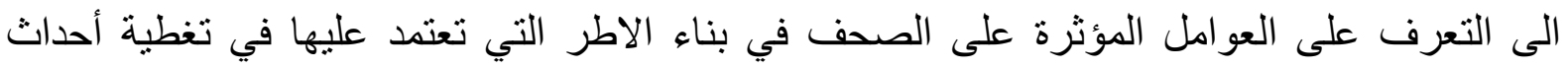

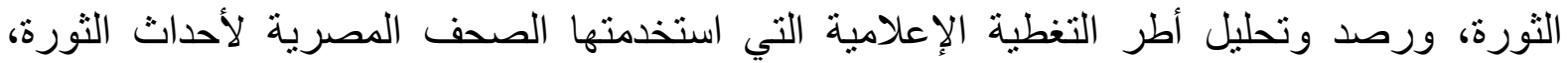

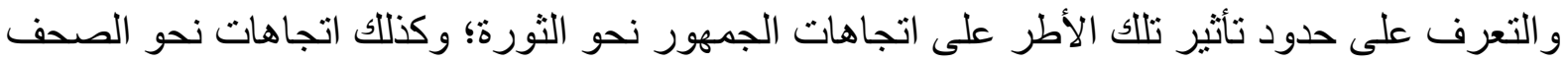

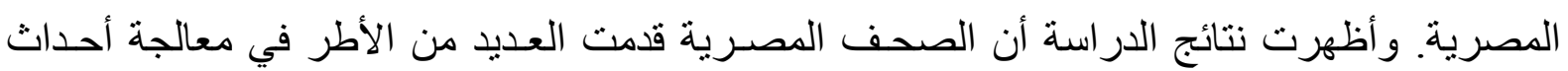

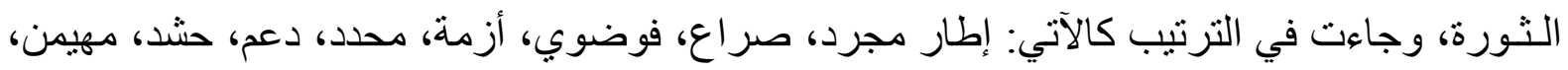

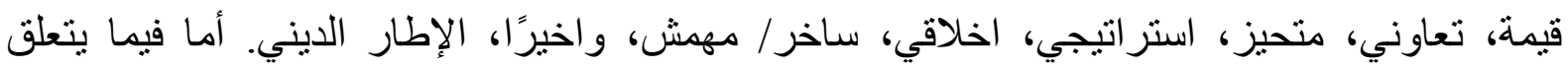

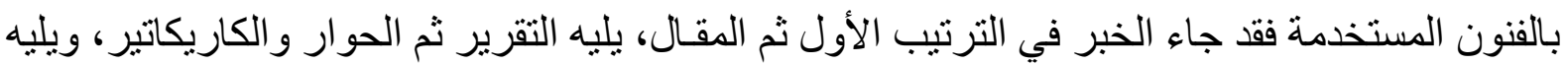

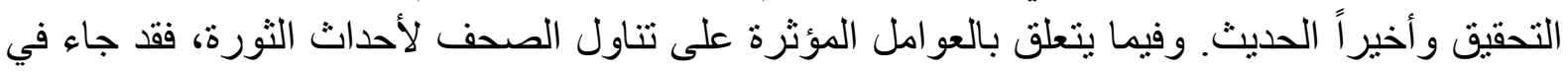

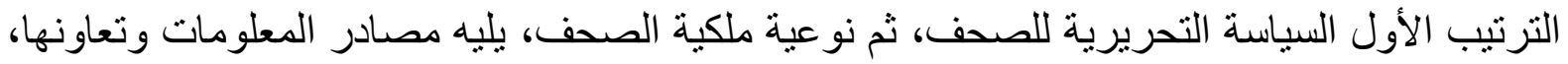

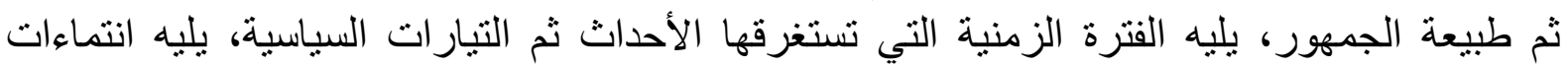

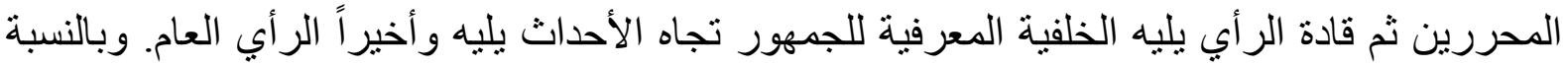

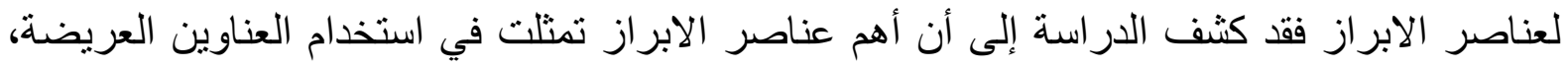

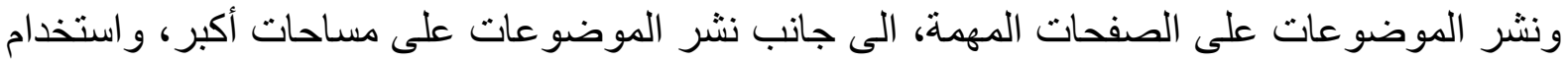

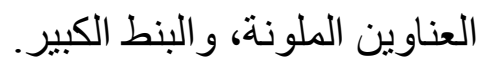

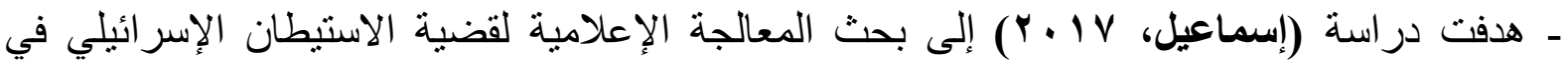

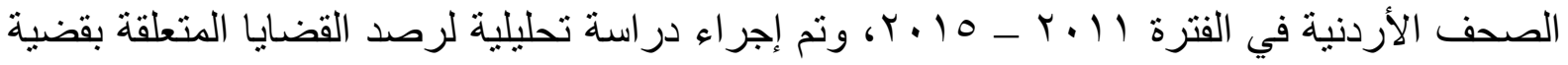

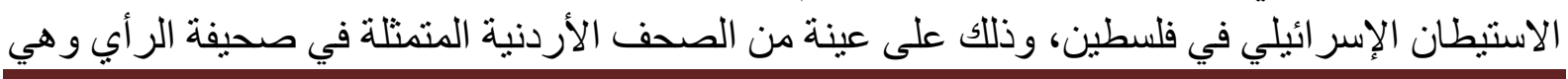


صحيفة حكومية، والغذ وهي صحيفة خاصة، والسبيل وهي صحيفة حزبية، وذللك باستخدام استمارة

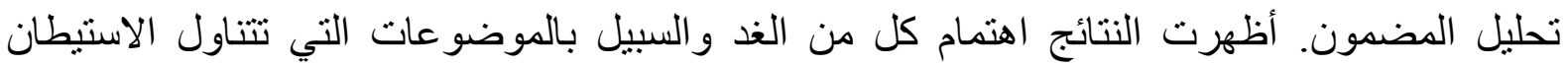

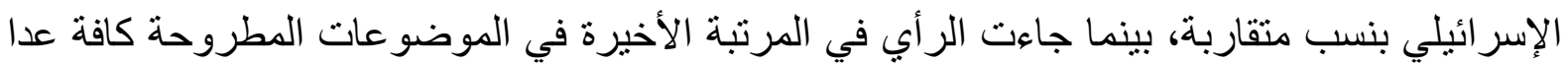

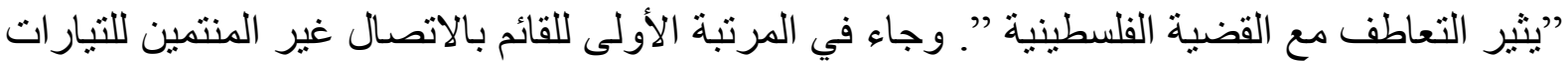

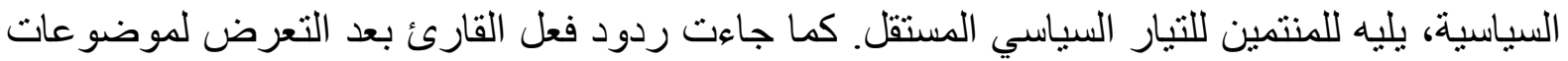

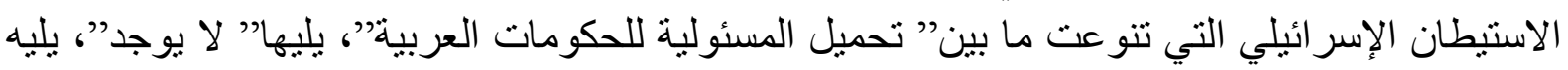

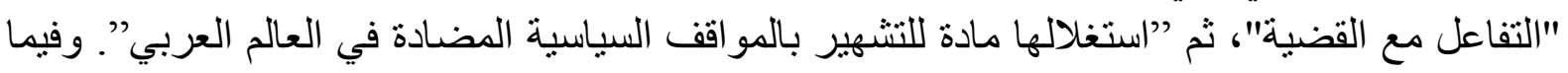

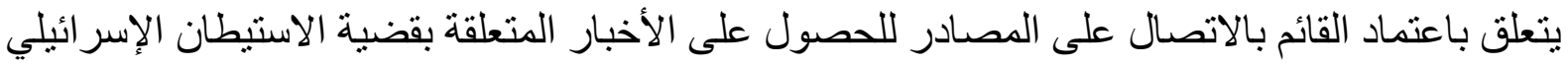

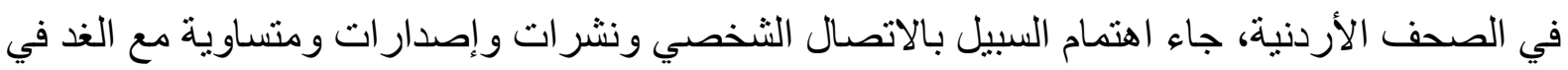

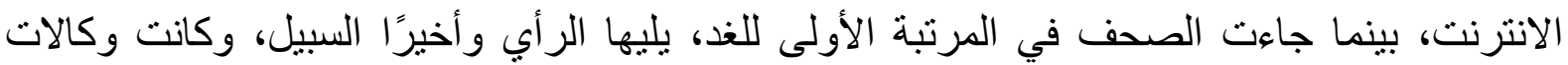

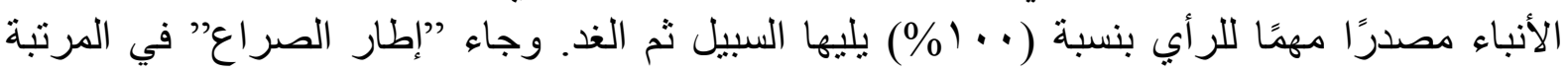

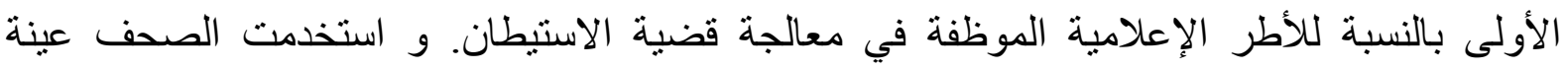

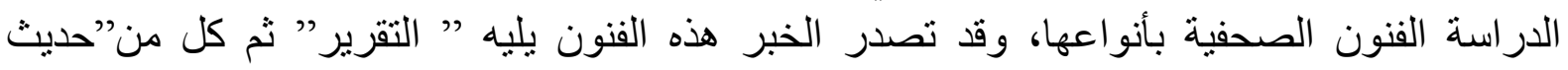

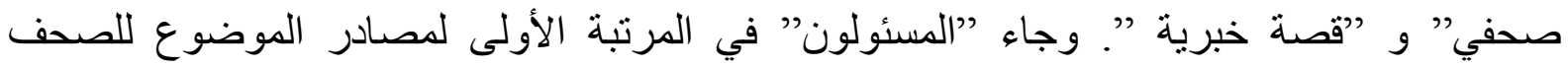

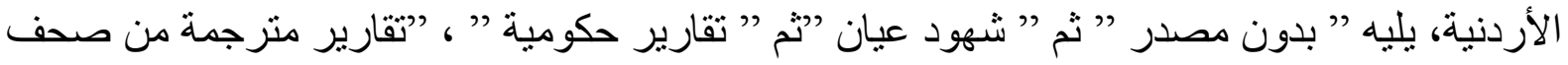

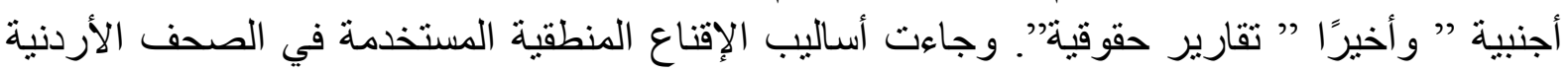

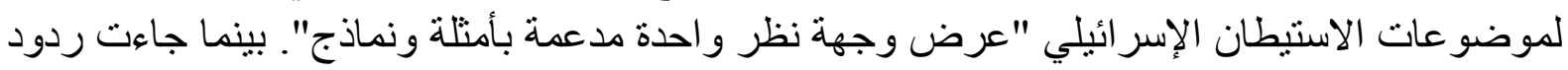

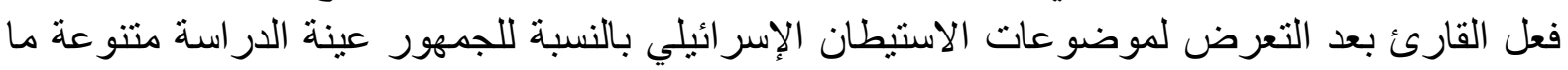
بين "لا يوجد"، يليه ” المشاركة في الفعاليات المناهضة للاستيطان".

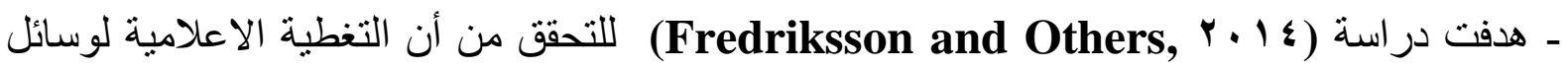

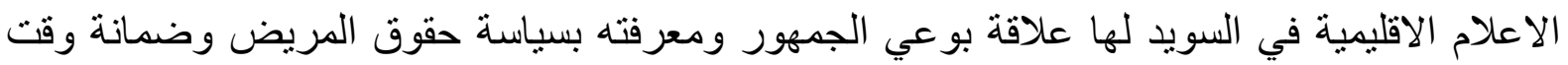

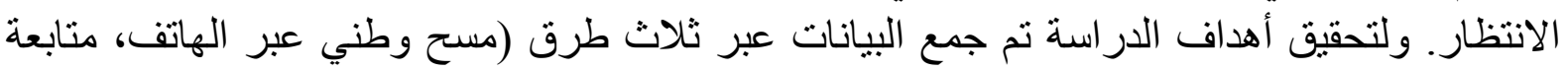

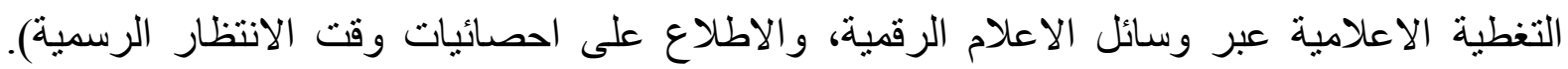

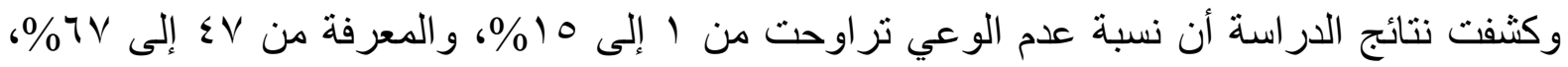

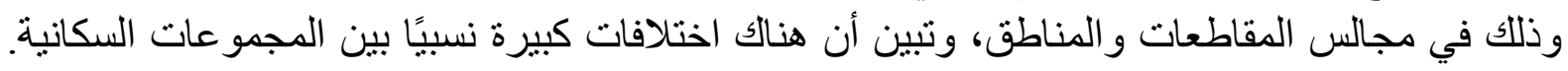

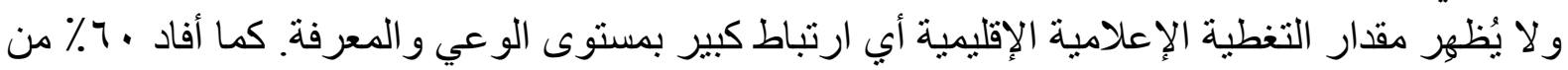

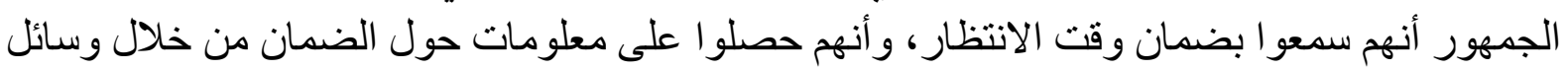

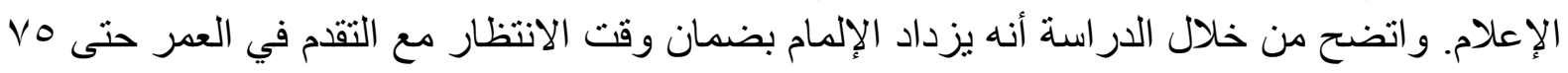

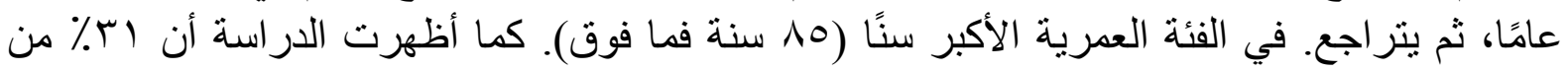

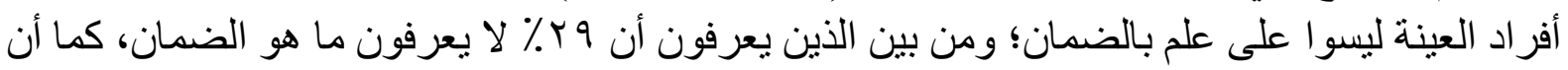
لاى النساء مستوى معرفة أعلى من الرجال. التعليق على الاراسات السابقة 
ـ لاحظت الباحثة وفرة في الدراسات العربية الحديثة لاسيما في المحور المتعلق بأطر المعالجة الاعلامية

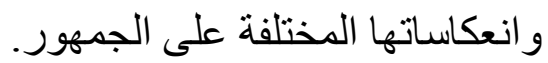

ـ اتفقت جميع الدراسات في الدحور الثاني على أن أسلوب المعالجة الاعلامية للقضايا (باختلاف أنو اعها) لها دور بارز في تشكيل اتجاهات الجمهور.

ــ اتفقت أغلب الدراسات أن الاتجاهات تتأثر وفقًا للعوامل الوسيطة وبالأخص العوامل الديموغر افية،

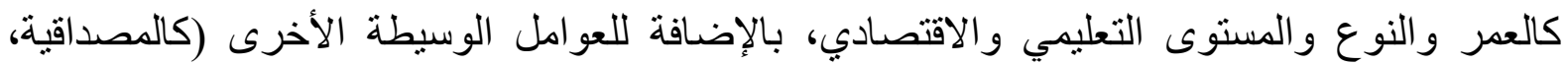
وكثافة التعرض).

ـ تبين أن أغلب الدراسات العربية استخدمت أداتي تحليل المحتوى والاستبيان، في حين أن ركزت

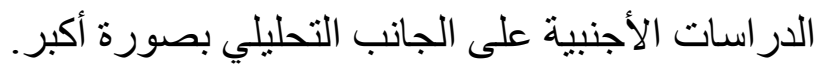

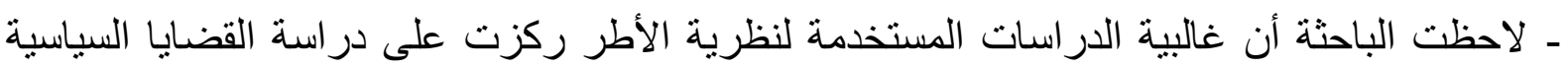

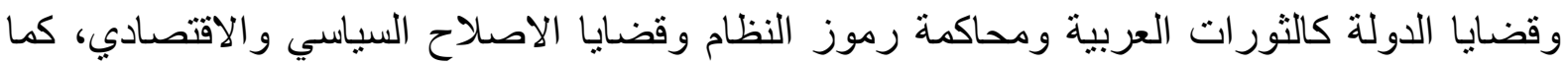

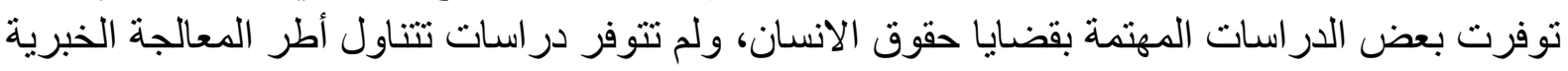

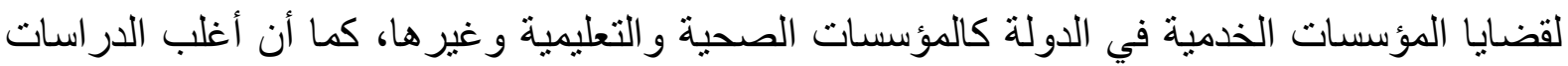

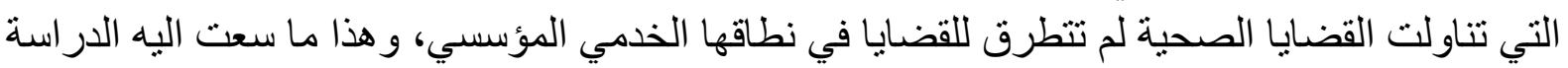
الحالية.

أوجه الاستفادة من الدراسات السابقة: أفادت الدراسات السابقة الباحثة في بلورة مشكلة البحث

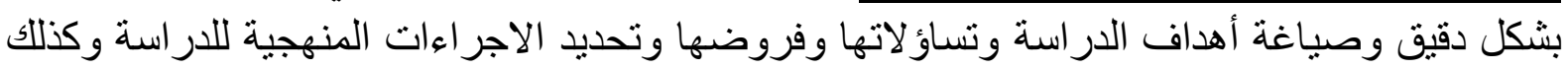

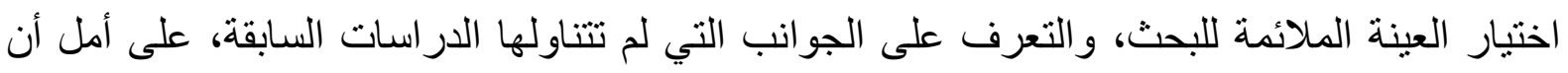

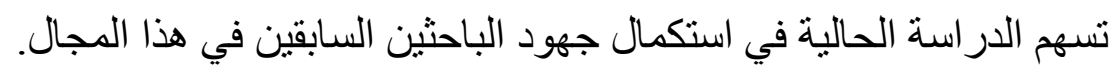
مشكلة الدراسة: لاحظت الباحثة اهتمام الصحافة البحرينية بقضايا المؤسسات الصحية والتغطية

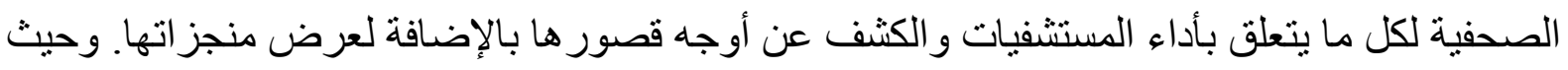

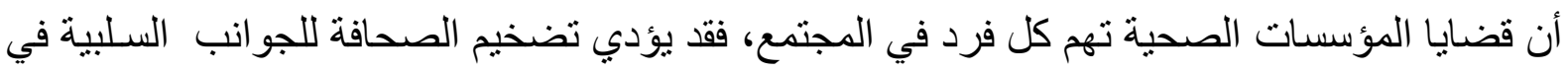

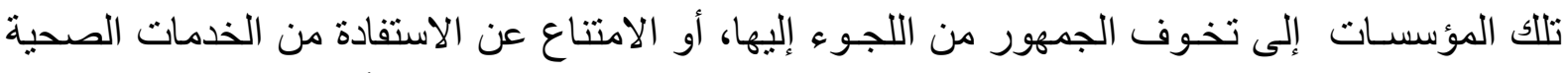

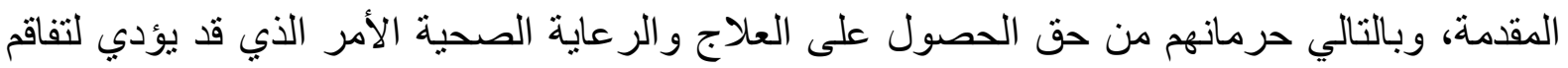

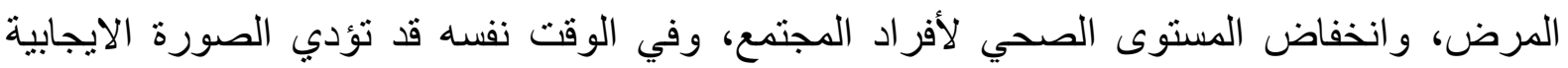

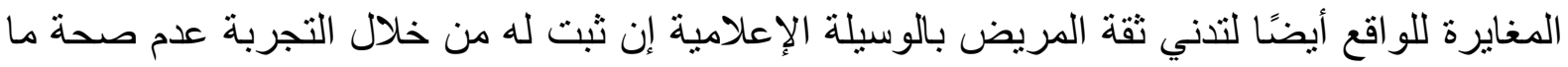

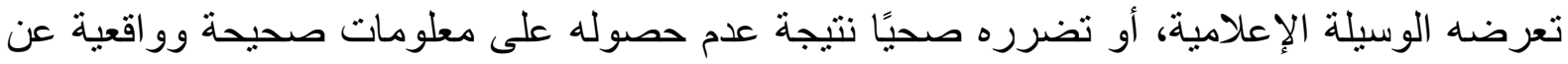

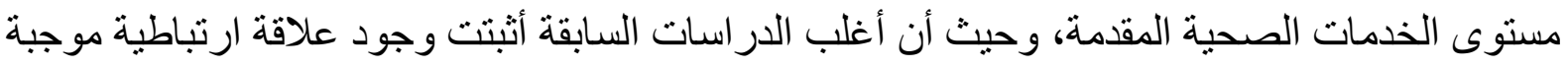

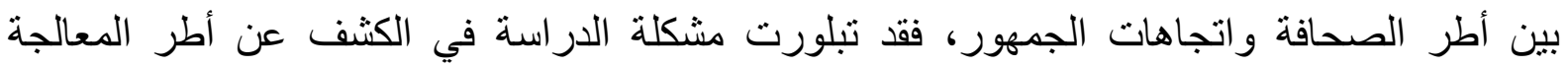


الاعلامية للقضايا المتعلقة بالمؤسسات الصحية في الصحافة البحرينية، وانعكاساتها على اتجاهات الجمهور.

الأهمية النظريـة للاراسة: تكمن أهمية الدراسة الحالية في ندرة الدراسات الخليجية التي تناولت هذا

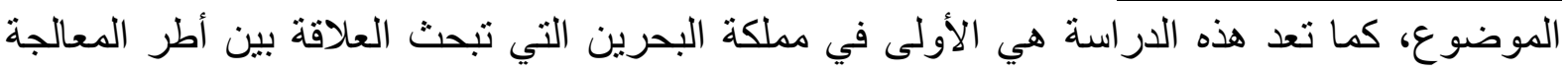

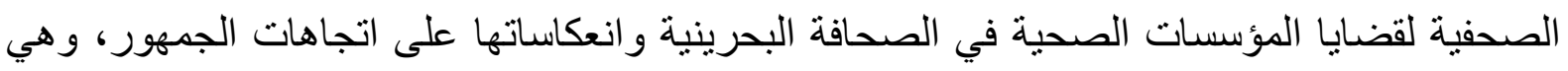

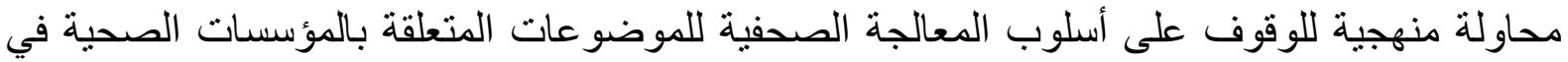

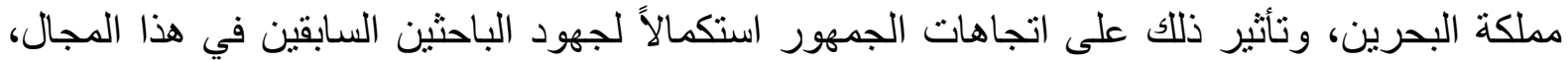

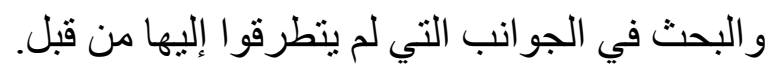

الأهمية العملية للار اسة: تنبع الأهمية العملية للار اسة من أهمية الدور الذي تؤديه الصحافة كوسيلة

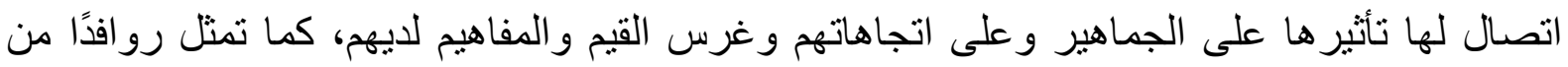

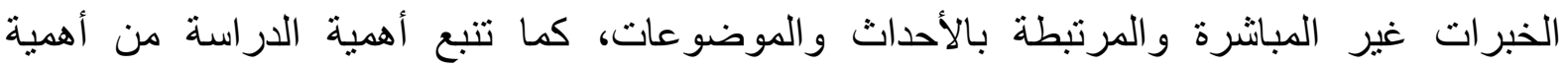

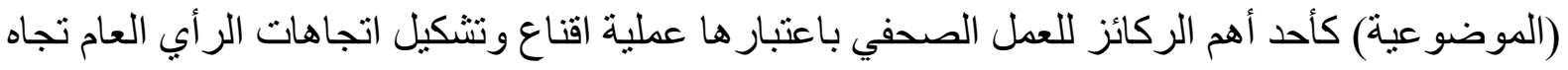

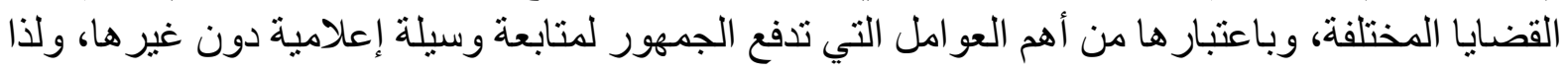

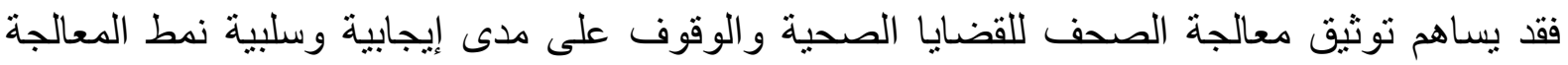

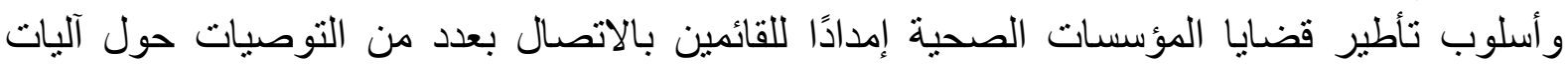

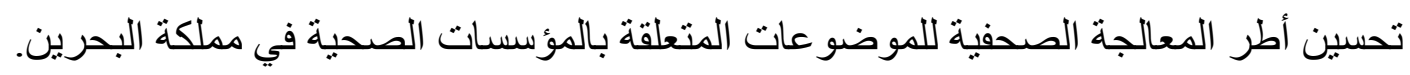

تساؤلات الاراسة: تسعى هذه الدراسة للإجابة على تساؤل رئيس ألا وهو : ما أطر المعالجة الصحفية

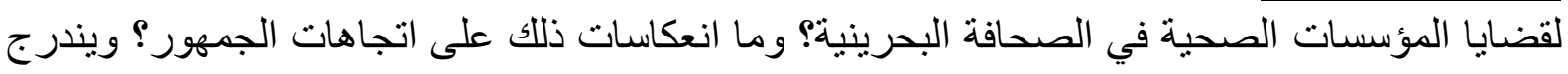
تحت هذا التساؤل عدد من التساؤلات الفر عية تلتمثل في:

ما القضايا الصحية التي تعالجها الصحافة البحرينية اليومية؟ الصائ

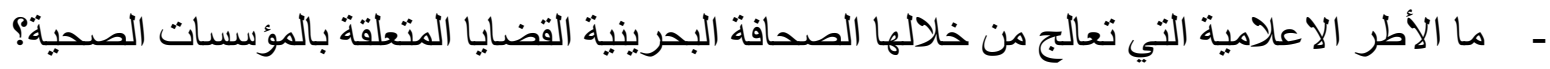

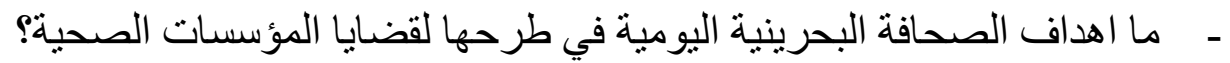

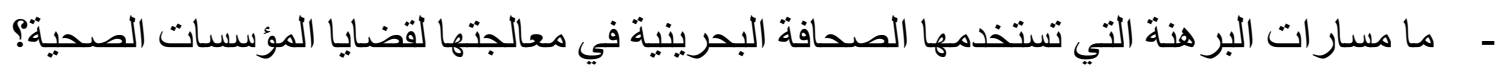
- ما انعكاس أسلوب المعالجة الصحفية للقضايا الصحية في الصحافة البحرينية على اتجاهات الجمهور

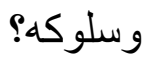

\section{فروض الدراسة:}

- توجد علاقة ارتباطية بين الأطر الإعلامية المستخدمة في معالجة قضايا المؤسسات الصحية والأطر المتشكلة لاى الجمهور نحو تلإلك المؤسسات. ـ ـ توجد فروق ذات دلالة إحصائية بين اتجاهات الصحافة في معالجتها لقضايا المؤسسات الصحية ونوع المؤسسة (حكومية / خاصة). 
- توجد فروق ذات دلالة إحصائية في اتجاهات الجمهور حول المؤسسات الصحية تعزى للمتغيرات

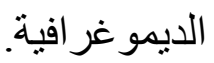

نوع الدراسة: تنتمي هذه الدراسة للدراسات الوصفية التي تستهدف التعرف على الأوصاف الدقيقة

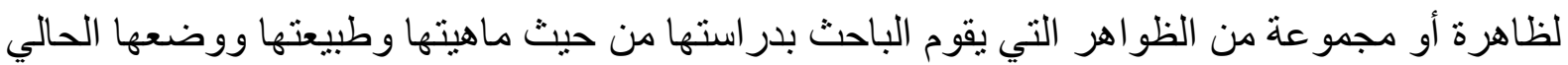

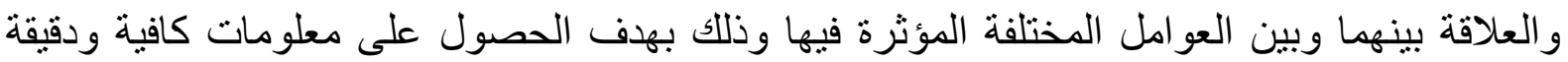

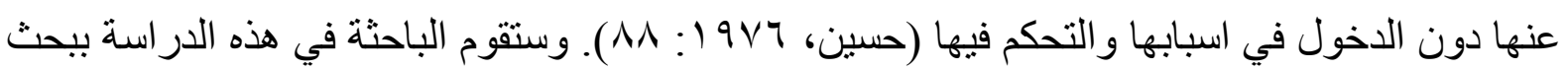

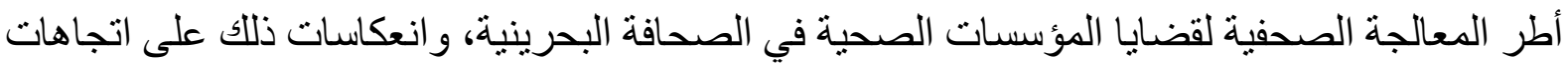

منهج الدراسة: تعتمد الاراسة الحالة على منهج المسح من خلال (تحليل الأطر): وذللك عن طريق

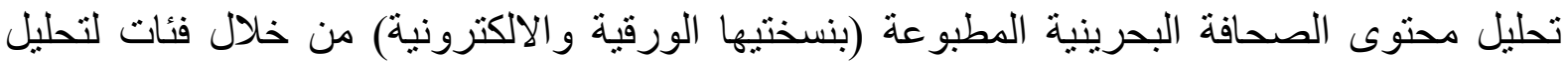

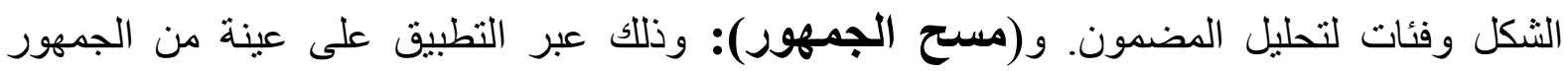
البحريني المتعرض للصحافة البحرينية المطبو عة (بنسختيها الورقية والالكترونية).

\section{أدوات جمع البيانات}

ـ الدراسة التحليلية: وفيه سيتم استخدام أداة تحليل الأطر الاعلامية لعيّنة الصحف البحرينية وأسلوب

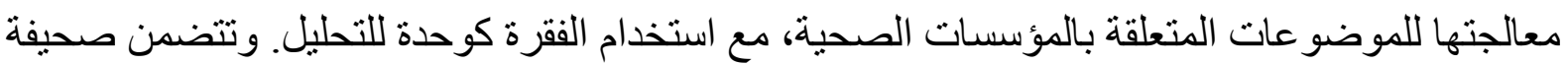
التحليل فئات الثكل المتمثلة في (كيف قيل) وفئات المضمون المتمنلة في (ماذا قيل). ـ الار اسة الميدانية: وفيه سيستخدم أداة الاستبيان 》استمارة الاستبيان) على عيّنة الجمهور البحريني. مجتمع الدراسة: مجتمع الدراسة هو جميع الوحدات التي يقوم الباحث بدر استها؛ أي مجموع الدفردات

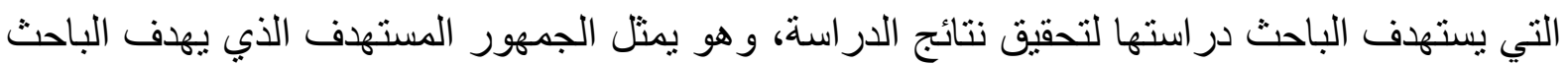

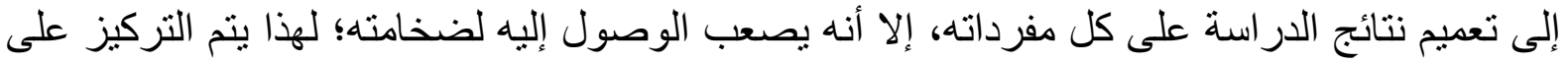

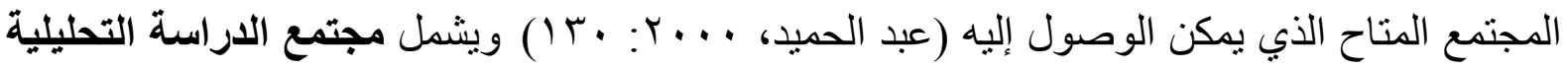

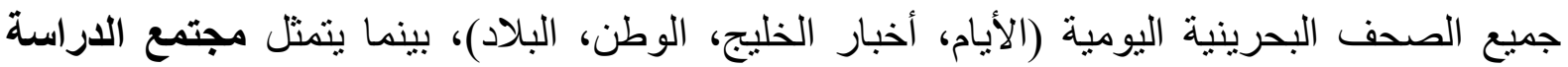

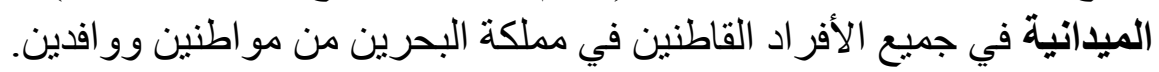

عينة الدراسة: العينة عبارة عن مجموعة جزئية من مفردات المجتمع ويعرف بعدد المفردات التي

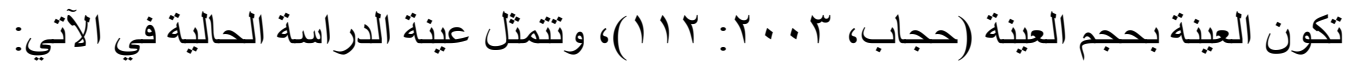

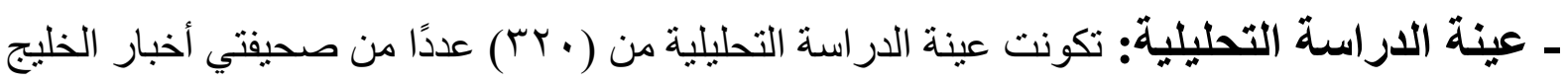

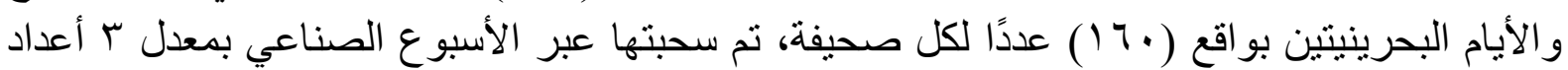
من كل أسبوع. بحيث نم في الأسبوع الأول سحب أعداد يوم (السبت و الاثثين و الأربعاء) لصحيفة أخبار 
الخليج، وسحب أعداد يوم (الأحد و الثلاثاء و الخميس) لصحيفة الأيام، وفي الأسبو ع الثاني تم سحب أعداد

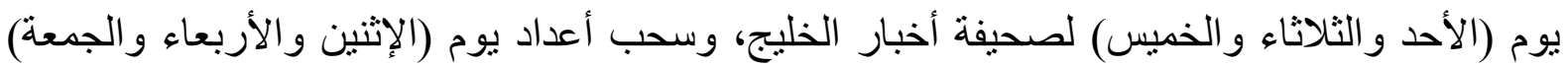

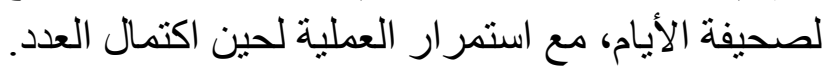

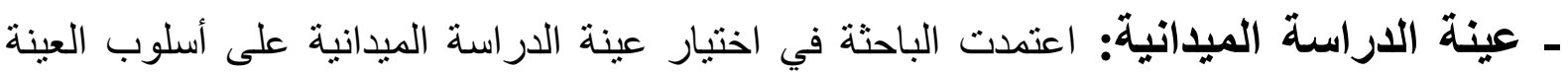

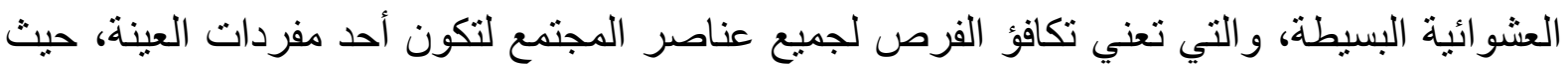

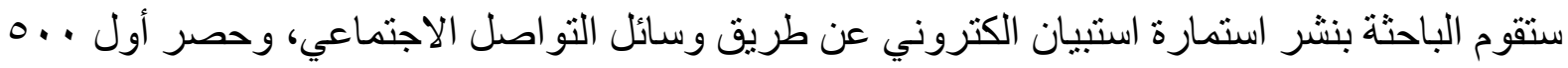

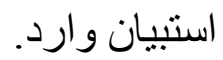

\section{إجراعات الصدق والثبات}

- صدق المحمين: قامت الباحثة بعرض استمارة تحليل الأطر لمحتوى الصحف البحرينية، وكذلك

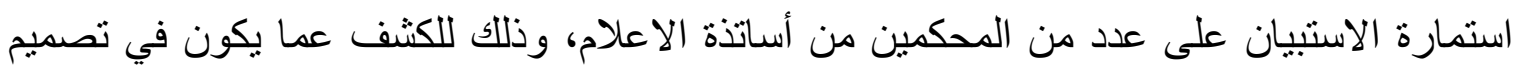

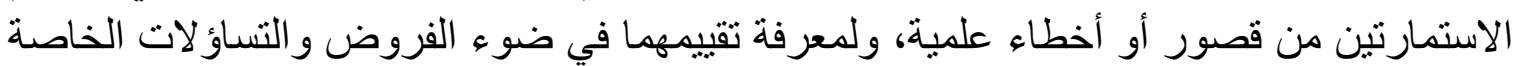
بالدر اسة. - صدق الأداة بالنسبة لصحيفة تحليل الأطر: قامت الباحثة قبل بدء عملية تحليل الأطر بإجر اء تحليل

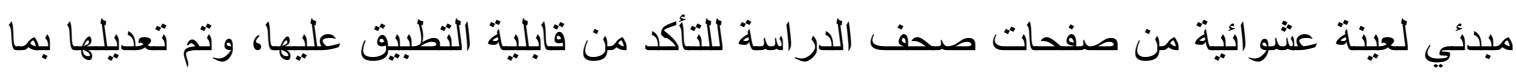

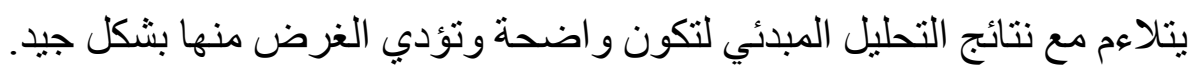

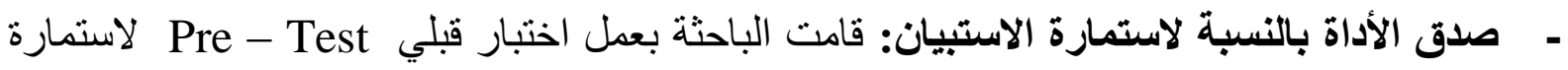

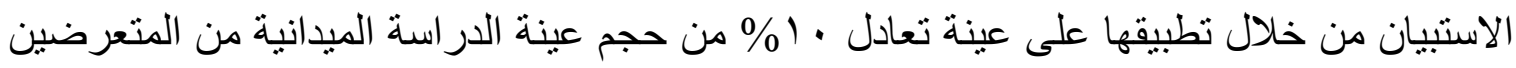

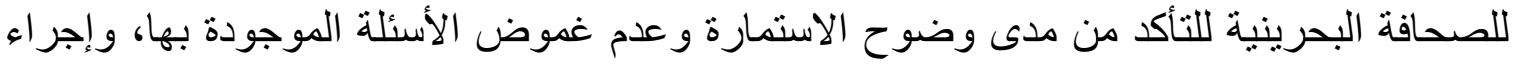

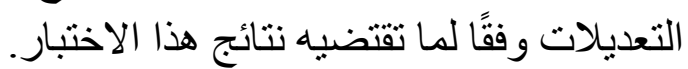

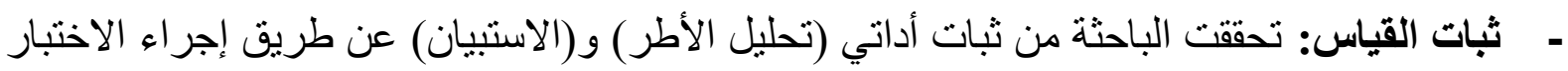

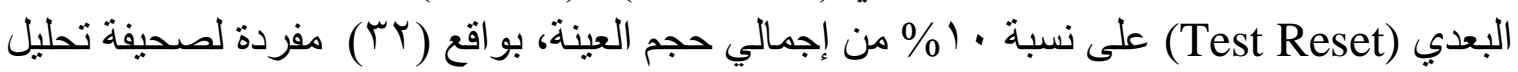

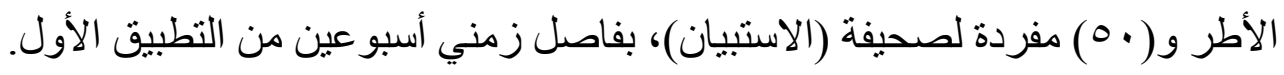

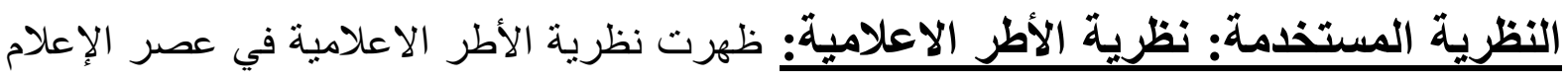

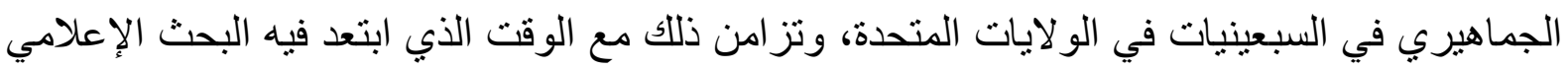

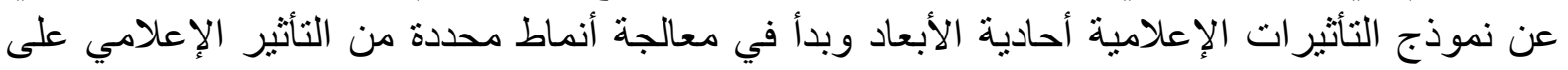

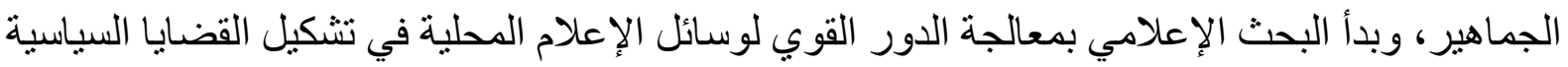

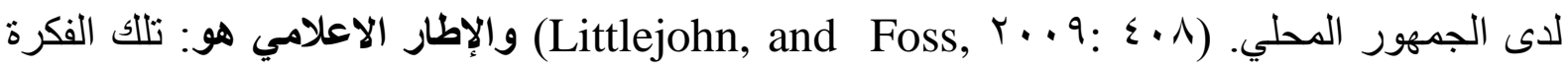

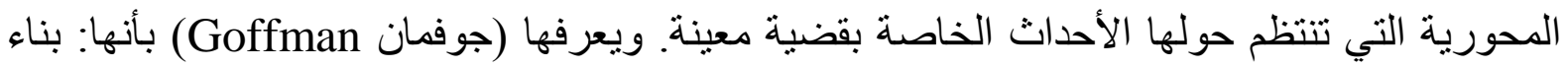

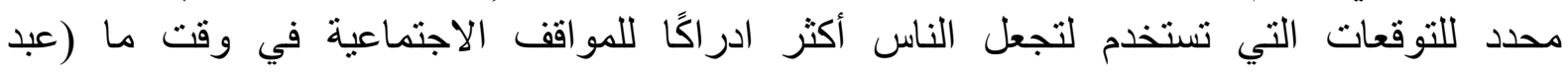




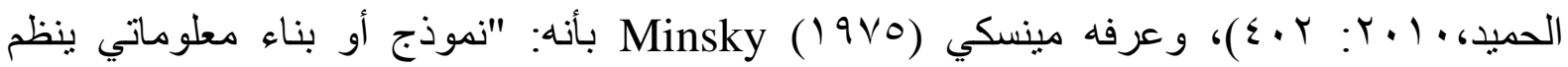

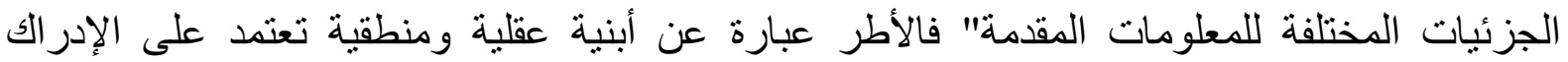

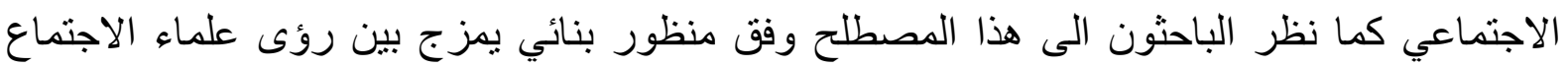

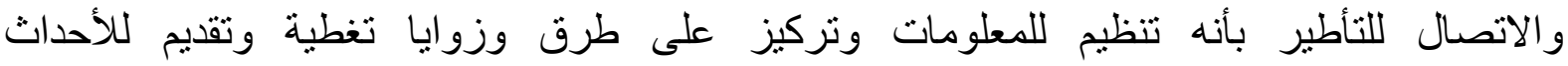

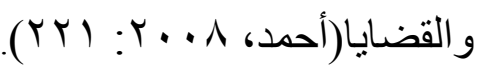
ووفقًا لتعريف Entman للتأطير فإن الأطر تعمل على تعريف وتحدد المشكلات وتثخيص أسبابها

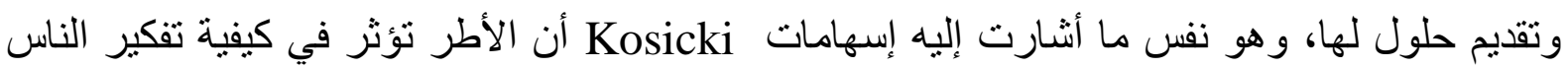

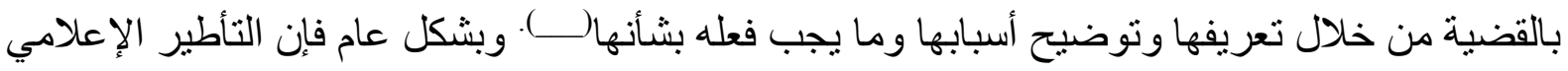

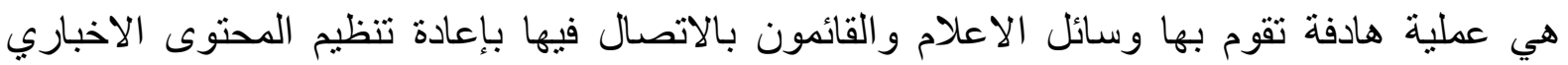

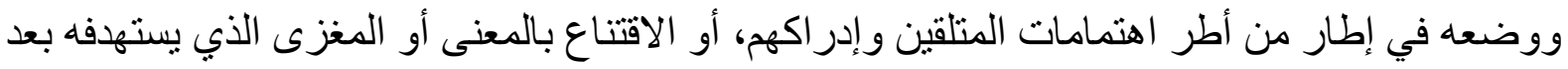

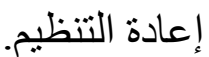

فروض النظرية وآلياتها: تفترض هذه النظرية أن الأحداث لا تنطوي في حد ذاتها على مغزى معين،

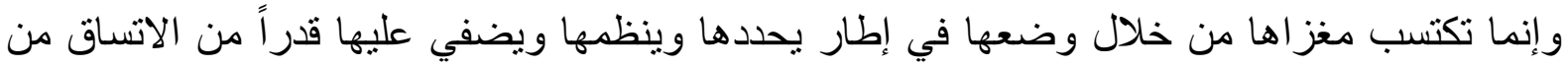

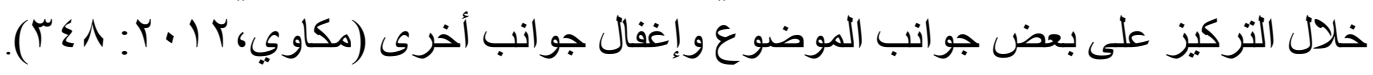

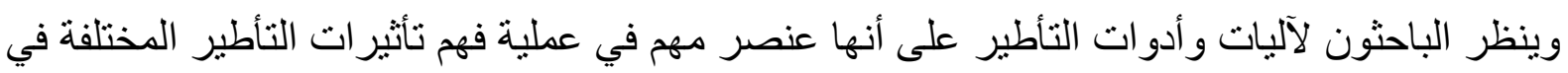

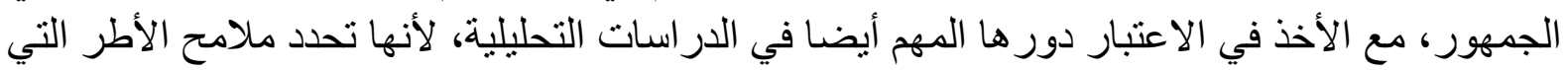
يتم من خلالها تغطية الأحداث و القضايا و الثخصيات الآختلفة. وتتمثل أهم هذه الآليات في الآتي:

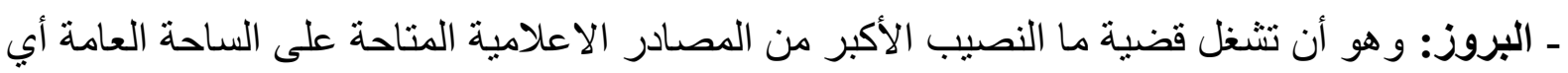

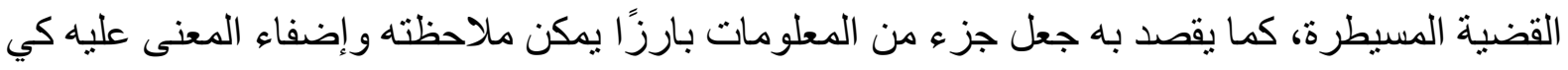

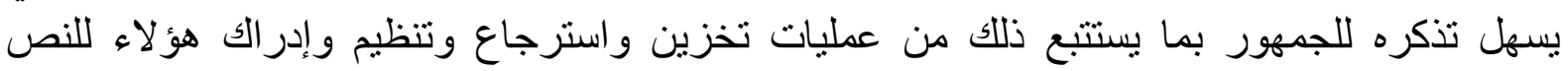

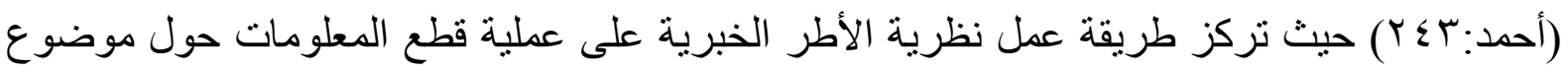

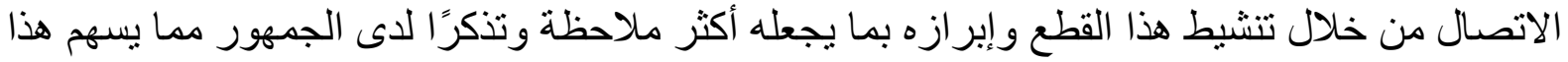

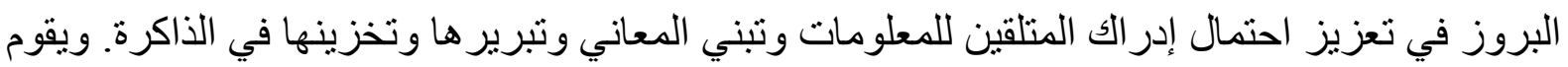

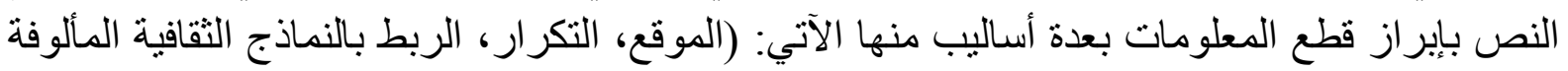

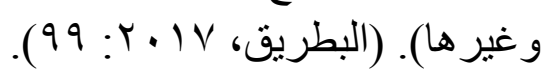

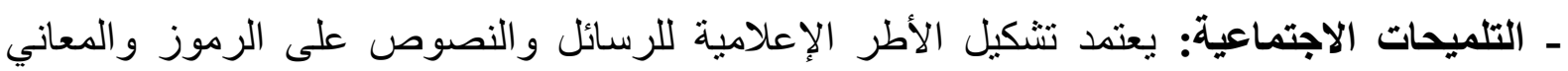

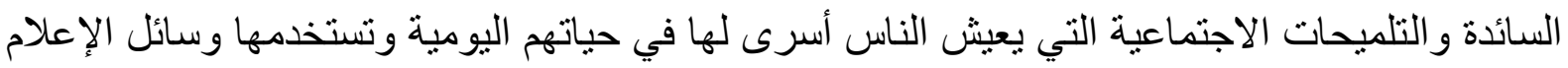
لنشر الأفكار والآراء المستهدفة وتتعزيز هاء. ـ نغمة أو نبرة التغطية: وتعد أحد أهم الآليات المستخدمة في تغطية أنو اع المحتوى الإعلامي لأنها تحدد طبيعة هذه التغطية وميول ومو اقف الوسيلة الاعلامية تجاه هذا المحتوى. 


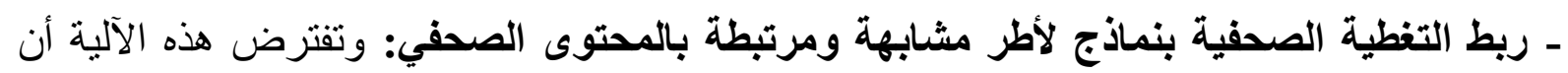

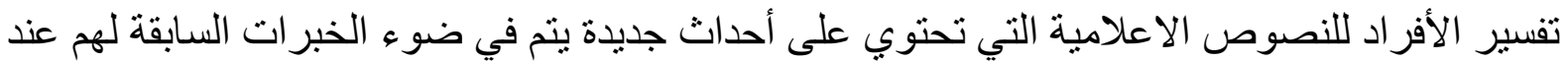

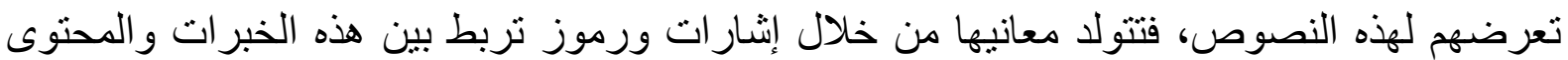

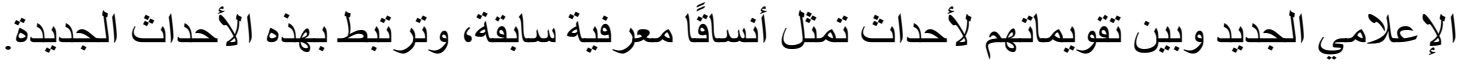
ـ آليات خاصة بالثكلية في النصوص الصحفية: كالصور وموقع التغطية الصحفية وحجمها و المساحة

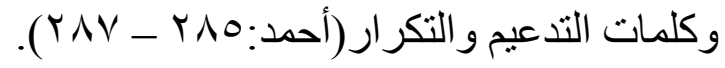

تطبيق النظرية في هذه الدراسة: سوف تقوم الباحثة بتطبيق نظرية الأطر الاعلامية في هذه

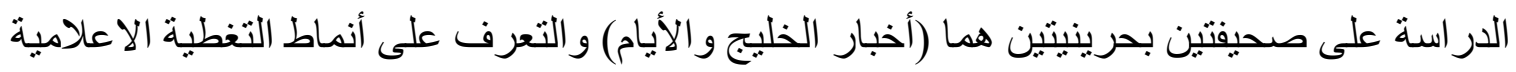

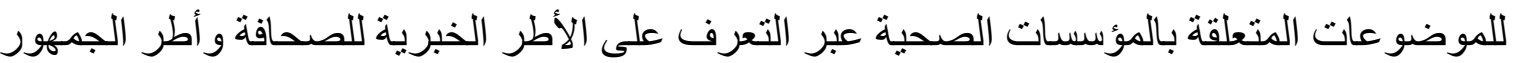

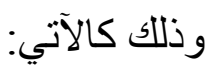

ـ أطر الصحافة: وذلك من خلال التعرف على أنماط التغطية الإعلامية لقضايا المؤسسات الصحية من الصنا

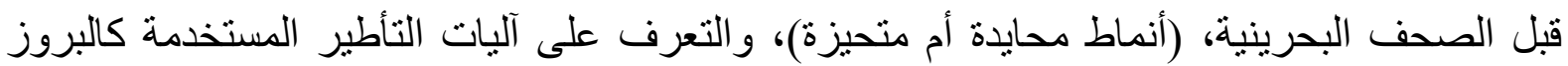

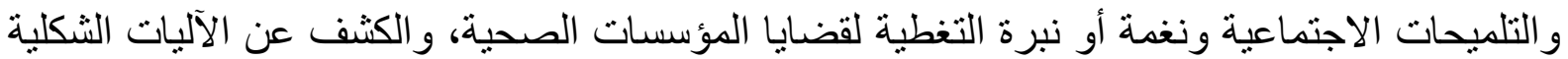

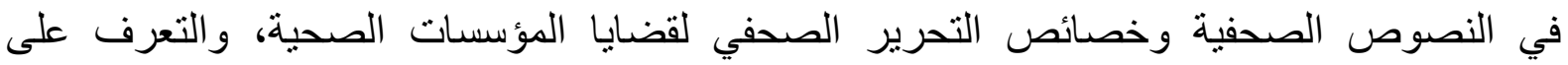
الأساليب الإقناعية ومسار ات البر هنة المتمثلة في مسار ات البر هنة العقلانية والعاطفية والأساليب اللغوية ودلالات الألفاظ ومعاني التوكيد في سياق الخبر.

ـ أطر الجمهور: وذلك من خلال التعرف على العلاقة بين أطر الصحافة والأطر التي يكونها الجمهور

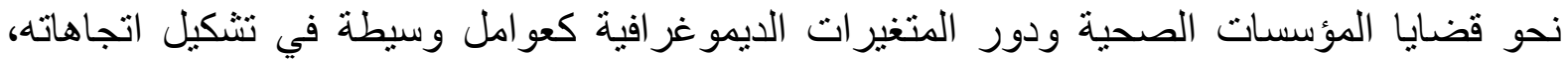

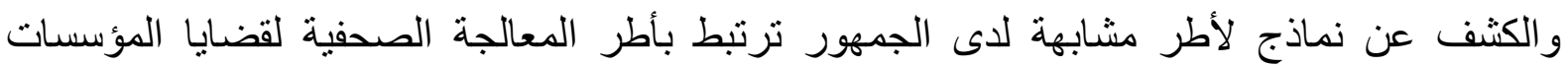

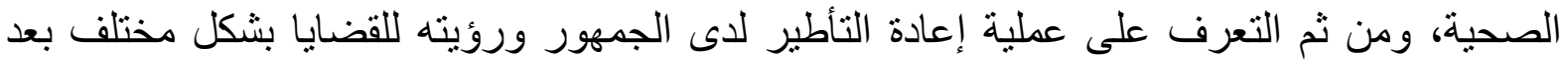

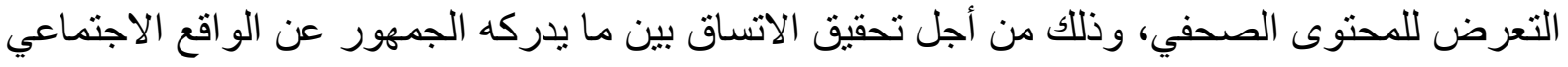

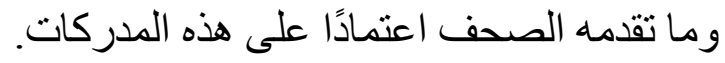




\section{نتائج الدراسة التحليلية}

ا ـ فئة الأشكال الصحفية:

جدول ( ) : بوضح فئة الأشكال الصحفية

\begin{tabular}{|c|c|c|c|c|c|c|c|c|c|}
\hline \multicolumn{3}{|c|}{ الصحف ككل } & \multicolumn{3}{|c|}{ الأيام } & \multicolumn{3}{|c|}{ أخبار الخليج } & \multirow{2}{*}{ الفئات } \\
\hline الترتيب & النسبة \% & التكر ار & الترتيب & النسبة\%\% & التكر ار & الترتيب & النسبة\%\% & التكر ار & \\
\hline 1 & $\Lambda \cdot . \Sigma \%$ & $r \leqslant \wedge$ & 1 & Vฯ..$\%$ & 101 & 1 & $\wedge \varepsilon .1 \%$ & 19 & الخبر الصحفي \\
\hline$r$ & Ir. $\%$ & Or & $r$ & $1 T .0 \%$ & TA & $r$ & $1 . .7 \%$ & T乏 & الحديث الصحفي \\
\hline$r$ & $V . r \%$ & M & $r$ & $1 . .1 \%$ & YI & $r$ & $\varepsilon . \leqslant \%$ & 1 . & التقرير الصحفي \\
\hline$\varepsilon$ & $.0 \%$ & $r$ & $\varepsilon$ & $\because \%$ & • & $\xi$ & $.9 \%$ & $r$ & التحقيق الصحفي \\
\hline- & $1 \ldots \%$ & $\varepsilon r r$ & - & $1 \ldots \%$ & $r \cdot V$ & - & $1 \ldots \%$ & YYY & المجموع \\
\hline
\end{tabular}

يتضح من الجدول السابق عدم وجود فروق بين صحيفتي أخبار الخليج والأيام من حيث الأشكال

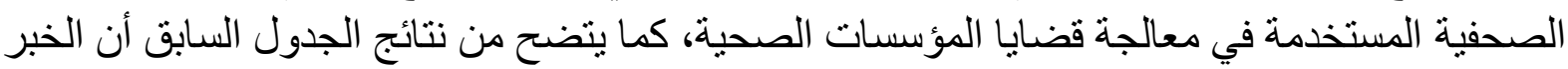
الصحفي كان الثكل الصحفي الأساسي الذي عالجت من خلاله الصحافة البحرينية قضايا المؤسسات

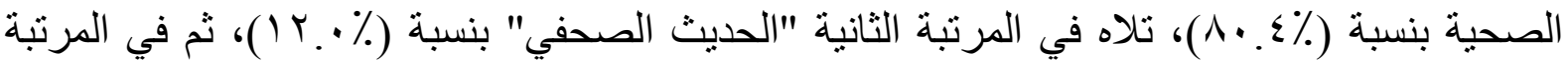

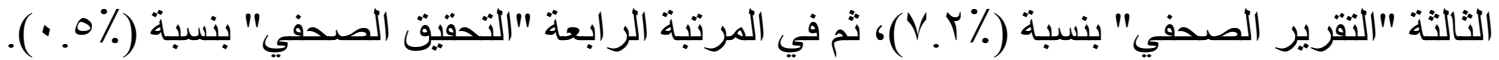
وقد يرتبط ندرة التحقيق الصحفي في صحيفة الأيام مقارنة ببروز الخبر الصحفي كأبرز الأشكال

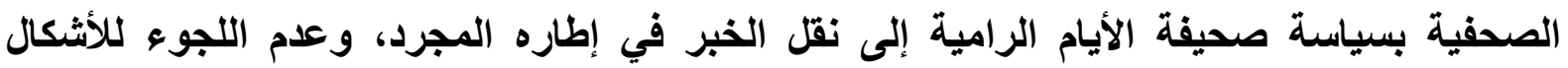

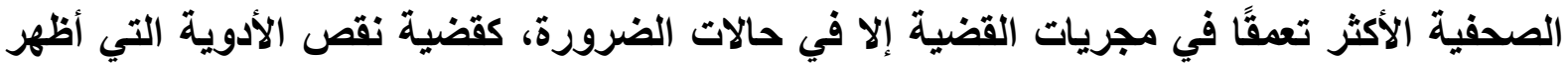

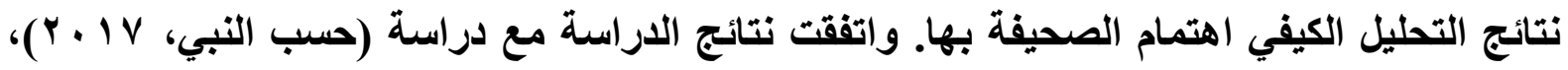

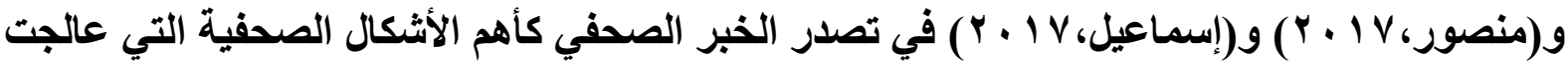

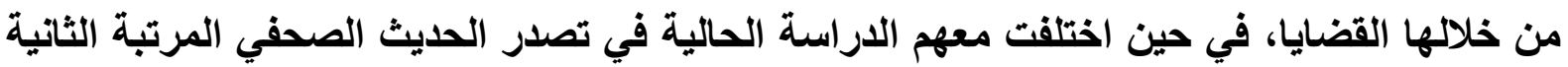

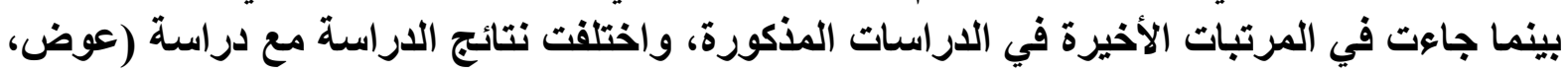
التي أظهرث بروز التقرير الصحفي على بقية الأثكال الصحفية.

r. فئة اتجاه التغطية للمؤسسات الصحية الحكومية:

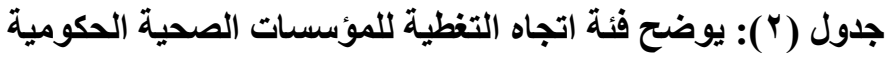

\begin{tabular}{|c|c|c|c|c|c|c|c|c|c|}
\hline \multicolumn{3}{|c|}{ الصحف ككل } & \multicolumn{3}{|c|}{ الأيام } & \multicolumn{3}{|c|}{ أخبار الخليج } & \multirow{2}{*}{ الفئات } \\
\hline الترتيب & النسبة \% & التكرار & الترتيب & النسبة\% & التكرار & الترتيب & النسبة\%\% & التكرار & \\
\hline 1 & $\vee 1 . \wedge \%$ & $T V V$ & 1 & $V T . Y \%$ & $1 \leqslant 0$ & 1 & $V \cdot r \%$ & ITr & ايجابي \\
\hline r & $10 . \wedge \%$ & 71 & r & 1 r. $7 \%$ & ro & r & $19.1 \%$ & ד & غير محدد \\
\hline$r$ & Ir. $\varepsilon \%$ & $\sum \wedge$ & $r$ & $1 \varepsilon .1 \%$ & rᄉ & $r$ & $1 \cdot .7 \%$ & $r$. & سلبي \\
\hline - & $1 \ldots \%$ & r^q & - & $1 \ldots \%$ & 191 & - & $1 \ldots \%$ & $1 \wedge 1$ & المجموع \\
\hline
\end{tabular}




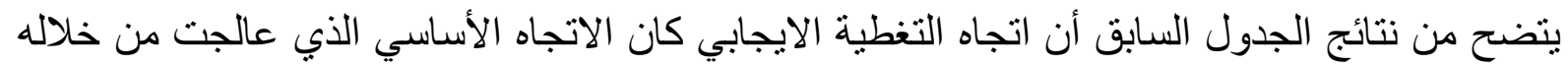

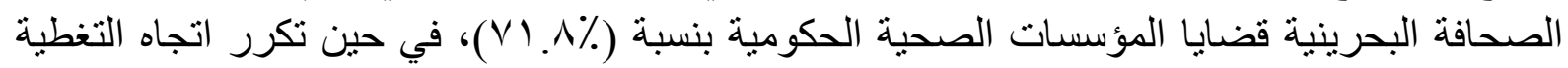

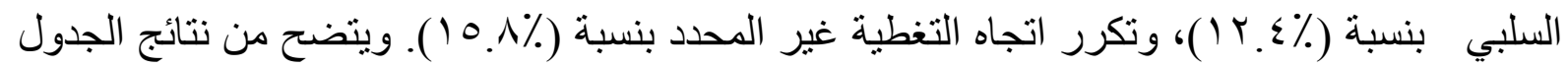

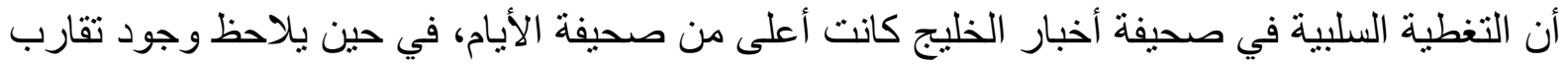
بين الصحيفتين في نسب استخدام اتجاه التغطية الايجابي.

وقد يعود ذلك إلى أن المصدر الرئيس الذي تعتمد عليه الصحافة البحرينية في تغطية قضايا

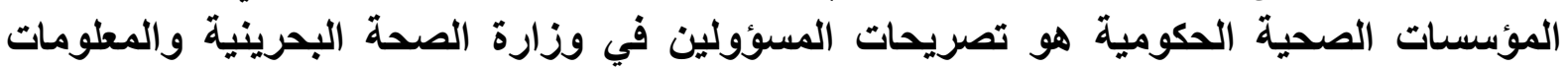

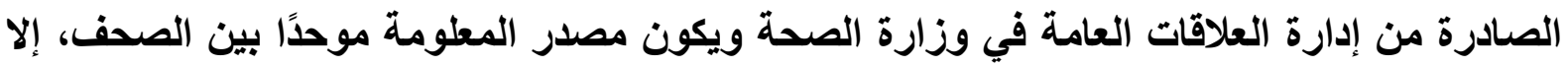
أن الاختلاف قد يوجد في القالب الذي تعالج فيه كل صحيفة للخبر.

r. فئة اتجاه التغطية للمؤسسات الصحية الخاصة:

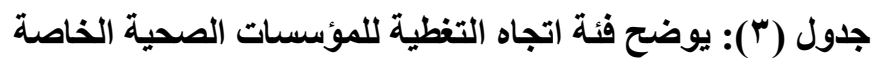

\begin{tabular}{|c|c|c|c|c|c|c|c|c|c|}
\hline \multicolumn{3}{|c|}{ الصحف ككل } & \multicolumn{3}{|c|}{ الأيام } & \multicolumn{3}{|c|}{ أخبار الخليج } & \multirow{2}{*}{ الفئات } \\
\hline الترتيب & النسبة\%\% & التكرار & |الترتيب| & النسبة\%\% & التكرار & الترتيب & النسبة\%\% & التكرار & \\
\hline 1 & $\vee \wedge . \vee \%$ & rV & 1 & $\vee \vee . \wedge \%$ & V & 1 & $\vee \wedge .9 \%$ & $r$. & ايجابي \\
\hline$r$ & $1 \mathrm{~V} . \%$ & $\Lambda$ & $r$ & TY.T\% & T & $r$ & $10 . \wedge \%$ & 7 & غير محدد \\
\hline$r$ & $\varepsilon . \Gamma \%$ & $r$ & r &..$\%$ & - & $\mu$ & $0 . r \%$ & $r$ & سلبي \\
\hline- & $1 \ldots \%$ & $\varepsilon V$ & - & $1 \ldots \%$ & 9 & - & $1 \ldots \%$ & $r \wedge$ & المجموع \\
\hline
\end{tabular}

يتضح من نتائج الجدول السابق أن الصحافة البحرينية عالجت قضايا المؤسسات الصحية الخاصة من الهن

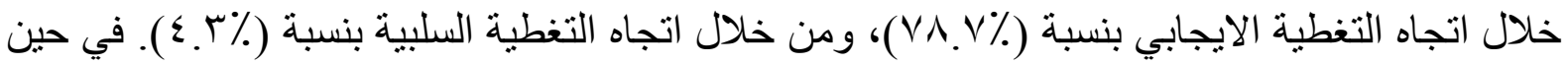
تكرر اتجاه التغطية غير المحدد بنسبة (\%) . IV)، ويلاحظ عدم وجود فروق بين الصحيفتين في اتجاه التغطية للمؤسسات الصحية الخاصة.

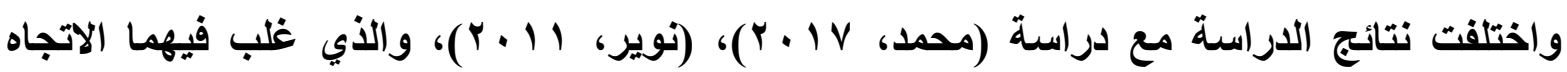

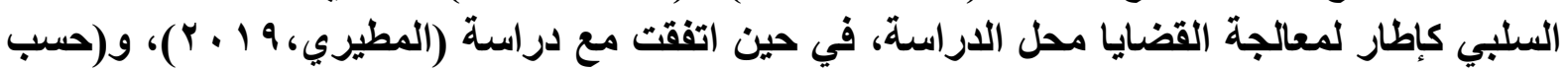

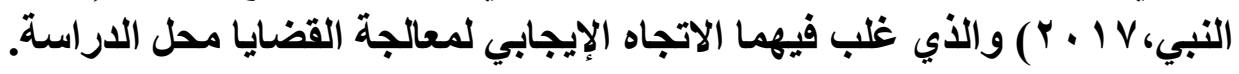

ع. فئة نمط التغطية للمؤسسات الصحية الحكومية:

جدول (؛ ): يوضح فئة نمط التغطية للمؤسسات الصحية الصية الحكومية

\begin{tabular}{|c|c|c|c|c|c|c|c|c|c|}
\hline \multicolumn{3}{|c|}{ الصحف ككل } & \multicolumn{3}{|c|}{ الأيام } & \multicolumn{3}{|c|}{ أخبار الخليج } & \multirow{2}{*}{ الفئات } \\
\hline الترتيب & النسبةة\% & التكرار & الترتيب & |النسبة\%\% & التكرار & الترتيب & النسبةة\% & التكرار & \\
\hline 1 & 1). $.9 \%$ & T17 & 1 & $V \leqslant . Y \%$ & $1 \leqslant V$ & 1 & $\wedge 9.9 \%$ & 179 & التغطية المحايدة \\
\hline r & $1 \wedge .1 \%$ & $V$. & $r$ & Yo.^\% & 01 & r & $1 . .1 \%$ & 19 & التغطية المتحيزة \\
\hline - & $1 \ldots \%$ & 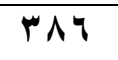 & - & $1 \ldots \%$ & 191 & - & $1 \ldots \%$ & $1 \wedge \Lambda$ & المجموع \\
\hline
\end{tabular}


يتضح من نتائج الجدول السابق أن "التغطية الدحايدة" طغت على معالجة الصحافة البحرينية لقضايا

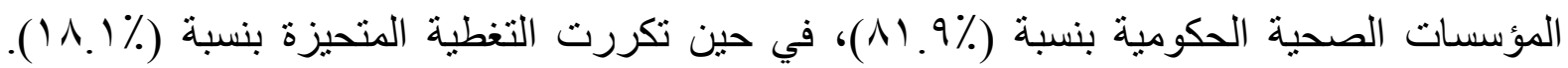

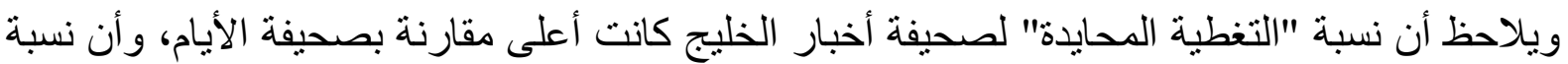
"التغطية المتحيزة " لصحيفة الأيام كانت أعلى مقارنة بصحيفة أخبار الخليج.

هـ فئة نمط التغطية للمؤسسات الصحية الخاصة:

جدول (•) : يوضح فئة نمط التظطية للمؤسسات الصحية الخاصة

\begin{tabular}{|c|c|c|c|c|c|c|c|c|c|}
\hline \multicolumn{3}{|c|}{ الصحف ككل } & \multicolumn{3}{|c|}{ الأيام } & \multicolumn{3}{|c|}{ أخبار الخليج } & \multirow{2}{*}{ الفئات } \\
\hline الترتيب & النسبة\%\% & التكرار & الترتيب & النسبة\%\% & التكرار & الترتيب & |النسبة\%\% & التكرار & \\
\hline$T$ & $09.7 \%$ & YA & 1 & $00.7 \%$ & 0 & 1 & $7 . .0 \%$ & $\overline{r r}$ & التغطية المحايدة \\
\hline r & $\varepsilon .\{\%$ & 19 & r & «ะ.६\% & $\varepsilon$ & $r$ & $r 9.0 \%$ & 10 & التغطية المتحيزة \\
\hline - & $1 \ldots \%$ & $\leqslant v$ & - & $1 . . \%$ & 9 & - & $1 \ldots \%$ & $r \wedge$ & المجموع \\
\hline
\end{tabular}

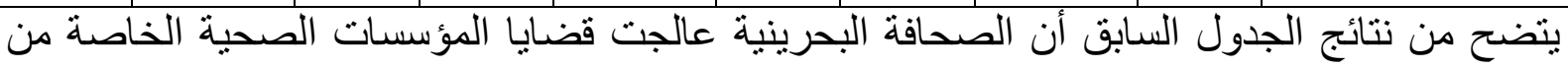

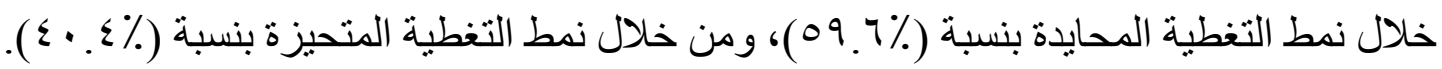
ويلاحظ أن نسبة "التغطية المحايدة" لصحيفة أخبار الخليج كانت أعلى مقارنة بصحيفة الأيام، وأن نسبة "التغطية المتحيزة " لصحيفة الأيام كانت أعلى مقارنة بصحيفة أخبار الخليج.

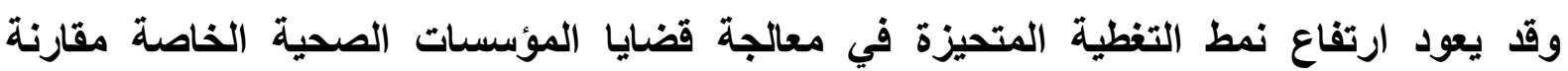

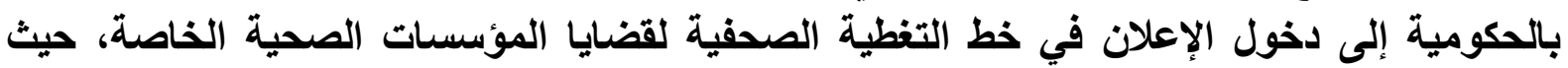

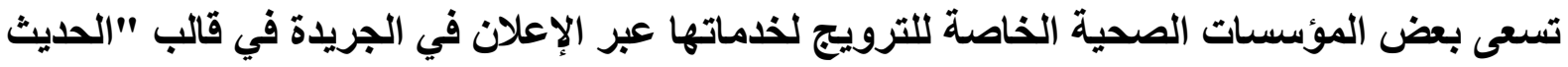
الصحفي" مع أحد طواقمها الطبية.

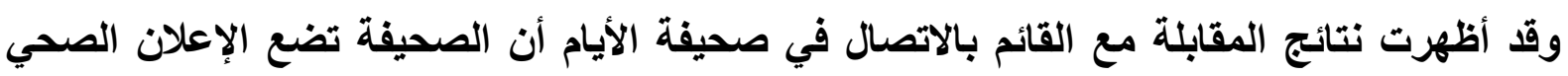

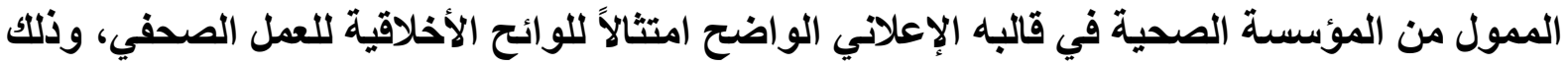

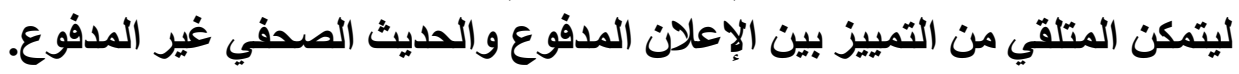

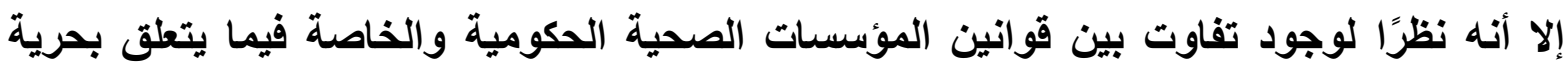

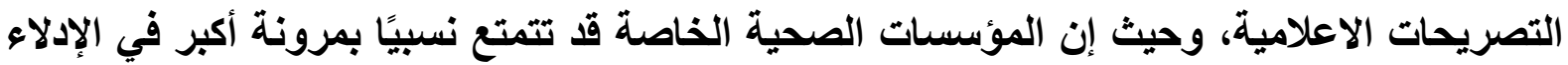

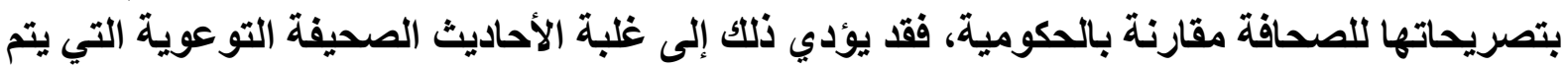

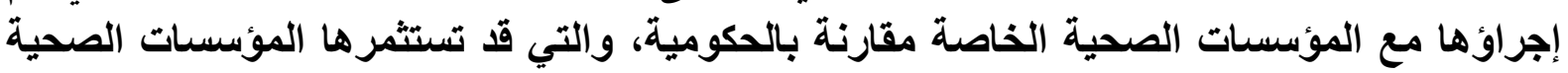
الخاصة للترويج ضمنيًا لجودة خدماتها من خلال الحديث الصحفي التوعوي. 
7. فئة أهداف الصحافة في طرح قضايا المؤسسات الصحية: جدول (ج): يوضح فئة أهداف الصحافة في طرح قضايا المؤسسات الصحية الصاية

\begin{tabular}{|c|c|c|c|c|c|c|c|c|c|}
\hline \multicolumn{3}{|c|}{ الصحف ككل } & \multicolumn{3}{|c|}{ الأيام } & \multicolumn{3}{|c|}{ أخبار الخليج } & \multirow{2}{*}{ الفئات } \\
\hline الترتيب & |النسبة\%\% & التكرار & الترتيب & النسبة\%\% & التكرار & الترتيب & النسبة\%\% & التكرار & \\
\hline 1 & $\leqslant \tau .0 \%$ & $r 90$ & 1 & $\varepsilon r . \%$ & IVV & 1 & $\varepsilon r .9 \%$ & r) & الثرح و والتفسير \\
\hline r & 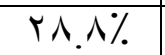 & TIY & $r$ & YO.A\% & 1.7 & $r$ & MI. $\varepsilon \%$ & 107 & الثكر و الإشادة \\
\hline$r$ & 1 1.. $T \%$ & 110 & $r$ & Ir.T\% & or & $r$ & $1 T .7 \%$ & זי & الإقناع بتبني \\
\hline$\varepsilon$ & $7.1 \%$ & 00 & 0 & $7.1 \%$ & To & $\varepsilon$ & $7 . \%$ & $r$. & التو عبة و الوقاية \\
\hline 0 & $0.9 \%$ & $0 \leqslant$ & $\varepsilon$ & ^. $\vee \%$ & r4 & 0 & $\Gamma .7 \%$ & 11 & التأكيد \\
\hline 7 & $1 . Y \%$ & 11 & V & $1 . \%$ & $\varepsilon$ & 7 & $1 . \varepsilon \%$ & V & شكوى ش \\
\hline 7 & $1 . r \%$ & 11 & 7 & $1.9 \%$ & $\wedge$ & V & $\cdot .7 \%$ & $r$ & نفي \\
\hline$\Lambda$ & $\cdot . \mathrm{V} \%$ & 7 & V & $1 . \%$ & $\varepsilon$ & $\Lambda$ & $\cdot . £ \%$ & $r$ & مناشدة \\
\hline $1 \ldots \%$ & - & 9.9 & $1 \ldots \%$ & - & \&ार & - & $1 \ldots \%$ & $\varepsilon q V$ & المجموع \\
\hline
\end{tabular}

يتضح من نتائج الجدول السابق أن أكثر الأهداف التي ركزت عليها الصحافة البحرينية خلال طرح التهاء

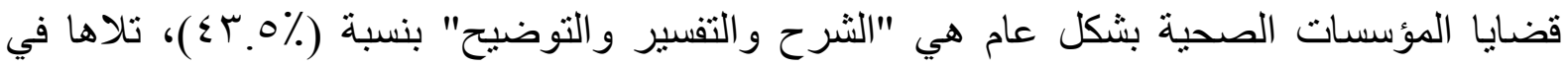

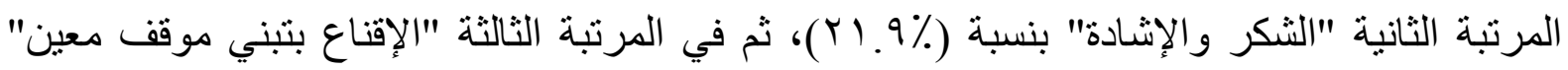

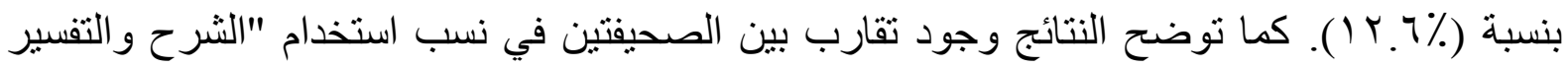

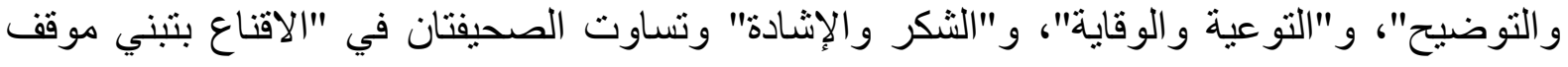

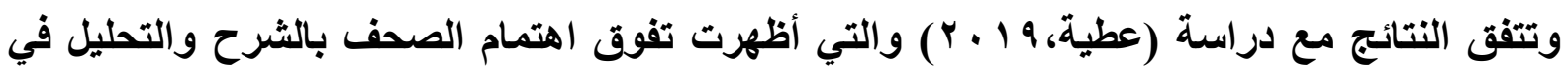
القضية محل الاراسة.

V ل فئة نوع الاتجاه المراد تكوينه:

جدول (V): يوضح فئة نوع الاتجاه المراد تكوينه

\begin{tabular}{|c|c|c|c|c|c|c|c|c|c|}
\hline \multicolumn{3}{|c|}{ الصحف ككل } & \multicolumn{3}{|c|}{ الأيام } & \multicolumn{3}{|c|}{ أخبار الخليج } & \multirow{2}{*}{ الفئات } \\
\hline الترتيب & النسبة\%\% & التكرار & الترتيب & النسبة\%\% & التكرار & الترتيب & النسبة\%\% & التكرار & \\
\hline 1 & $7 \cdot .7 \%$ & $\varepsilon \cdot 1$ & 1 & ov. ¿\% & 19. & 1 & 7r.V\% & YIA & الاتجاه المعرفي \\
\hline $\bar{r}$ & rY. T\% & 104 & $\bar{r}$ & ห.. $\%$ & NV & r & $19 . \%$ & 70 & الاتجاه الوجداني \\
\hline r & $17 . \wedge \%$ & $11 \%$ & $r$ & $17.4 \%$ & $0 \leqslant$ & $\mu$ & IV.r\% & 09 & الاتجاه السلوكي \\
\hline - & $1 \ldots \%$ & TVT & - & $1 \cdots \%$ & rrI & - & $1 \ldots \%$ & $r \leqslant r$ & المجموع \\
\hline
\end{tabular}

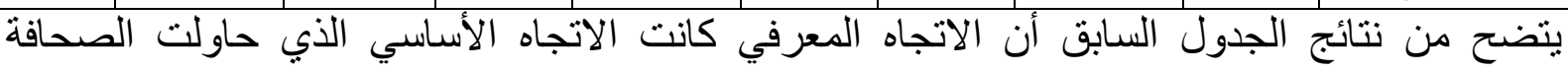

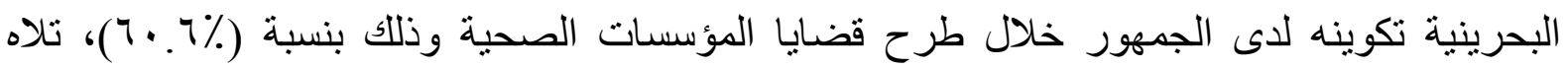

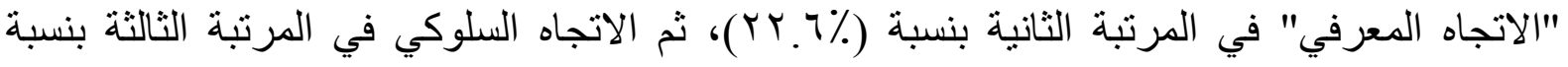


(1\%.4\%) (1). ويلاحظ أن نسبة تركيز صحيفة أخبار الخليج على الاتجاه المعرفي كانت أعلى مقارنة

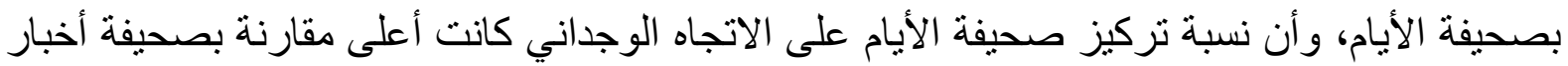
الخليج، في حين كان هنالك تقارب بين الصحيفينتين في نسبة التركيز على الاتجاه السلوكي.

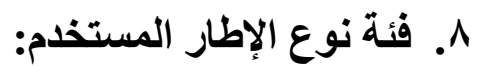
جدول (^): يوضح فئة نوع الإطار المستخذم

\begin{tabular}{|c|c|c|c|c|c|c|c|c|c|}
\hline & د ككل & الصحف & & الأيام & & & لار الخليج & & \\
\hline الترتيب & $\mid$ & التكرار & | الترتيب | & النسبة\%\% & التكرار & يب & $\begin{array}{l}\text { النسبة } \\
\text { \% }\end{array}$ & التكرار & الفئات \\
\hline 1 & $\begin{array}{c}74.7 \\
\%\end{array}$ & $r .9$ & 1 & $7 \leqslant .0 \%$ & $1 \pi \Lambda$ & 1 & T1. $8 \%$ & $|v|$ & إطار المسؤولية \\
\hline$r$ & \begin{tabular}{|c|}
10.1 \\
$\%$
\end{tabular} & v. & r & $1 т .7 \%$ & rq & $r$ & $17.8 \%$ & $\varepsilon 1$ & إطار الإهتمامات \\
\hline$\varepsilon$ & $0 . 々 \%$ & ro & $\varepsilon$ & v. $\%$ & 10 & $r$ & ะ. $\%$ & 1. & إطار الصراع \\
\hline$\mu$ & \begin{tabular}{|c|}
$11 . \varepsilon$ \\
$\%$
\end{tabular} & or & $r$ & $1 \pi .1 \%$ & rA & $\varepsilon$ & $1 . . \%$ & ro & إطار النتائج \\
\hline 0 & $1.0 \%$ & V & 0 & $1.9 \%$ & $\varepsilon$ & 0 & 1. $\%$ & $r$ & إطار المبادئ \\
\hline - & $1 \%$ & $\leqslant 7 \leqslant$ & - & $1 \ldots \%$ & rus & - & $1 \ldots \%$ & Yo. & المجموع \\
\hline
\end{tabular}

يتضح من نتائج الجدول السابق أن أكثر إطار عالجت من خلاله الصحافة البحرينية قضايا المؤسسات

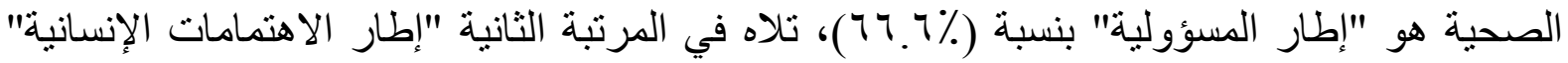

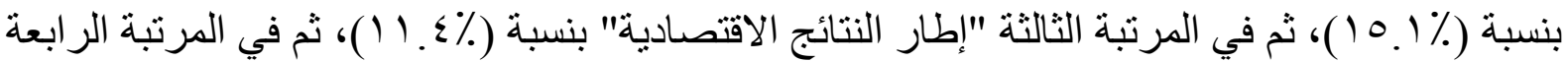

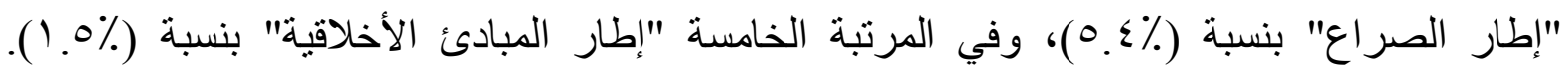

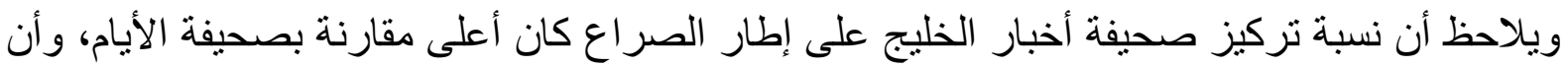

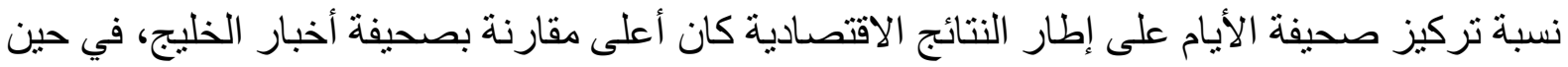
كان هنالك تقارب بين الصحيفتين في التركيز على إطار المبادئ الأخلاقية.

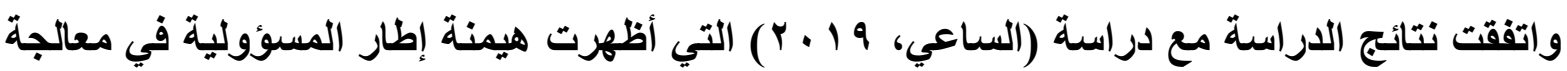

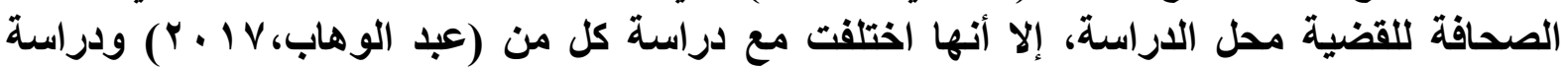

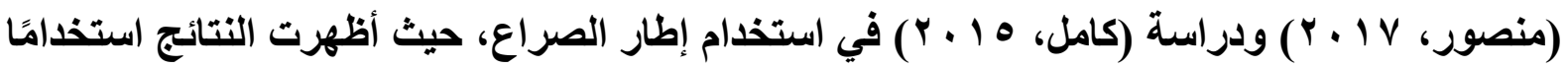

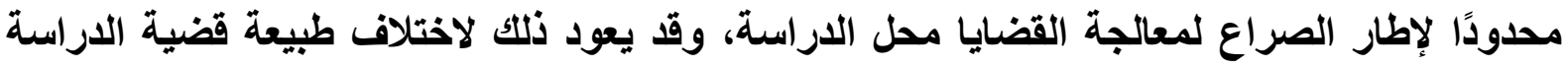

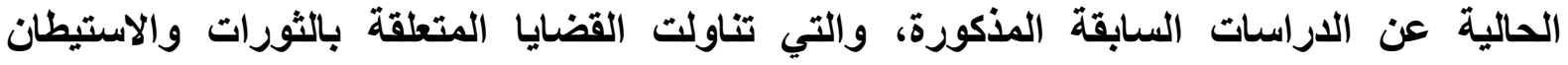

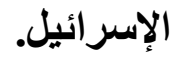


جدول (9): يوضح فئة مسارات البرهنة

\begin{tabular}{|c|c|c|c|c|c|c|c|c|c|}
\hline \multicolumn{3}{|c|}{ الصحف ككل } & \multicolumn{3}{|c|}{ الأيام } & \multicolumn{3}{|c|}{ أخبار الخليج } & \multirow{2}{*}{ الفئات } \\
\hline الترتيب & النسبة\%\% & التكرار & الترتيب & |النسبةة\% & التكرار & الترتيب & النسبة\%\% & التكرار & \\
\hline 1 & $r v_{.} \cdot \%$ & $r \varepsilon r$ & 1 & TV.V\% & 118 & 1 & $\varepsilon \varepsilon . \wedge \%$ & YYT & وصف القضية \\
\hline$r$ & $11.9 \%$ & 1Vo & $\varepsilon$ & $19.5 \%$ & AT & $r$ & $11 . \leqslant \%$ & 94 & أسباب القضية \\
\hline$\varepsilon$ & $1 \wedge . \mu \%$ & IV. & $r$ & Tr.. $\%$ & 94 & $\varepsilon$ & $10.4 \%$ & $V V$ & معالجة القضية \\
\hline$r$ & $r \cdot .0 \%$ & 19. & $r$ & r૫. Y\% & 111 & $\mu$ & $10.7 \%$ & $v 9$ & نتائج القضية \\
\hline 0 & $0.5 \%$ & 0. & 0 & $\varepsilon . \vee \%$ & $r$. & 0 & $0.9 \%$ & $r$ & اقتراح الحلول \\
\hline- & $1 \ldots \%$ & $9 r \wedge$ & - & $1 \ldots \%$ & $\varepsilon r \mu$ & - & $1 \ldots \%$ & 0.0 & المجموع \\
\hline
\end{tabular}

يتضح من نتائج الجدول السابق أن أكثر مسار ات البر هنة التي استخدمنها الصحافة البحرينية خلال

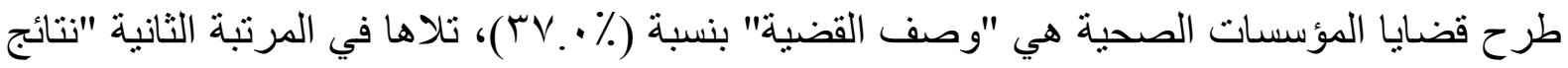

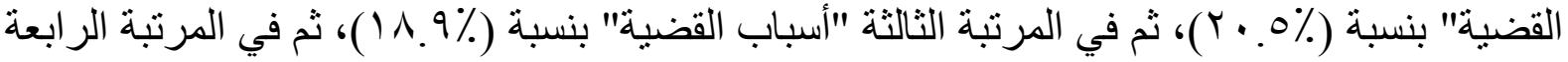

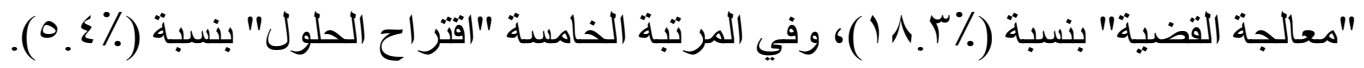
ويلاحظ أن أكثر مسار ات البرهنة التي استخدمنها صحيفة الأيام خلال طرح قضايا المؤسسات

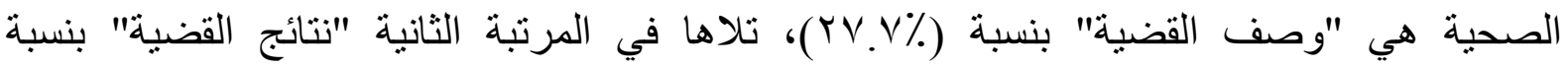

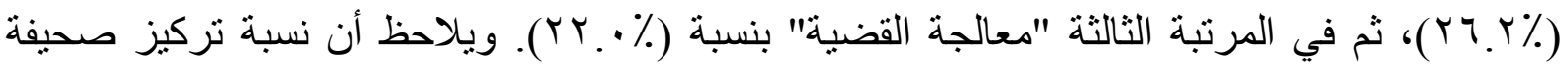

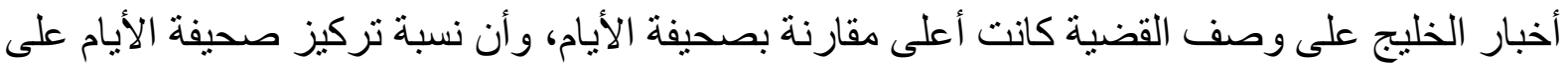

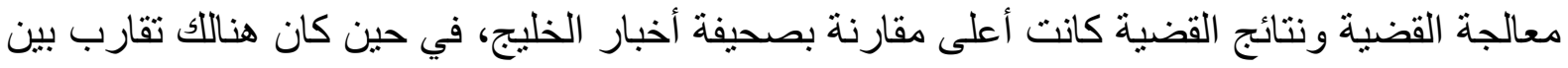
الصحيفتين في نسبة التركيز على أسباب القضية.

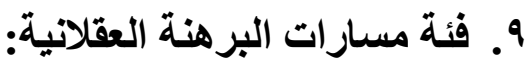

جدول (• ( ): يوضح فئة مسارات البرهنة العقلاتية

\begin{tabular}{|c|c|c|c|c|c|c|c|c|c|}
\hline \multicolumn{3}{|c|}{ الصحف ككل } & \multicolumn{3}{|c|}{ الأيام } & \multicolumn{3}{|c|}{ أخبار الخليج } & \multirow{2}{*}{ القئنات } \\
\hline الترتيب & |النسبة\%\% & التكرار & الترتيب & |النسبة\%\% & التكرار & الترتيب & النسبة\% & التكرار & \\
\hline 1 & \% . & YIV & 1 & r... & rTו & $r$ & r^. $0 \%$ & $\Lambda \varepsilon$ & إبراز تصريحات المولين \\
\hline r & rч. V\% & INV & $\mu$ & $r \cdot . \Sigma \%$ & NT & 1 & ro.r\% & $1 \cdot \varepsilon$ & ورض إحصاءات \\
\hline r & $\Uparrow . \wedge \%$ & $9 V$ & $r$ & r). r\% & $\Lambda 7$ & 0 & r.v\% & 11 & تقديم أدلة وشو اهد \\
\hline V & $\varepsilon .9 \%$ & $\Gamma \varepsilon$ & 0 & $7.9 \%$ & TA & V & T. $\%$ & 7 & عرض در اسات \\
\hline 0 & $\vee . 乏 \%$ & or & $\varepsilon$ & $1 . .1 \%$ & $\leqslant 1$ & 0 & T.V\% & 11 & عرض قو انين \\
\hline 7 & $0 . v \%$ & $\varepsilon$. & 0 & $7.9 \%$ & rA & $\varepsilon$ & $\varepsilon .1 \%$ & Ir & عرض نماذج لقضايا \\
\hline$\varepsilon$ & $1 . .7 \%$ & $V \varepsilon$ & V & $1 . v \%$ & V & $r$ & YY.V\% & $7 V$ & تقديم شهود العيان \\
\hline- & $1 \ldots \%$ & $v \cdot 1$ & - & $1 \ldots \%$ & $\varepsilon .7$ & - & $1 \ldots \%$ & Yqo & المجموع \\
\hline
\end{tabular}


يتضح من نتائج الجدول السابق أن أكثر مسارات البرهنة العقلانية التي استخدمتها الصحافة البحرينية

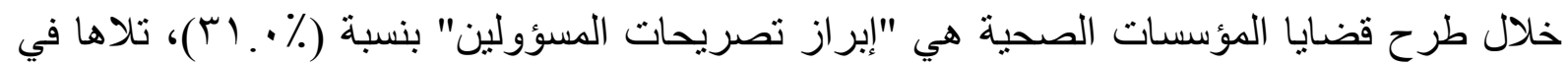

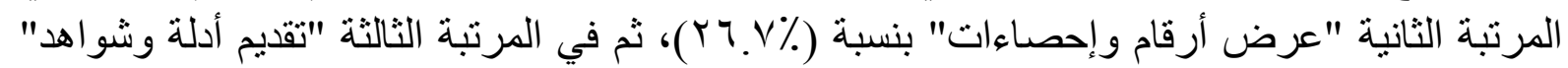

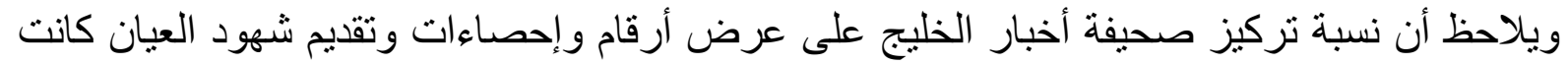

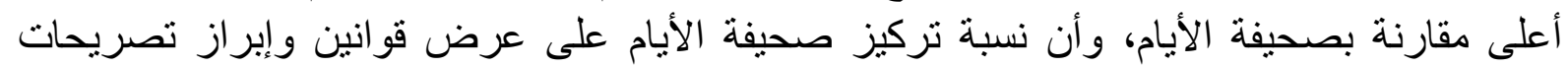

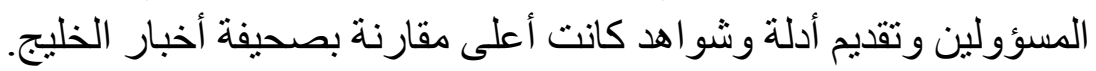

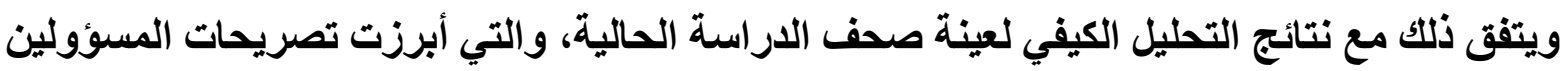

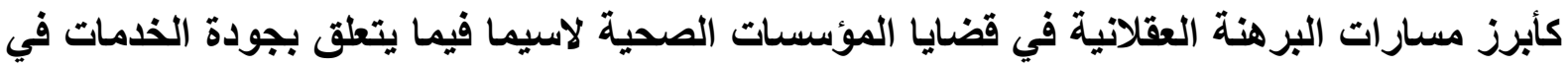

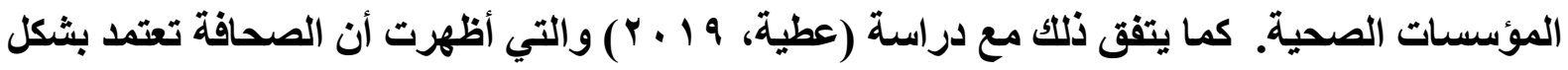

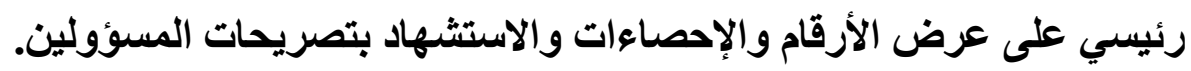

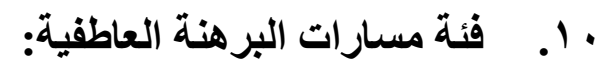

جدول (1 ال): يوضح فئة مسارات البرهنة العاطفية

\begin{tabular}{|c|c|c|c|c|c|c|c|c|c|}
\hline \multicolumn{3}{|c|}{ الصحف ككل } & \multicolumn{3}{|c|}{ الأيام } & \multicolumn{3}{|c|}{ أخبار الخليج } & \multirow{2}{*}{ الفئات } \\
\hline |الترتيب & |النسبةة\% & التكرار & الترتيب & النسبة\%\% & التكرار & الترتيب & النسبة\%\% & التكرار & \\
\hline 1 & r. & $1 Y 7$ & 1 & r. & $\varepsilon r$ & 1 & "ᄉ.V\% & $\Lambda \varepsilon$ & الطمأنة \\
\hline r & $r . r \%$ & 1.0 & r & rq. r\% & ऍ人 & r & $r \cdot .9 \%$ & $7 V$ & المبالغة في التركيز \\
\hline$\varepsilon$ & $\Lambda .7 \%$ & $r$. & $\mu$ & $11.0 \%$ & 10 & $\varepsilon$ & $7.9 \%$ & 10 & التعميم \\
\hline$\mu$ & $1 . .2 \%$ & rV & 7 & $7.9 \%$ & 9 & $\mu$ & $1 \% .9 \%$ & TA & التبرير \\
\hline 0 & $7 . r \%$ & TY & 0 & $1.0 \%$ & 11 & 0 & $0.1 \%$ & 11 & التخويف \\
\hline 7 & $0 . \wedge \%$ & $r$. & $\varepsilon$ & $9 . r \%$ & Ir & 7 & r.v\% & $\wedge$ & المبالغة في التركيز \\
\hline V & $r . \%$ & V & V & r.r\% & $r$ & V & $1 . \wedge \%$ & $\varepsilon$ & أخرى \\
\hline- & $1 \ldots \%$ & $r \leqslant V$ & $1 \ldots \%$ & - & $1 \%$ & - & $1 \ldots \%$ & YIV & المجموع \\
\hline
\end{tabular}

يتضح من نتائج الجدول السابق أن أكثر مسار ات البرهنة العاطفية التي استخدمتها الصحافة البحرينية

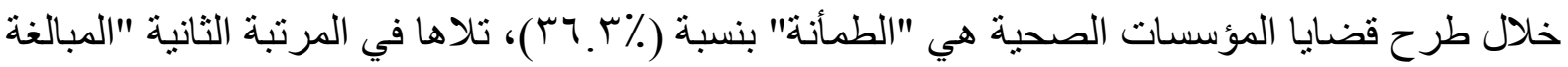

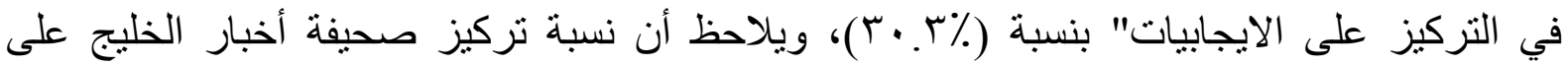

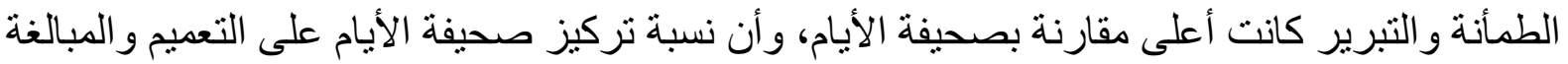

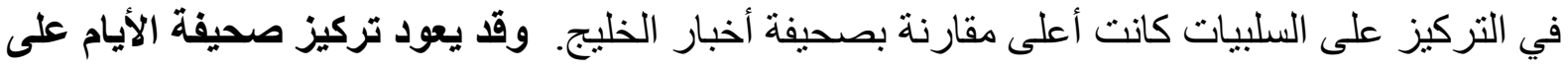

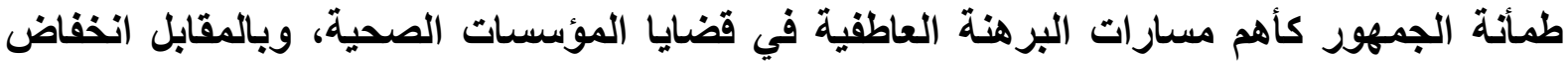

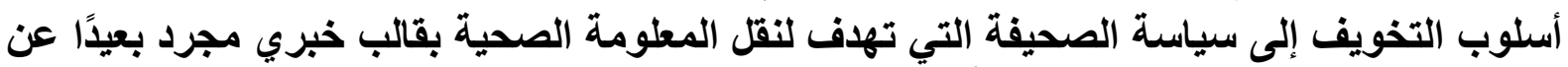
الإثارات والعناوين التي قد تخلق مخاوفًا لادى الجمهور. 
جدول (r ا I): يوضح فئة القضايا الصحية العامة

\begin{tabular}{|c|c|c|c|c|c|c|c|c|c|}
\hline \multicolumn{3}{|c|}{ الصحف ككل } & \multicolumn{3}{|c|}{ الأيـام } & \multicolumn{3}{|c|}{ أخبار الخليج } & \multirow{2}{*}{ الفئات } \\
\hline الترتيب & |النسبةة\% & التكرار & الترتيب & النسبةة\% & التكرار & الترتيب & النسبة\%\% & التكرار & \\
\hline 1 & rq.v\% & 0. & r & rq. r\% & Tr & 1 & $0 \leqslant .9 \%$ & rᄉ & الأزمات و المشكلات \\
\hline$r$ & $r \leqslant .9 \%$ & $\varepsilon \varepsilon$ & 1 & $\Sigma 1 . r \%$ & M & Y & ro. $0 \%$ & $\pi$ & الضمان الصحي \\
\hline$\mu$ & YO. ¿\% & Tr & $r$ & rq..$\%$ & TY & $\mu$ & $19.7 \%$ & 1. & التو عية الصحية \\
\hline- & $1 \ldots \%$ & $1 Y 7$ & - & $1 \ldots \%$ & Vo & - & $1 \ldots \%$ & 01 & المجموع \\
\hline
\end{tabular}

يتضح من نتائج الجدول السابق أن أكثر القضايا الصحية العامة التي طرحتها الصحافة البحرينية هي

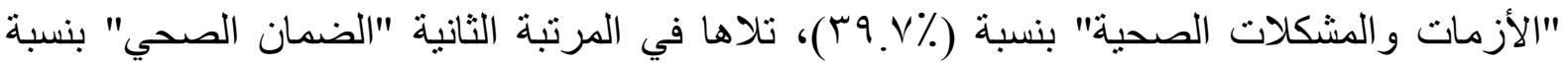

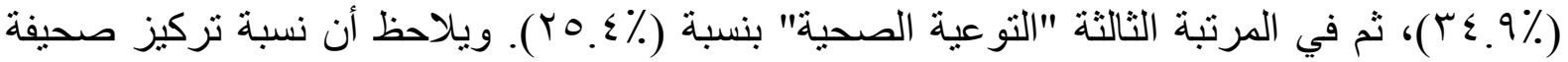
أخبار الخليج على "الأزمات و المشكلات الصحية" كانت أعلى مقارنة بصحيفة الأيام، وأن نسبة تركيز صحيفة الأيام على قضيتي "الضمان الصحي" و "التو عية الصحية" كانت أعلى مقارنة بأخبار الخليج.

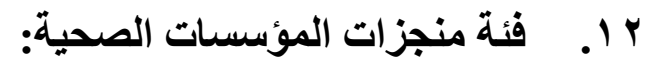
جدول (r ا ) يوضح فئة منجزات المؤسسات الصحية

\begin{tabular}{|c|c|c|c|c|c|c|c|c|c|}
\hline \multicolumn{3}{|c|}{ الصحف ككل } & \multicolumn{3}{|c|}{ الأيام } & \multicolumn{3}{|c|}{ أخبار الخليج } & \multirow{2}{*}{ الفئات } \\
\hline الترتيب & النسبة \% & التكرار & الترتيب & النسبة\% & التكرار & الترتيب & النسبة\% & التكرار & \\
\hline 1 & $71.4 \%$ & 104 & 1 & $\vee 1.7 \%$ & VT & 1 & $0 \leq .1 \%$ & $\Lambda$. & جودة الخدمات \\
\hline r & ґ..^\% & $9 V$ & $r$ & rA. $\varepsilon \%$ & rq & r & $\leq 0.9 \%$ & 71 & و الفعاليات و البر امجة الصنة \\
\hline - & $1 \ldots \%$ & Yo. & - & $1 \ldots \%$ & $1 \cdot r$ & - & $1 \ldots \%$ & $1 \leqslant 1$ & المجموع \\
\hline
\end{tabular}

يتضح من نتائج الجدول السابق أن أكثر منجزات المؤسسات الصحية التي طرحتها الصحافة البحرينية هي "جودة الخدمات الصحية والطبية" بنسبة (\% ب. (7)، تلاها "إقامة الأنشطة و الفعاليات و البرامج

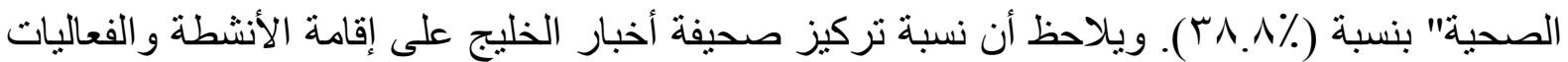

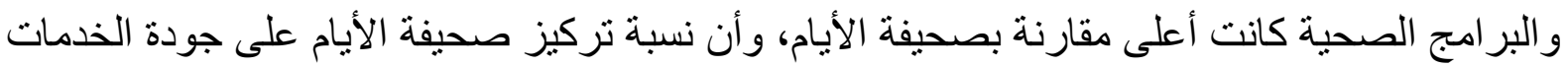
الصحية و الطبية كانت أعلى مقارنة بصحيفة أخبار الخليج. 
با 1. فئة القصور في المؤسسات الصحية:

جدول (؛ أ) يوضح فئة القصور في المؤسسات الصحية

\begin{tabular}{|c|c|c|c|c|c|c|c|c|c|}
\hline \multicolumn{3}{|c|}{ الصحف ككل } & \multicolumn{3}{|c|}{ الأيام } & \multicolumn{3}{|c|}{ أخبار الخليج } & \multirow{2}{*}{ الفئات } \\
\hline الترتيب & النسبة\%\% & التكرار & الترتيب & النسبة\%\% & التكرار & الترتيب & النسبة\%\% & التكرار & \\
\hline 1 & $09 . \vee \%$ & rV & 1 & ov. $1 \%$ & r. & 1 & \%. & IV & تذني جودة الخدمات \\
\hline r & $\varepsilon \cdot . r \%$ & ro & r & $\varepsilon$ «..$\%$ & 10 & $r$ & $r v_{.} . \%$ & 1. & والإخهاء الطبية \\
\hline - & $1 \ldots \%$ & 74 & - & $1 \ldots \%$ & ro & - & $1 . . \%$ & $r V$ & المجموع \\
\hline
\end{tabular}

يتضح من نتائج الجدول السابق أن أكثر جوانب القصور في المؤسسات الصحية التي طرحتها

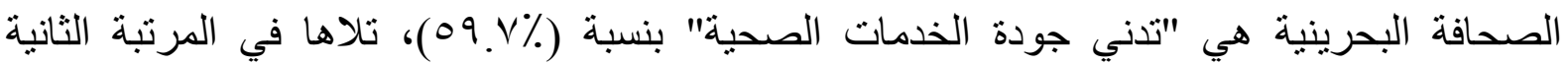

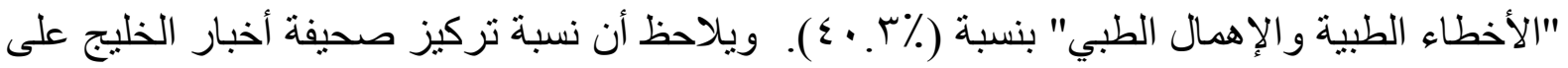

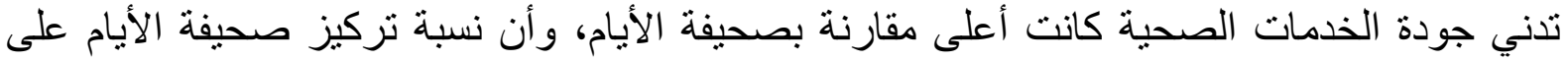
الأخطاء الطبية و الإهمال الطبي كانت أعلى مقارنة بصحيفة أخبار الخليج.

ع ا. . فئة الأطر المرجعية التي استندت إليها الصحف: جدول (10): يوضح فئة الأطر المرجعية التي استندت إليها الصحف

\begin{tabular}{|c|c|c|c|c|c|c|c|c|c|}
\hline \multicolumn{3}{|c|}{ الصحف ككل } & \multicolumn{3}{|c|}{ الأيام } & \multicolumn{3}{|c|}{ أخبار الخليج } & \multirow{2}{*}{ الفئات } \\
\hline الترتيب & النسبة\%\% & التكرار & الترتيب & النسبة\%\% & التكرار & الترتيب & النسبة\%\% & التكرار & \\
\hline 1 & $r \varepsilon . \vee \%$ & 110 & 1 & r. & 91 & 1 & rr.v\% & NV & المرجعية السياسية \\
\hline r & Y. $.7 \%$ & 110 & $r$ & $17.0 \%$ & $\varepsilon \varepsilon$ & r & rฯ. $\vee \%$ & VI & المرجعية العلمية \\
\hline$r$ & $T \cdot .0 \%$ & 1.9 & $r$ & TO.A\% & 79 & $r$ & $10 . \%$ & «. & المرجعية القانونية \\
\hline$\varepsilon$ & $1 . . V \%$ & ov & $\varepsilon$ & $9 . \%$ & $r \varepsilon$ & $\varepsilon$ & $1, \tau . \varepsilon \%$ & זT & المرجعية الاقتصادية \\
\hline 0 & $7.5 \%$ & r & 0 & 7. $\{\%$ & IV & 0 & $7 . \%$ & 17 & المرجعية الأخلاقية \\
\hline 7 & $\Gamma . \wedge \%$ & r. & 7 & r. $६ \%$ & 9 & 7 & $\varepsilon .1 \%$ & 11 & المرجعية التاريخية \\
\hline V & Y..$\%$ & $1 \varepsilon$ & V & T. . \% & 7 & $\bar{v}$ & r. $\%$ & $\Lambda$ & أخرى \\
\hline - & $1 \ldots \%$ & OrT & - & $1 \ldots \%$ & rqV & - & $1 \ldots \%$ & YIT & المجموع \\
\hline
\end{tabular}

يتضح من نتائج الجدول السابق أن أكثر الأطر المرجعية التي استندت إليها الصحافة البحرينية خلال

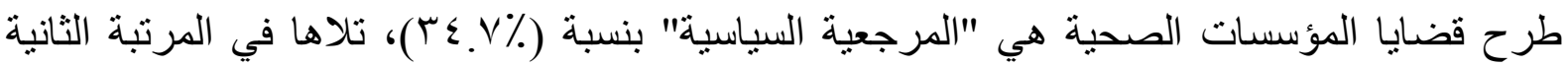

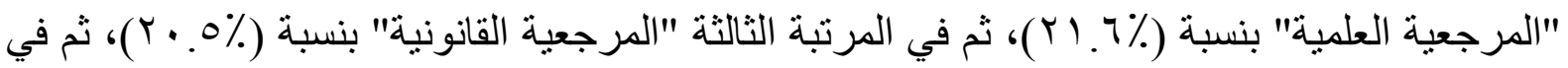

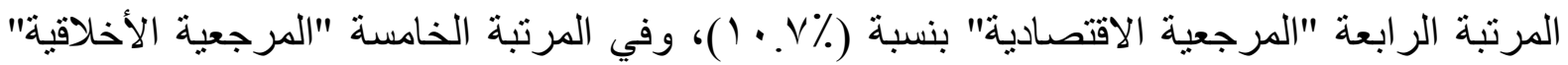

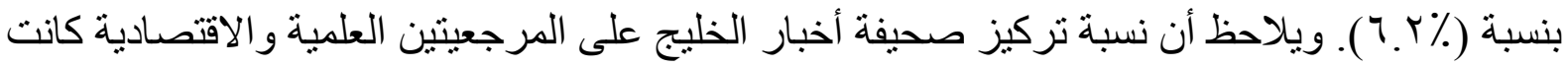

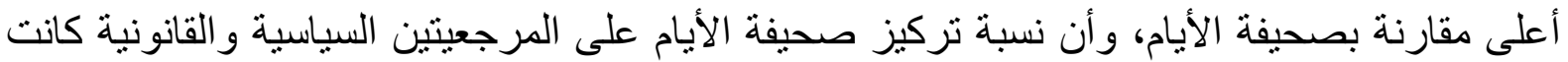

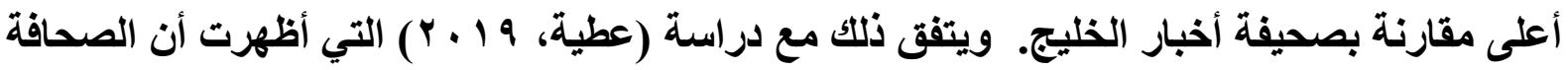


تستثد إلى أطر مرجعية متعددة تثمل النظام السياسي السائد، وقد يعود ذلك إلى خضوع جميع الصحف البحرينية لنظام الدولة وتعبر عن وجهة أطنة نظرها.

ه إئة المصادر التي اعتمدت عليها الصحف:

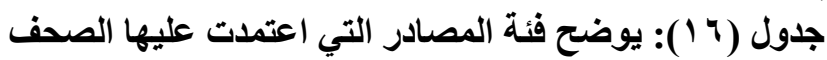

\begin{tabular}{|c|c|c|c|c|c|c|c|c|c|}
\hline \multicolumn{2}{|c|}{ الصحف ككل } & & \multicolumn{3}{|c|}{ الأيام } & \multicolumn{3}{|c|}{ أخبار الخليج } & \multirow{2}{*}{ الفئات } \\
\hline |الترتيب & النسبة\% & التكرار & الترتيب & النسبة\% & التكرار & الترتيب & النسبة\%\% & التكرار & \\
\hline 1 & $r \leq .1 \%$ & $11 r$ & 1 & rV. . \% & 77 & $r$ & $r \cdot . \Sigma \%$ & $\leqslant 7$ & المسؤولون \\
\hline r & $10.0 \%$ & VY & r & IV.r\% & \& & $r$ & IT.V\% & M & وزارة الصحة \\
\hline 1 & $Y \leq .1 \%$ & $11 Y$ & r & IV.r\% & $\leqslant$ & 1 & T. $.2 \%$ & VI & الطاقم الطبي \\
\hline$\varepsilon$ & $9.0 \%$ & $\leqslant \varepsilon$ & 0 & $1.0 \%$ & ro & $\varepsilon$ & ᄉ. $\leqslant \%$ & 19 & المجلس الأعلى \\
\hline 7 & $7 . \%$ & rA & V & $\varepsilon .7 \%$ & 11 & 0 & $\vee .0 \%$ & IV & الصيئة تتظيم المهن (نهرا) \\
\hline 0 & $\wedge . \uparrow \%$ & rᄉ & $\varepsilon$ & $1 Y .1 \%$ & rq & $\wedge$ & $\varepsilon . \%$ & 9 & مجلسا الثورى \\
\hline V & $0 . \wedge \%$ & TV & 7 & $0 . \%$ & Ir & 7 & $7.7 \%$ & 10 & الصحرفيون الصحون \\
\hline$\wedge$ & $\varepsilon .0 \%$ & YI & $\wedge$ & r. $9 \%$ & V & V & $7.4 \%$ & $1 \varepsilon$ & أخرى \\
\hline 9 & r. $₹ \%$ & 11 & $\wedge$ & r. $9 \%$ & V & 9 & $1 . \wedge \%$ & $\varepsilon$ & منظمة الصحة \\
\hline- & $1 \ldots \%$ & $\leqslant 70$ & - & $1 \ldots \%$ & rrq & - & $1 \ldots \%$ & YYY & المجموع \\
\hline
\end{tabular}

يتضح من نتائج الجدول السابق أن أكثر المصادر التي اعتمدت عليها الصحافة البحرينية خلال طرح

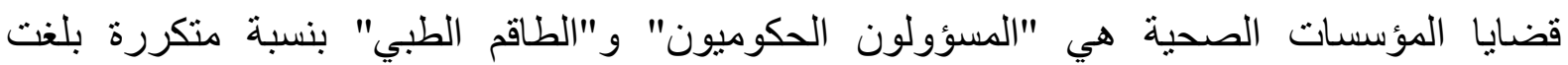

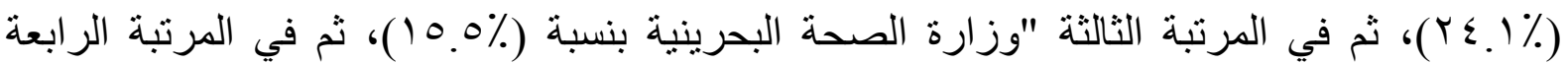

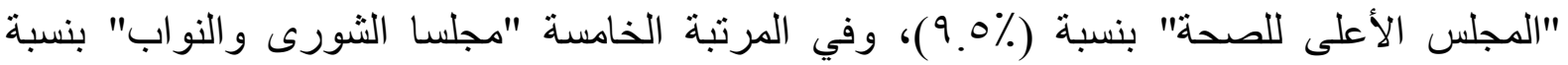

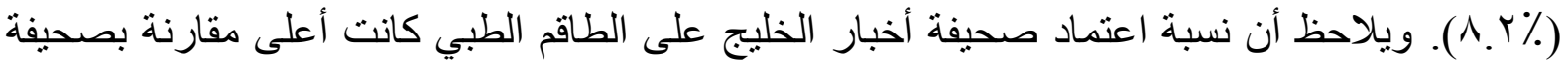

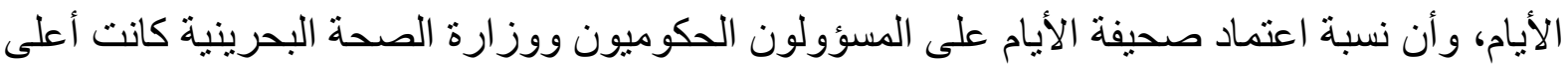

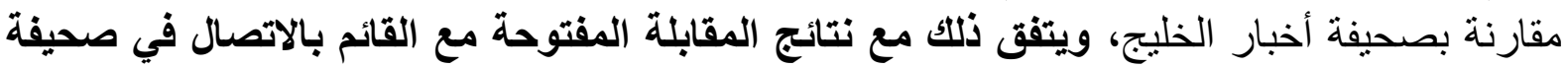

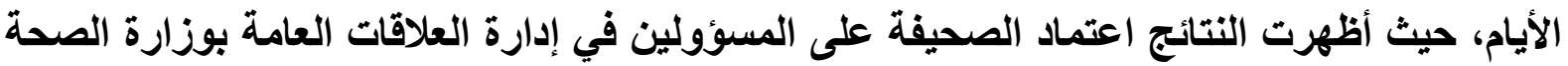

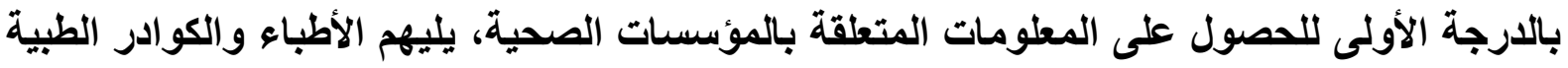
في المؤسسات الصحية الحكومية والخاصة، ثم المبول المرضى. 
نتائج الاراسة الميدانية

أولاً: خصائص عينة الاراسة 1. توزيع العينة حسب متغير النوع

شكل ( ) ) توزيع عينة الدراسة حسب متغير النوع

\begin{tabular}{|c|c|c|}
\hline المئوية & العدد & النوع \\
\hline$\leqslant 7 . \leqslant \%$ & TrT & ذكر \\
\hline or. $7 \%$ & YฯA & أنثى \\
\hline $1 . \%$ & 0. & المجموع \\
\hline
\end{tabular}

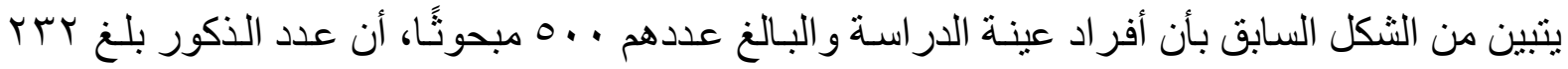

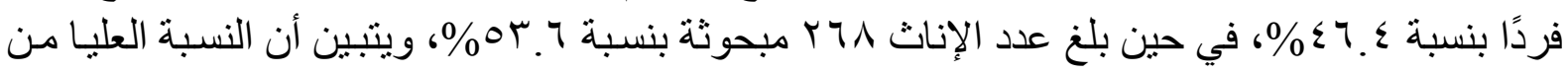
المبحوثين هم من فئة الإناث.

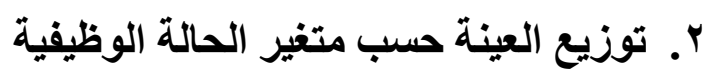
شكل (؟) توزيع عينة الاراسة حسب متغير الحالة الوظيفية

\begin{tabular}{|c|c|c|}
\hline النسبة المئوية & العدد & الحالة الوظيفية \\
\hline$r V . r \%$ & $1 \wedge 7$ & موظف \\
\hline$\wedge . \wedge \%$ & $\varepsilon \varepsilon$ & عمل حر \\
\hline Y..० & $1 \Gamma$ & متقاعد \\
\hline r^. $\%$ & $1 \leq$. & لا يعمل \\
\hline $1 \ldots \%$ & $0 \ldots$ & المجموع \\
\hline
\end{tabular}

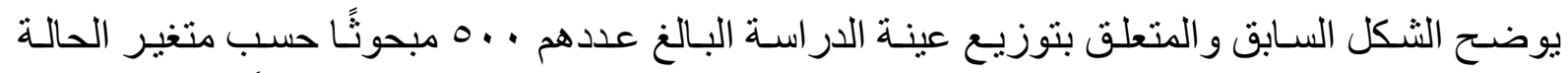

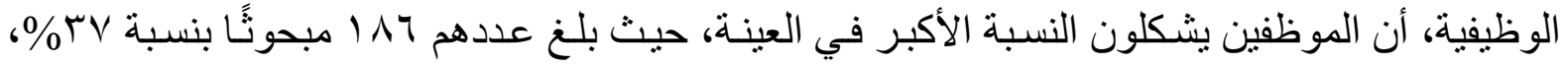

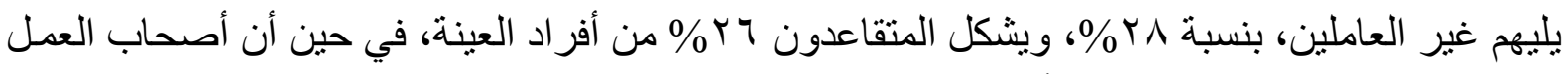
الحر، يشكلون ^^^^\% من إجمالي أفر اد العينة.

r. توزيع العينة حسب متغير الفئة العمرية

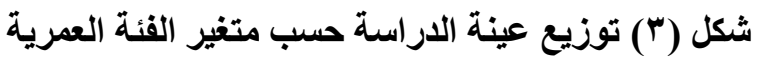

\begin{tabular}{|c|c|c|}
\hline النسبة المئوية & العدد & الفئة العمرية \\
\hline $10.5 \%$ & $V V$ & من ^/ لأقل من ·r عامًا \\
\hline$\leqslant 0 . \%$ & Yro & من ·r لأقل من 0؛ عامًا \\
\hline$r \cdot . \Sigma \%$ & $10 Y$ & من 0؛ لأقلل من • 7 عامًا \\
\hline $9 . r \%$ & $\leqslant 7$ & أكثر من • 7 عامًا \\
\hline $1 \ldots \%$ & $0 \ldots$ & المجموع \\
\hline
\end{tabular}




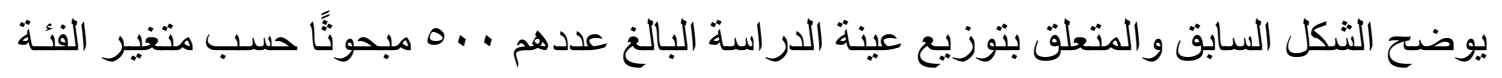

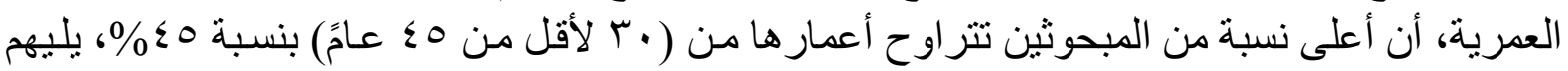

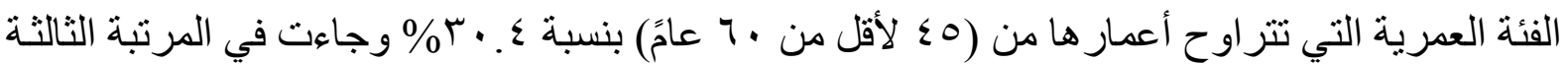

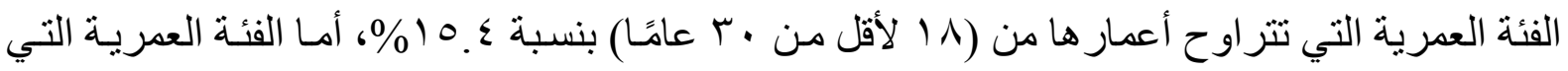

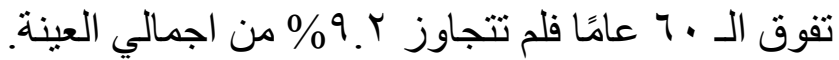

؛. توزيع العينة حسب متفير المستوى التعليمي شكل (؛) توزيع عينة الاراسة حسب متغير المستوى التطليمي

\begin{tabular}{|c|c|c|}
\hline النسبة المئوية & العدد & المستوى التعليمي \\
\hline YА. Y\% & $1 \xi 1$ & ثانوية عامة فأقلّ \\
\hline$r \cdot . \wedge \%$ & $1 . \varepsilon$ & 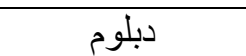 \\
\hline r.. & IAY & بكالوريوس \\
\hline $1 \leqslant .7 \%$ & $V T$ & در اسات عليا \\
\hline.$\%$ & $0 \ldots$ & المجموع \\
\hline
\end{tabular}

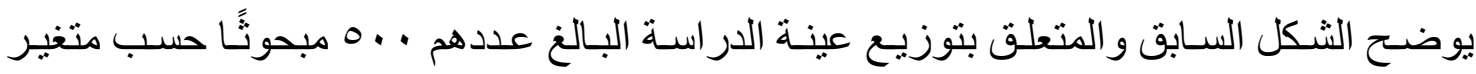

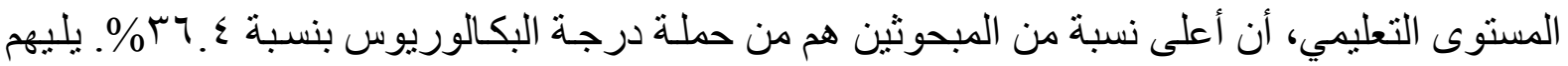

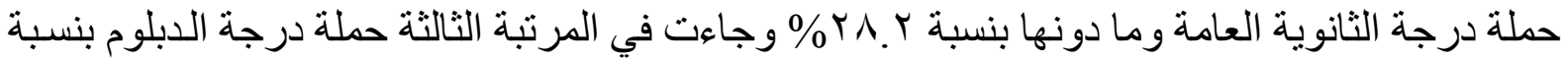

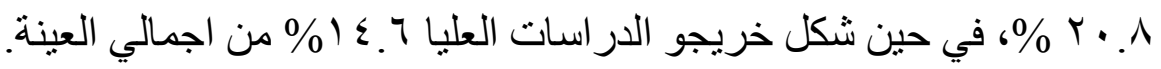

\section{المؤشرات التحليلية للاراسة الميدانية}

تم التوصل إلى هذه النتائج بعد تحليل البيانات باستخدام برنامج الحزمة الإحصائية للعلوم الاجتماعية

:SPSS

ا . معدل متابعة الصحف البحرينية اليومية في الأسبوع سواء بنستها الورقية أو الاكترونية:

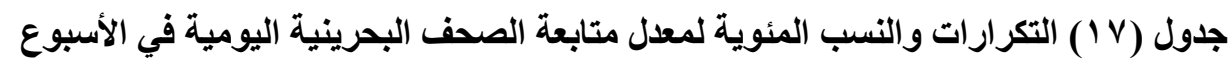

\begin{tabular}{|c|c|c|}
\hline النسب المئوية & | التكرارات & الاستجابة \\
\hline r..А\% & $1 \pi \varepsilon$ & يوميًا \\
\hline rY.A\% & $11 \varepsilon$ & من ثلاث إلى ست مرات في الأسبوع \\
\hline $0 . .2 \%$ & YOY & مرة أو مرتين في الأسبوع \\
\hline $1 \ldots \%$ & $0 \ldots$ & المجموع \\
\hline
\end{tabular}

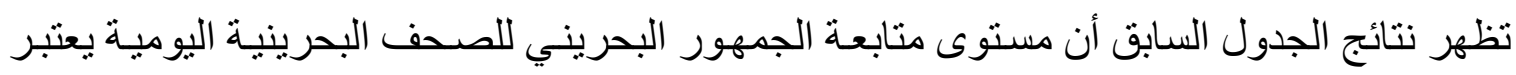

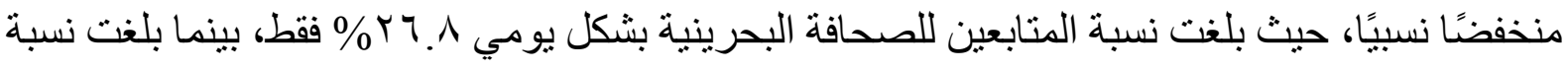




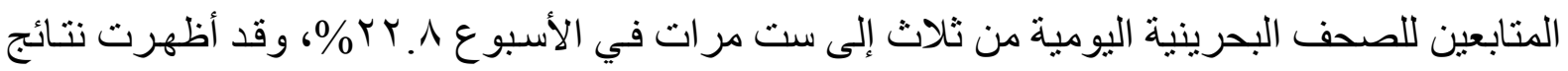

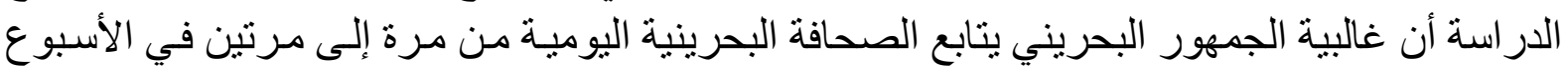

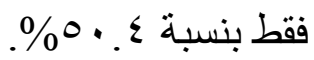

وقد يعود هذا الانخفاض إلى ظهور وسـائل الاتصـال الحديثة المنافسـة لوسيائل الاعلام التقليدية،

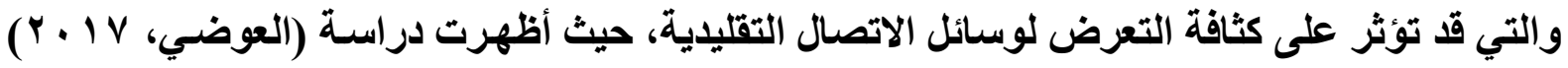

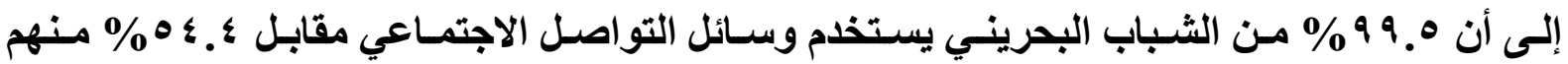

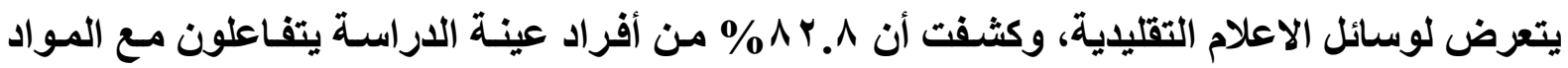

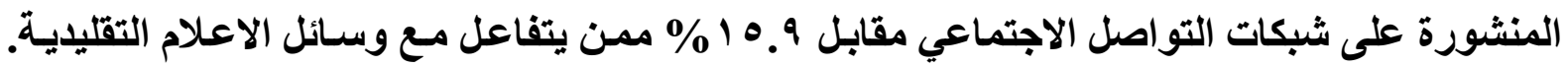

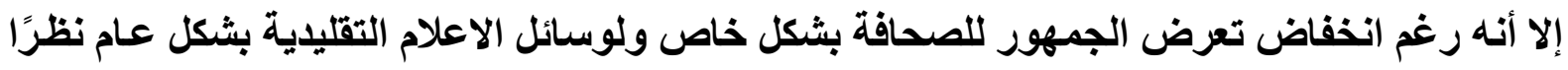

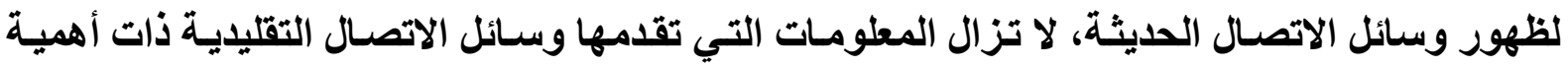

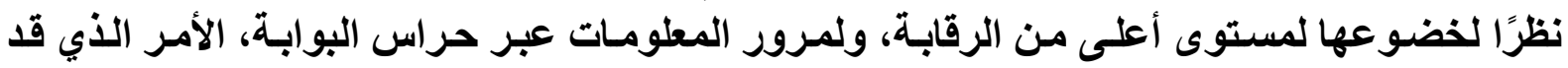
يفسر حرض فئة من الجمهور على الحصول على المعلومات ولمن من خلال الصحافة التقليدية.

r. معدل متابعة الصحف البحرينية اليومية للتعرف على أخبار وقضايا المؤسسات الصحية:

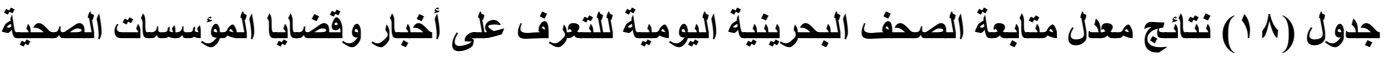

\begin{tabular}{|c|c|c|c|c|c|c|c|c|c|c|}
\hline \multirow{2}{*}{ الألهبية } & \multirow{2}{*}{ المعياري } & \multirow{2}{*}{ الحسابي } & \multicolumn{2}{|c|}{ أبدًا } & \multicolumn{2}{|c|}{ أحيانًا } & \multicolumn{2}{|c|}{ دائمًا } & \multirow{2}{*}{ الصحيفة } & \multirow{2}{*}{ |الرقم| } \\
\hline & & & $\%$ & $\ddot{ت}$ & $\%$ & $ت$ & $\%$ & 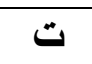 & & \\
\hline $7.9 \%$ & $\cdot v \cdot 1$ & $r . \cdot r T$ & YY.A\% & $11 \varepsilon$ & $\cdot . \wedge \%$ & YOS & Yฯ. \&\% & ITr & أخبار الخليج & 1 \\
\hline $1.0 \%$ & .701 & $r_{.} .1 \leq T$ & $10.5 \%$ & $V V$ & $0 \leqslant .7 \%$ & $r V T$ & $\Gamma \cdot . \%$ & 10. & الأيام & T \\
\hline IT.r\% & $\cdot . T V V$ & $1 . \wedge V$. & $r \cdot . r \%$ & 101 & or. $7 \%$ & YTr & TV.Y\% & 14 & الوطن & $r$ \\
\hline А. $\{\%$ & $\therefore .779$ & $1 . V O r$ & $r v . \wedge \%$ & 119 & $\sum q .4 \%$ & $r \leq 7$ & $1 \% . \%$ & 70 & البلاد & $\varepsilon$ \\
\hline
\end{tabular}

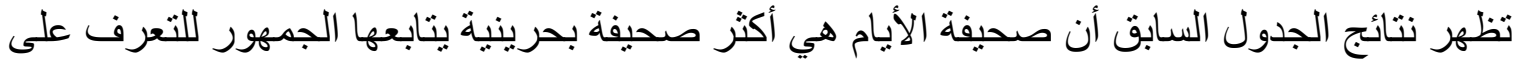

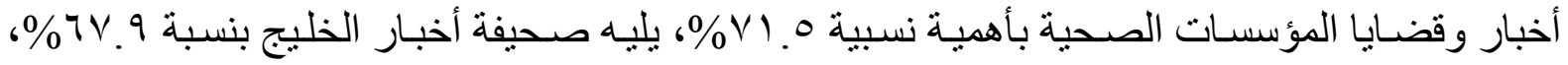

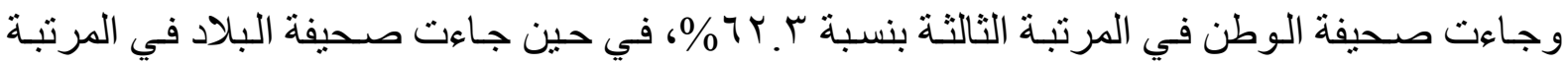

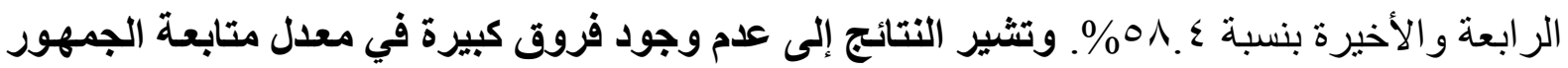

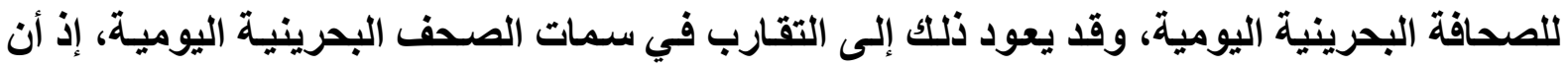

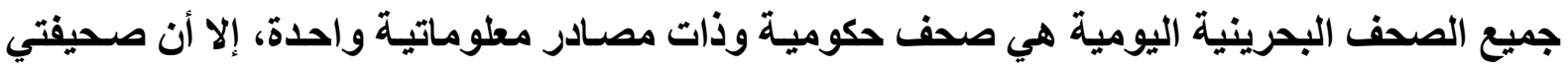

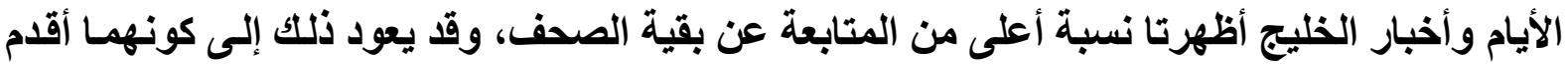

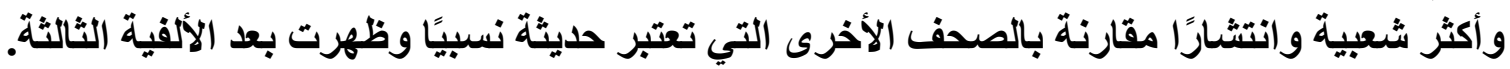


r. درجة الثقة بالمعلومات التي تقدمها الصحافة البحرينية اليومية حول قضايا المؤسسات الصحية:

جدول (9 1 ) درجة الثقة بالمعلومات التي تقدمها الصحافة البحرينية اليومية حول قضايا المؤسسات الصحية

\begin{tabular}{|c|c|c|c|c|c|c|c|c|c|c|}
\hline الأهمية & الانحراف & المتوسط & \multicolumn{2}{|c|}{ أبدًا } & \multicolumn{2}{|c|}{ أحيانًا } & \multicolumn{2}{|c|}{ دائمًا } & \multirow{2}{*}{ الصحيفة } & \multirow{2}{*}{ الرقم } \\
\hline النسبية & المعياري & الحسابي & $\%$ & ت & $\%$ & ت & $\%$ & ت & & \\
\hline $79.8 \%$ & .719 & r.9. & $10 . \%$ & Vo & $71 . \%$ & $r .0$ & $r \leqslant . \%$ & Tr. & أخبار الخليج & 1 \\
\hline$V \cdot .0 \%$ & .017 & $r .117$ & $1 Y . \%$ & 7. & $7 £ . \S \%$ & MYY & YT. T\% & 111 & الأيام & r \\
\hline $7 \leqslant .1 \%$ & $\because 7 Y 9$ & $1.9 Y 5$ & YT.A\% & 119 & $7 . . \%$ & r.. & $17.4 \%$ & $\wedge 1$ & الوطن & $\mu$ \\
\hline $7 r .0 \%$ & .7 .0 & 1.9 .7 & rT.६\% & $11 \mathrm{~V}$ & 7 7. $7 \%$ & TIT & $1 \leqslant . \%$ & $v$. & البلاد & $\varepsilon$ \\
\hline
\end{tabular}

تظهر نتائج الجدول السابق أن صحيفة الأيام هي أكثر صحيفة بحرينية يثق الجمهور بالمعلومات التي

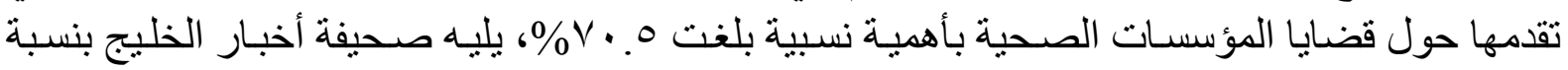

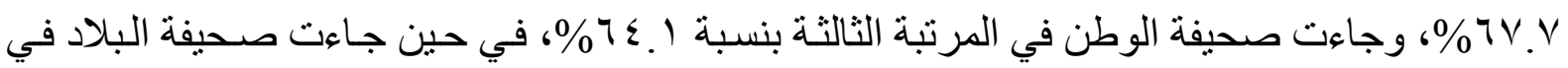

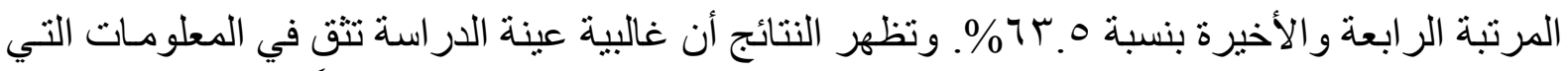

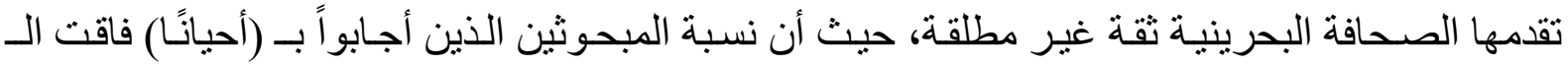
• ^\% في جميع الصحف. إلا أن النتائج أظهرت مستوى ثقة أعلى في صحيفتي الأيسام وأخبـار الخليج

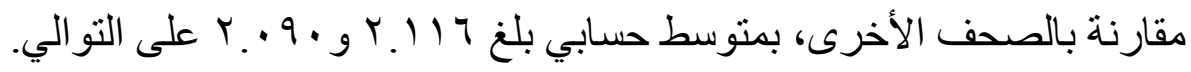
وقد ترجع الثقة النسبية للمبحوثين إلى عدة أسباب، منها: أن غالبيـة المبحوثين هم من الفئة العمريـة

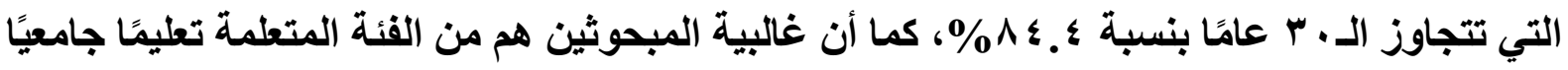

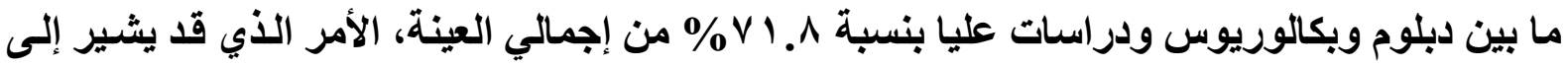

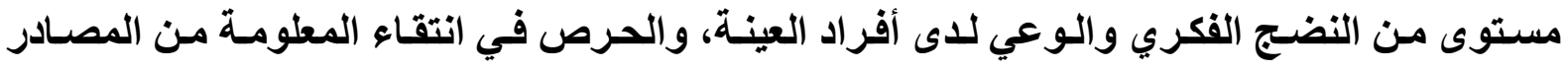
الإعلامية دون منح الثقة المطلقة.

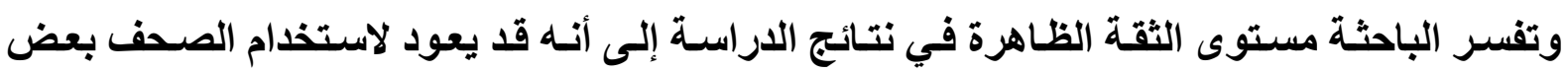

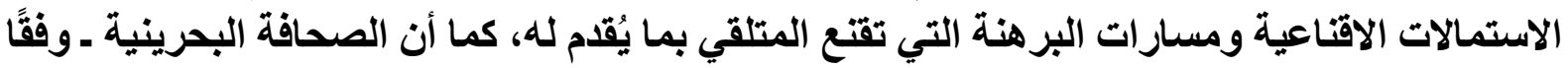

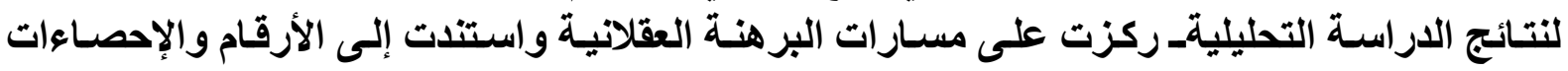

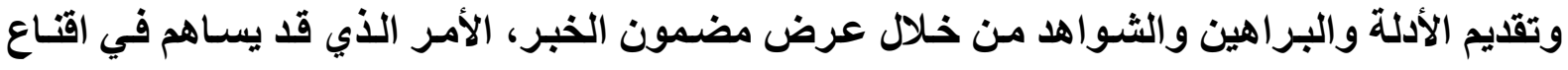

المتلقي وتبنيه التوجه العام للصحيفة.

؛. أطر الجمهور نحو المؤسسات الصحية البحرينية وفقًا لتتائج الدراسة

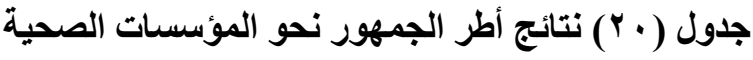

\begin{tabular}{|c|c|c|c|c|c|}
\hline الترتيب & الأهمية & الالمعراف & الحستوسطي & 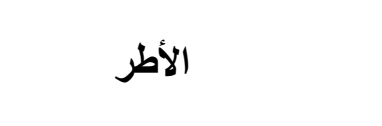 & الرقم \\
\hline 1 & $\wedge r_{.} \%$ & 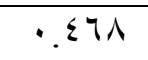 & Y. $\{71$ & إطار الاهتمامات الإنسانية & 1 \\
\hline T & $\Lambda 1 . r \%$ & $\because \varepsilon V \leqslant$ & T. $\varepsilon r V$ & إطار النتائج الاقتصادية & 0 \\
\hline
\end{tabular}




\begin{tabular}{|c|c|c|c|c|c|}
\hline الترتيب & الأهمية & الانحراف & الحستوسطي & الأطر & الرقم \\
\hline$r$ & $\vee \neg . \vee \%$ & $\cdot$ r YVA & r.r... & إطار الصراع & $r$ \\
\hline$\varepsilon$ & $V \leqslant .9 \%$ & $\cdot \varepsilon r \leqslant$ & $Y . Y \leqslant V$ & إطار المسؤولية & $\varepsilon$ \\
\hline 0 & $\vee r . \wedge \%$ & $\cdot \varepsilon \wedge \vee$ & Y.YIO & إطار المبادئ الأخلاقية & r \\
\hline
\end{tabular}

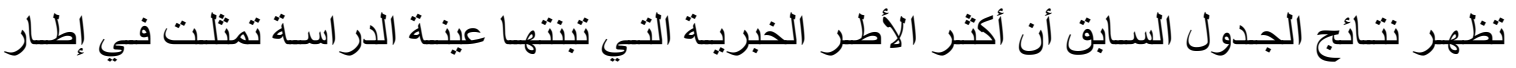

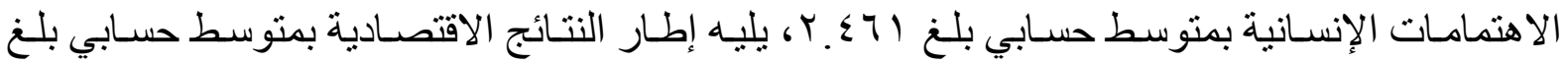

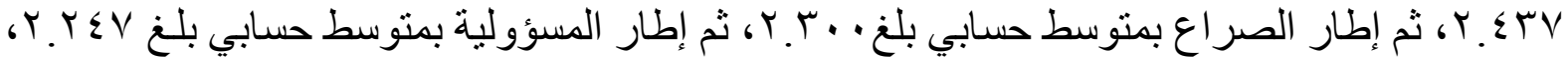

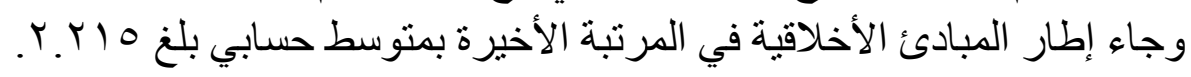

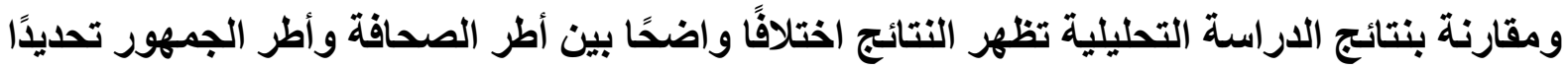

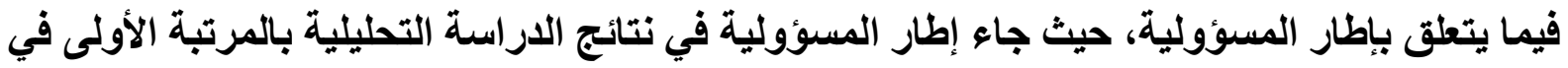

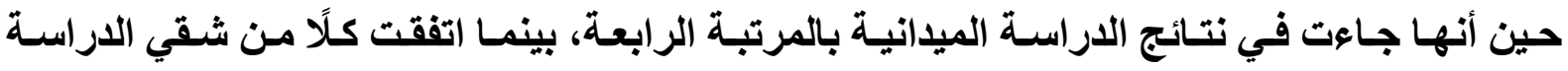

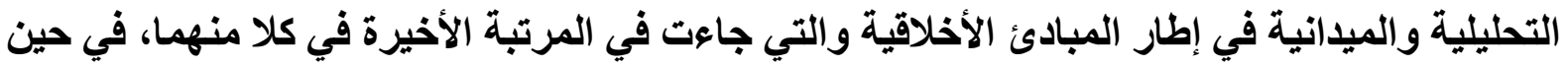

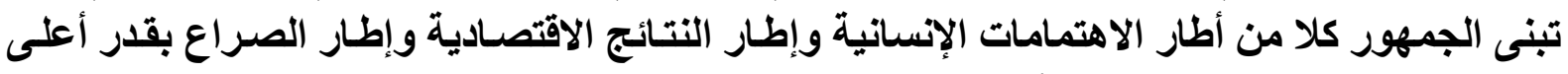
من استخدام الصحافة البحرينية للأطر المذكورة.

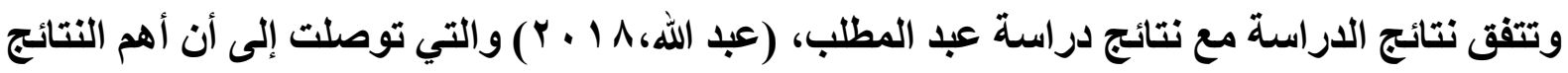

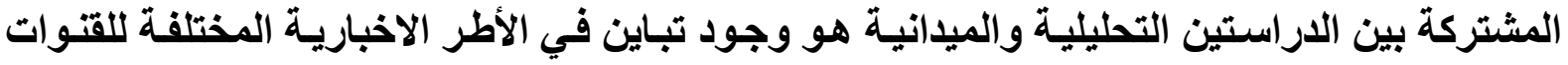

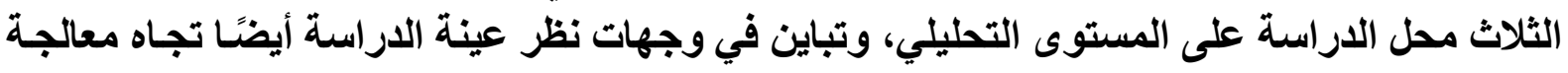
القتوات والأطر التي تم استخدامها.

كما تم حساب المتوسطات الحسابية والانحر افات المعيارية و الأهمية النسبية و الترتيب لاستجابات

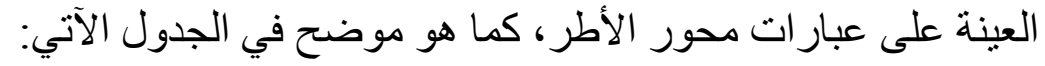
جدول ( آץ) نتائج استجابات العينة على عبارات محور أطر معالجة الصحافة البحرينية لقضايا المؤسسات الصحية

\begin{tabular}{|c|c|c|c|c|c|c|c|c|c|c|}
\hline \multirow{2}{*}{ 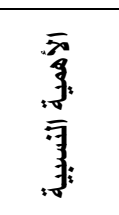 } & \multirow{2}{*}{ 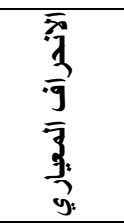 } & \multirow{2}{*}{$\begin{array}{l}\overline{\overline{3}} \\
\overline{3} \\
\overline{3} \\
\overline{3} \\
\frac{3}{3}\end{array}$} & \multicolumn{2}{|c|}{ 咩, 商 } & \multicolumn{2}{|c|}{$\Rightarrow \bar{y}$} & \multicolumn{2}{|c|}{ के } & \multirow{2}{*}{ العبارة } & \multirow[t]{2}{*}{ - } \\
\hline & & & $\%$ & $ت$ & $\%$ & $ت$ & $\%$ & $ت$ & & \\
\hline 1...\&\% & $\because V \leqslant \Lambda$ & r.\&IT & $10 . \wedge \%$ & vq & 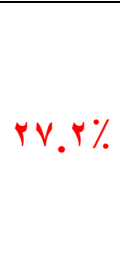 & 144 & ov. $\%$ & rAo & 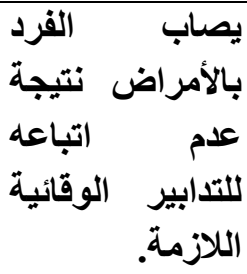 & $\frac{7}{3}$ \\
\hline$v_{v} v_{.} \%$ & TYYT & r.r. & $10.4 \%$ & VV & $r v . r \%$ & 114 & $\leq V . \& \%$ & rTV & تصعية المؤسسات & \\
\hline
\end{tabular}




\begin{tabular}{|c|c|c|c|c|c|c|c|c|c|c|}
\hline \multirow{2}{*}{ 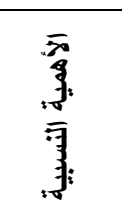 } & \multirow{2}{*}{$\begin{array}{l}\bar{y} \\
\frac{3}{9} \\
\overline{3} \\
3: \\
y\end{array}$} & \multirow{2}{*}{$\begin{array}{l}\overline{3} \\
3 \\
\overline{3} \\
\overline{3} \\
3 \\
3\end{array}$} & \multicolumn{2}{|c|}{ 秘; } & \multicolumn{2}{|c|}{$\Rightarrow \bar{q}$} & \multicolumn{2}{|c|}{ 高 } & \multirow{2}{*}{ العبارة } & $\overline{8}$ \\
\hline & & & $\%$ & $ت$ & $\%$ & ت & $\%$ & 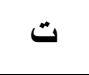 & & \\
\hline & & & & & & & & & 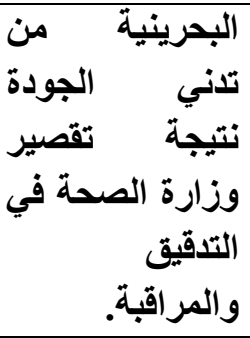 & \\
\hline$\vee 0.9 \%$ & .787 & Y.YVY & IY.A\% & $7 \varepsilon$ & $\leq 7 . \wedge \%$ & rMs & $\varepsilon . . \varepsilon \%$ & $r \cdot r$ & 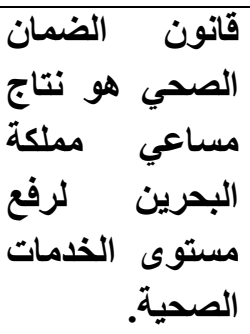 & \\
\hline $77.1 \%$ & $\because V \wedge r$ & $1.9 \wedge r$ & ए I. & $10 \mathrm{~V}$ & $r q . * \%$ & 190 & ห৭. $\% \%$ & $1 \leqslant 1$ & 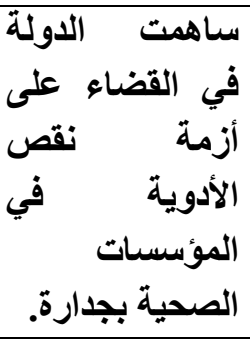 & \\
\hline 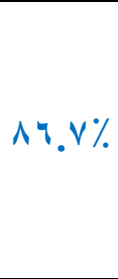 & $\because 0 \vee 7$ & $r . T \cdot r$ & ะ.7\% & $r r$ & $\mu . .7 \%$ & 104 & $\curlyvee \leqslant . \wedge \%$ & rY & 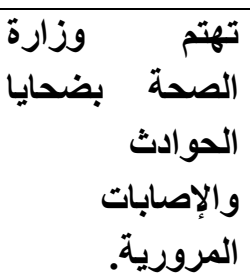 & \\
\hline A r.r\% &. .791 & $r . \leqslant V$. & $11 . \varepsilon \%$ & ov & $r . . r \%$ & 101 & $\bullet \wedge . \& \%$ & rqr & 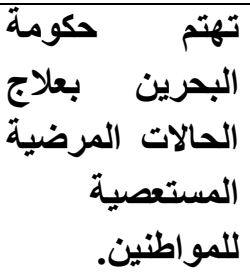 & 羿 \\
\hline$\left.v v_{.1}\right)$ &. .79. & $r . r \mid r$ & $1 \% . \%$ & 70 & $\varepsilon r . \wedge \%$ & YIE & $\varepsilon \& . r \%$ & YYI & التقيم التحرية المؤسسات & \\
\hline
\end{tabular}




\begin{tabular}{|c|c|c|c|c|c|c|c|c|c|c|}
\hline \multirow{2}{*}{ 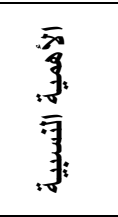 } & \multirow{2}{*}{ 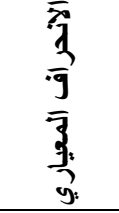 } & \multirow{2}{*}{$\begin{array}{l}\overline{3} \\
3 \\
\overline{3} \\
\overline{3} \\
\frac{3}{3}\end{array}$} & \multicolumn{2}{|c|}{ 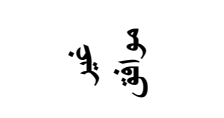 } & \multicolumn{2}{|c|}{$x \bar{q}$} & \multicolumn{2}{|c|}{ 商 } & \multirow{2}{*}{ العبارة } & \multirow{2}{*}{-1} \\
\hline & & & $\%$ & ت & $\%$ & ت & $\%$ & ت & & \\
\hline$\wedge . .1 \%$ & .711 & $r_{.} \varepsilon \cdot \varepsilon$ & $v_{.} . \%$ & ro & $\leq 0.7 \%$ & rYA & $\varepsilon V . \leqslant \%$ & rrv & تالعانتي & \\
\hline$\vee 1 . \wedge \%$ & $\because .7 \wedge v$ & r. $10 \leq$ & $1 v_{.} \cdot \%$ & 10 & $0 . .7 \%$ & ror & ru. $\{\%$ & 194 & التشرص الديعي & $\begin{array}{l}\overline{\text { न }} \\
\overline{\text { a }} \\
\frac{1}{\omega}\end{array}$ \\
\hline$v \cdot .9 \%$ & $\because v q r$ & r.I rA & $r \bullet . \wedge \%$ & $14 q$ & $r 0.7 \%$ & $1 \vee \wedge$ & ґ^. ૧\% & 194 & 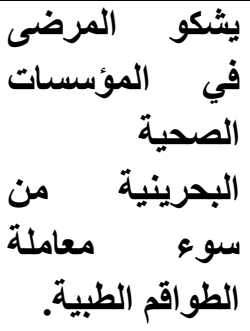 & \\
\hline$\Lambda . . \mu \%$ & $\because v \cdot q$ & Y. $\leqslant 1$. & $14.0 \%$ & 70 & rr.. & 170 & $0 \leqslant . \%$ & $r v$. & الصحية المانية المؤسسات & \\
\hline$v 0.1 \%$ & $\because V I V$ & Y. YO & $17.8 \%$ & $\wedge 1$ & $\varepsilon r . r \%$ & YII & $\approx 1.7 \%$ & $r \cdot \Lambda$ & الصحية المرئية & 势 \\
\hline $77.1 \%$ & $\because \vee \wedge q$ & $1.9 \wedge r$ & $r r_{.} \cdot \%$ & 17. & $r v . \wedge \%$ & $1 \wedge 9$ & $r . . r \%$ & 101 & 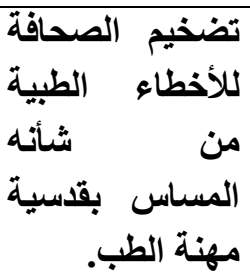 & \\
\hline$\wedge \bullet . \vee \%$ & $\because \Delta \vee \wedge$ & $r . \Delta V Y$ & $\varepsilon . \& \%$ & rr & $r \varepsilon_{.} . \%$ & IV. & $71.7 \%$ & $r \cdot \Lambda$ & الصتحداث البحرينية وزارة & 10 \\
\hline
\end{tabular}




\begin{tabular}{|c|c|c|c|c|c|c|c|c|c|}
\hline \multirow{2}{*}{ 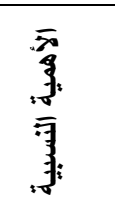 } & \multirow{2}{*}{ 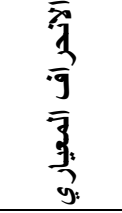 } & \multirow{2}{*}{$\begin{array}{l}\overline{3} \\
\frac{3}{3} \\
\overline{3} \\
\frac{3}{3}\end{array}$} & \multicolumn{2}{|c|}{ 的, 票 } & \multicolumn{2}{|c|}{$>\bar{y}$} & \multicolumn{2}{|c|}{ 高 } & \multirow{2}{*}{ العبـارة } \\
\hline & & & $\%$ & $ت$ & $\%$ & 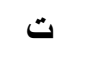 & $\%$ & ت & \\
\hline & & & & & & & & & الموحد المستشفيات \\
\hline Ar.q\% & $\because 7 \leqslant V$ & r.017 & ^.૬\% & $\varepsilon r$ & $+1.7 \%$ & 101 & $7 . . . \%$ & $r .$. & الصحية المانية \\
\hline ^ґ.^\% & וזים. & $Y . \varepsilon \wedge \varepsilon$ & V.๕\% & rV & 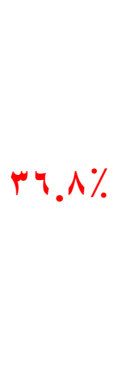 & $1 \wedge \varepsilon$ & $00 . \wedge \%$ & $r \vee q$ & الصي الصوئس \\
\hline$v 0.1 \%$ & .704 & $r . Y \otimes \varepsilon$ & $11 . \wedge \%$ & 09 & $01 . \%$ & YOO & $r v . r \%$ & 114 & 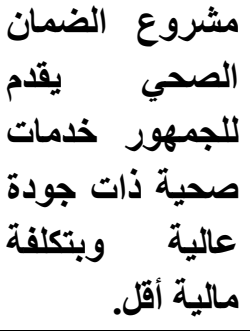 \\
\hline
\end{tabular}

تظهر نتائج الجدول السابق وفقًا للقضايا المطروحة الآتي:

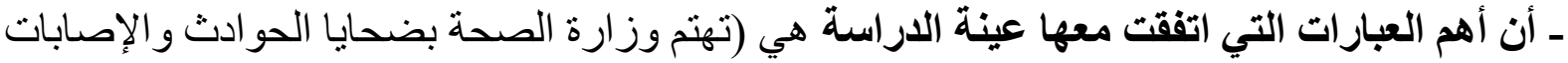

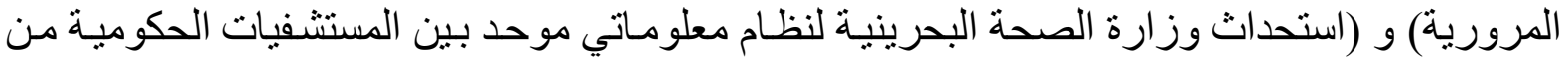

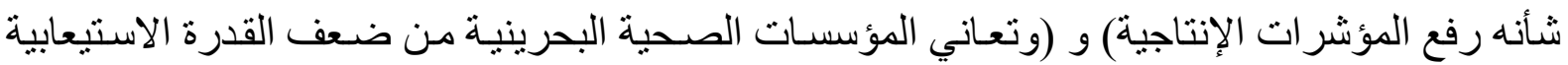

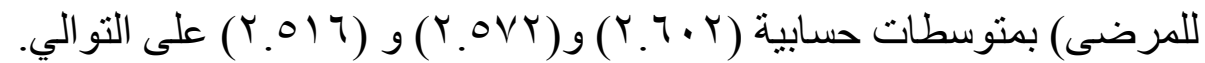

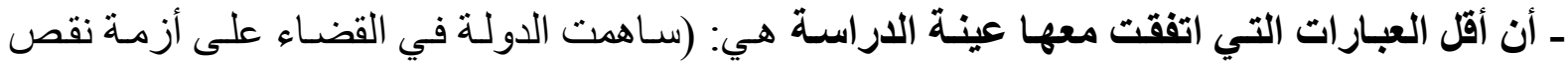

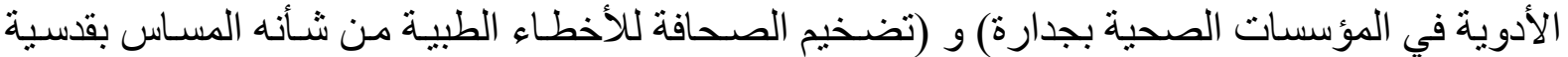


مهنة الطب)، بمتوسطات حسابية (r 919 ( ) مكرر للعبارتين، و(يشكو المرضى في المؤسسات لصحية

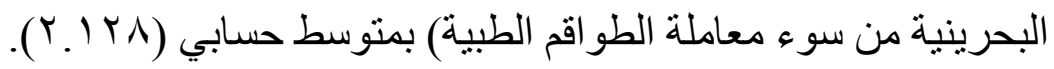

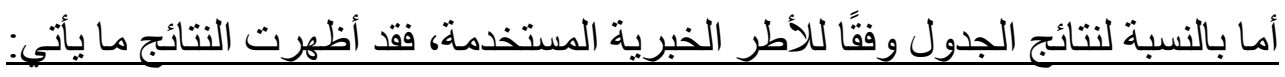

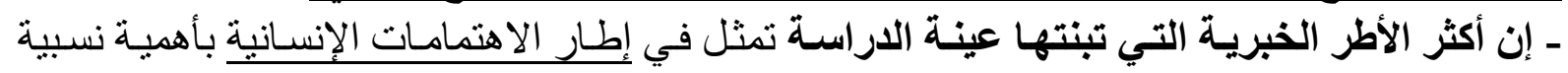

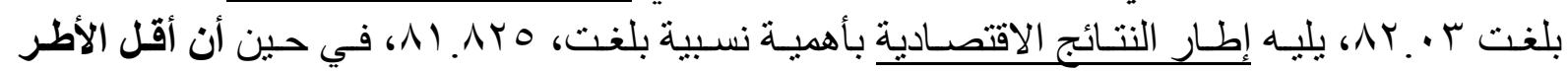

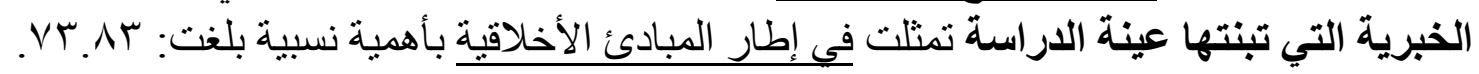

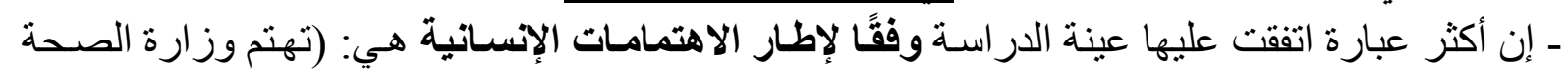

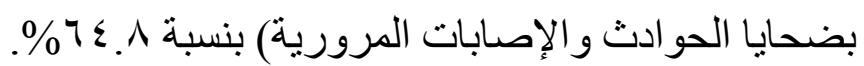
- إن أكثر عبارة اتفقت عليها عينة الدراسة وفقةًا لإطار الصراع الصاع هي: (يعاني الأطباء العاطلون من تعنت

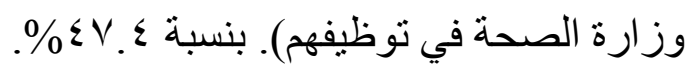

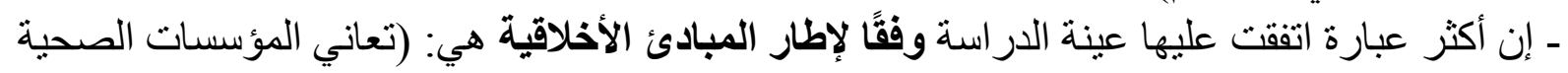

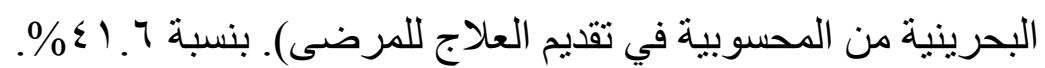

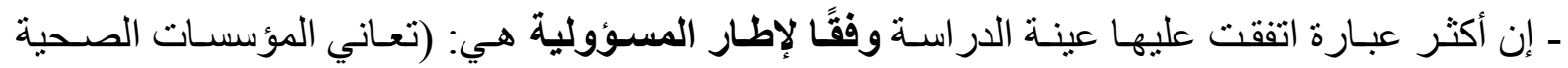

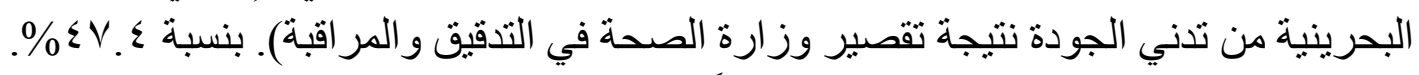

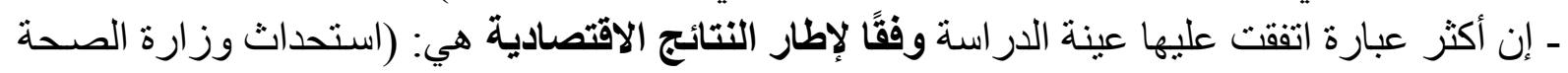

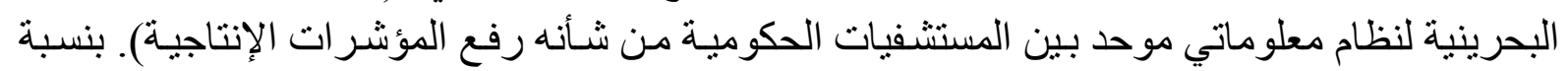
$\%$ \% . 1

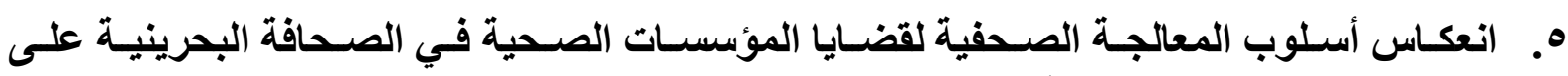

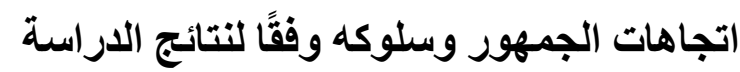
تم أو لاً حساب المنوسطات الحسابية والانحر افات المعيارية و الأهمية النسبية و الترتيب لاستجابات

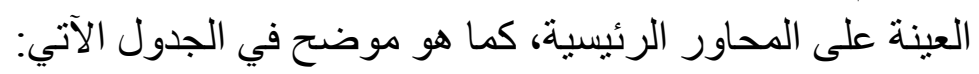
جدول (r Y) انعكاس أسلوب المعالجة الصحفية لقضايا المؤسسات الصحية في الصحافة البحرينية على اتجاهات

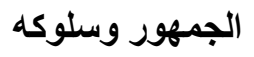

\begin{tabular}{|c|c|c|c|c|c|}
\hline الترتيب & الأهمبية & الالمعياري & الحسابي & الآثا & الرقم \\
\hline 1 & $V \vee .7 \%$ & $.0 Y r$ & T.rYA & التأثنير ات المعرفية & 1 \\
\hline$r$ & $V V_{.} \cdot \%$ & $\because 0 \leqslant 9$ & r.r.q & التأثثير ات الوجدانية & $r$ \\
\hline r & $V O . r \%$ & .041 & T.YOO & التأثنير ات السلوكية & $\mu$ \\
\hline
\end{tabular}

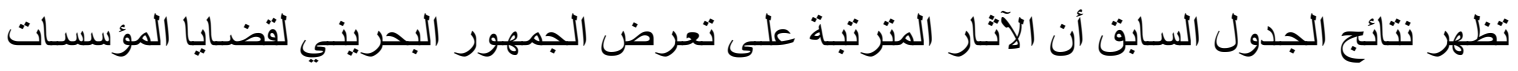

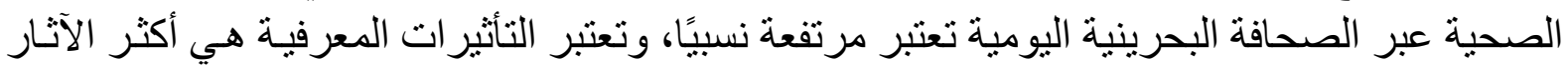

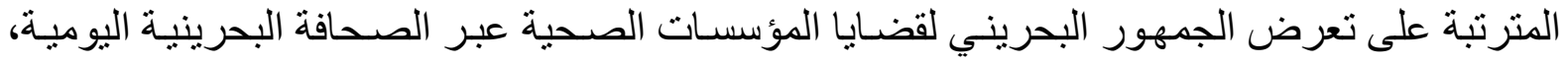

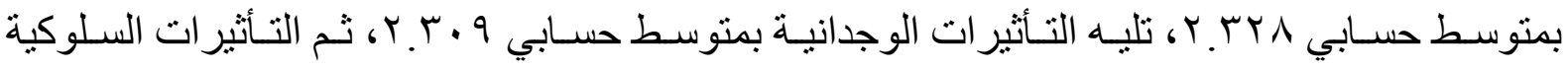




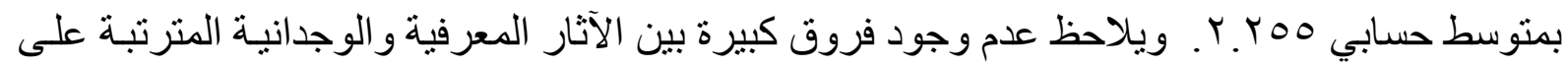
تعرض الجمهور البحرينية لقضايا المؤسسات الصحية.

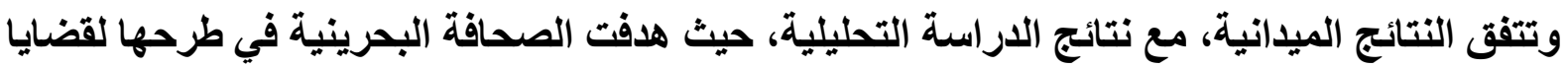

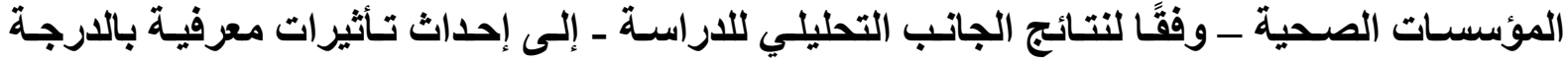

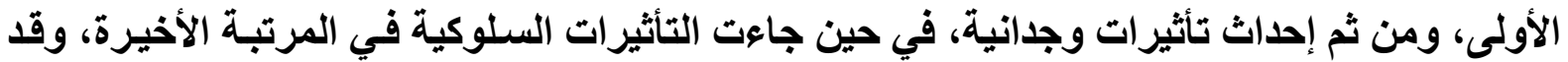

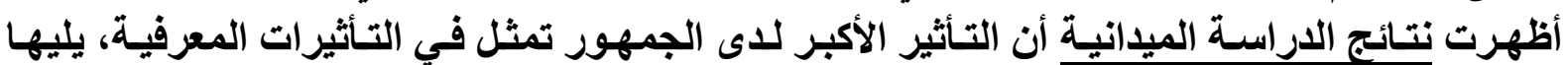

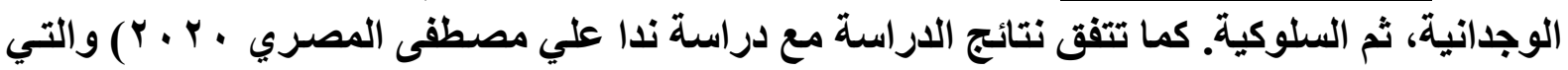

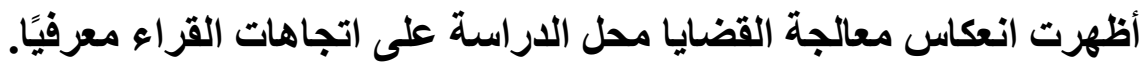

كما تم حساب المتوسطات الحسابية و الانحر افات المعيارية و الأهمية النسبية و الترتيب لاستجابات

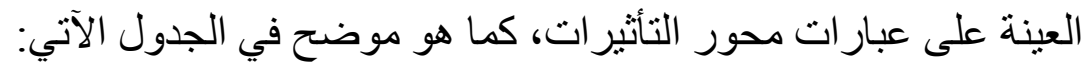

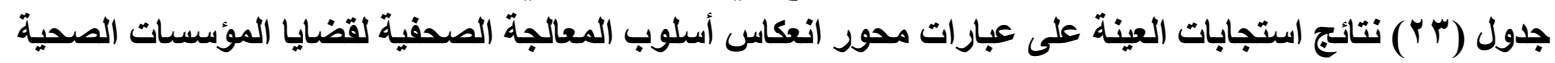

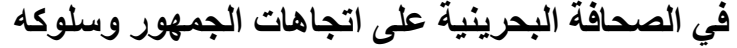

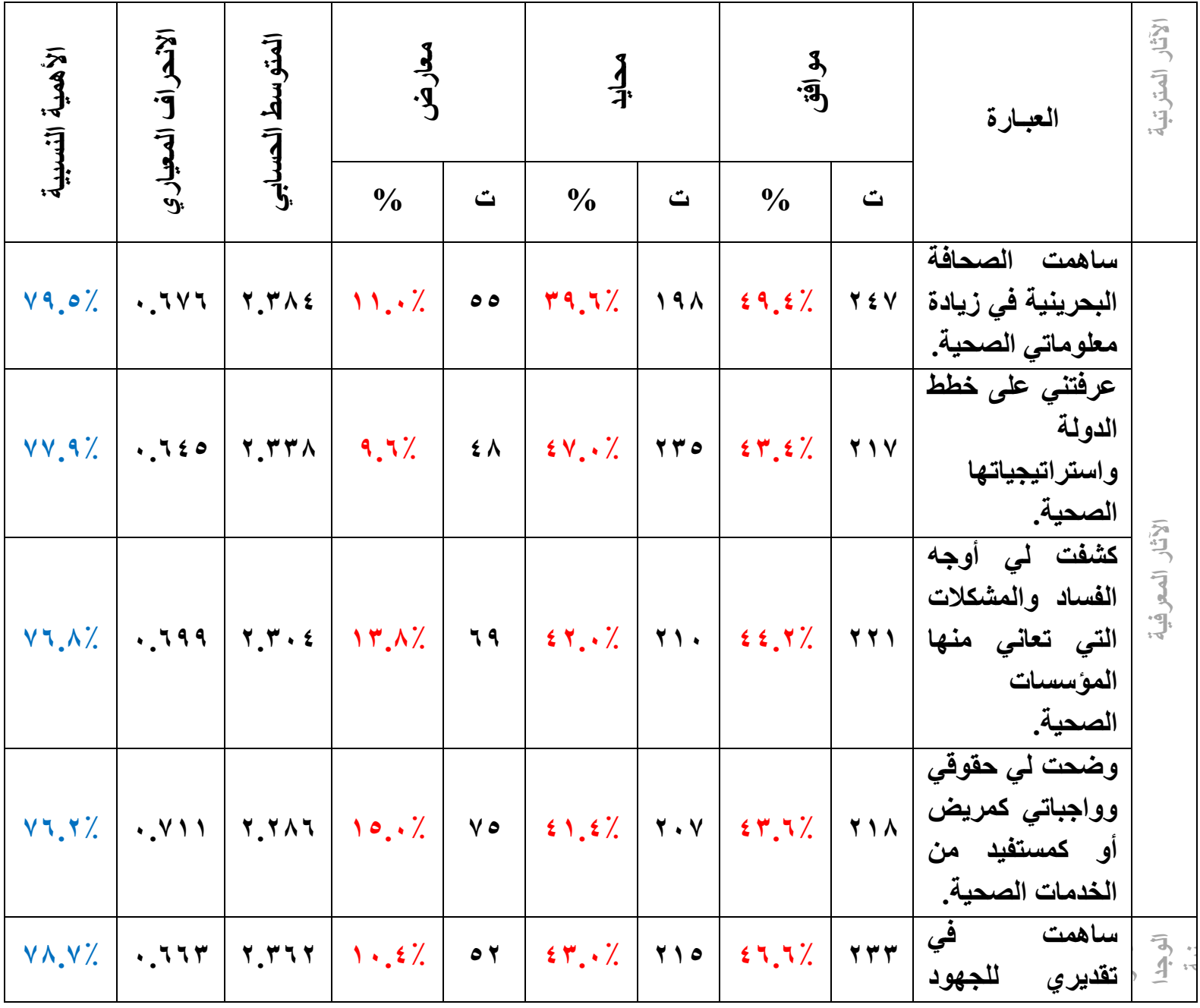


" العلوم الاجتماعية والانسانية"

\begin{tabular}{|c|c|c|c|c|c|c|c|c|c|c|}
\hline \multirow{2}{*}{ : } & \multirow{2}{*}{$\begin{array}{l}\frac{\overline{3}}{3} \\
\bar{y} \\
\overline{3} \\
\frac{9}{y}:\end{array}$} & \multirow{2}{*}{$\begin{array}{l}\bar{y} \\
3 \\
\overline{3} \\
\overline{7} \\
3 \\
3\end{array}$} & \multicolumn{2}{|c|}{$\frac{3}{3}$} & \multicolumn{2}{|c|}{$\frac{g}{7{ }^{\prime}}$} & \multicolumn{2}{|c|}{ क) } & \multirow{2}{*}{ العبـارة } & \\
\hline & & & $\%$ & $ت$ & $\%$ & $ت$ & $\%$ & $ت$ & & \\
\hline & & & & & & & & & الصي سبيل تبذلها الدولة & \\
\hline VV. $1 \%$ & $\because \vee r q$ & $r . r \mid r$ & $10 . \wedge \%$ & $v q$ & $r v . r \%$ & 114 & $\varepsilon V_{.} \cdot \%$ & rro & 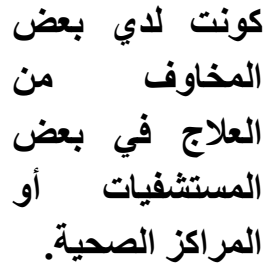 & \\
\hline vo. $1 \%$ & .211 & $r . Y \circ r$ & $10 . \wedge \%$ & $v q$ & $\varepsilon r . r \%$ & Y19 & $\leqslant 1.0 \%$ & $r . \theta$ & الصأل الصأنتي حول بعضية & \\
\hline$\vee \wedge .9 \%$ & $.7 V$. & צ. & $1 . . \wedge \%$ & $0 \leqslant$ & $\approx 1 . \wedge \%$ & $r \cdot q$ & $\leqslant V . \& \%$ & $r r v$ & سلصاهمت في تحسين & \\
\hline VV. $1 \%$ & $.7 \vee 9$ & Y.MI & $1 \% . r \%$ & 71 & ะ ะ. $\%$ & YYI & $\leq \Psi .7 \%$ & Y^ & 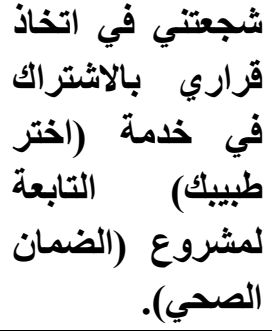 & 茨 \\
\hline $79.0 \%$ & 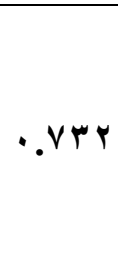 & $r_{.} \cdot \wedge \tau$ & r.т.А & $11 \varepsilon$ & $\leqslant 0 . \wedge \%$ & YYq & $-1.8 \%$ & $10 \mathrm{~V}$ & 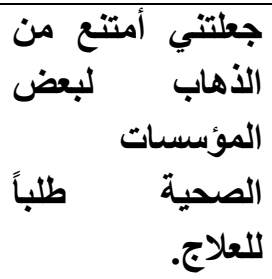 & \\
\hline
\end{tabular}




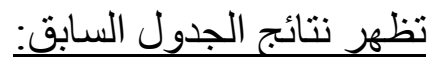

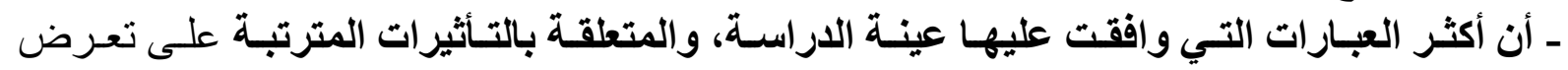

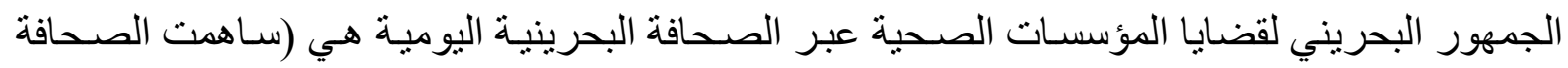
البحرينية في زيادة معلوماتي الصحية) و (ساهمت في تحسين بعض سلوكياتي الصحية) و (سـاهمت في

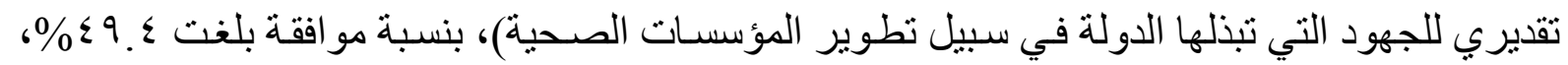

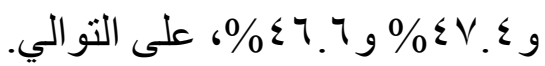
ـ أن أقل العبارات التي وافقت عليها عينة الدراسة، والمتعلقة بالتأثيرات المترتبة على تعرض الجمهور

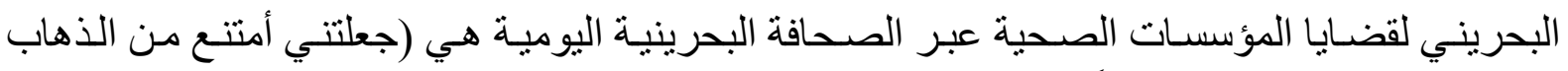

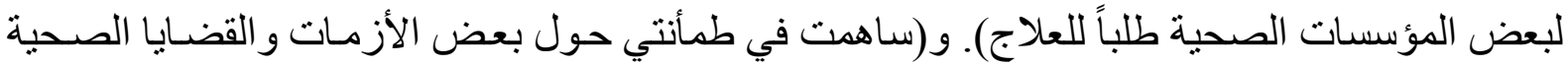
الر اهنة) و (وضحت لي حقوقي وو اجباتي كمريض أو كمستفيد من الخدمات الصحية) بنسبة مو افقة بلغت

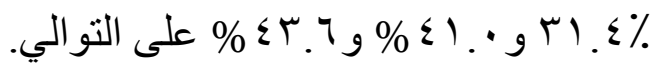

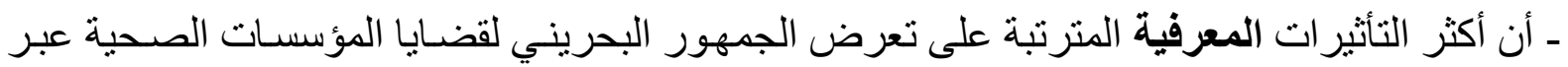

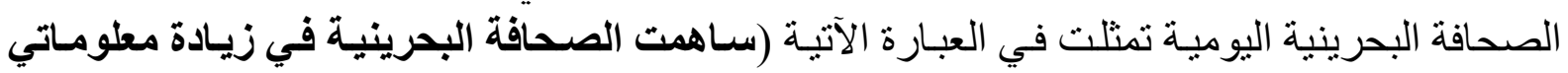

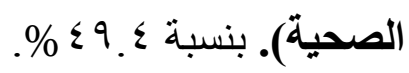
ـ أن أكثر التأثثر ات الوجدانية المترتبة على تعرض الجمهور البحريني لقضايا المؤسسـات الصـحية عبر

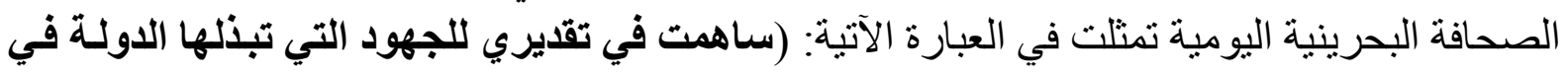

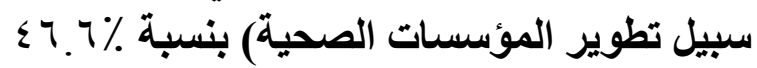

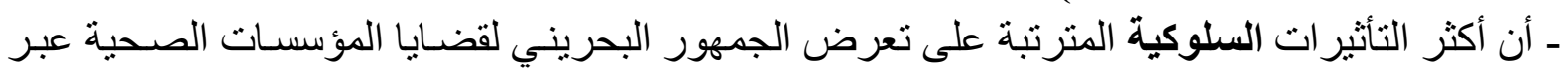

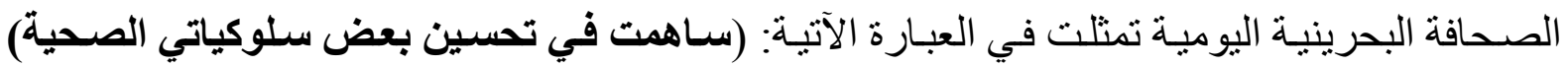
. $\leqslant V . 乏 \%$ بنسبة 
الفرض الأول: توجد فروق ذات دلالة إحصائية بين اتجاهات الصحافة في معالجتها لقضايا المؤسسات

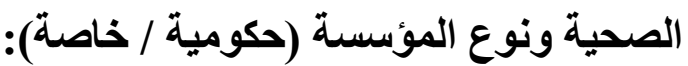
جدول (צ Y): يوضح دلالة الفروق بين اتجاهات الصحافة في معالجتها لقضايا المؤسسات الصحية ونوع المؤسسة

\begin{tabular}{|c|c|c|c|c|c|c|c|c|}
\hline \multicolumn{2}{|c|}{ اختبار كاr } & \multicolumn{2}{|c|}{ 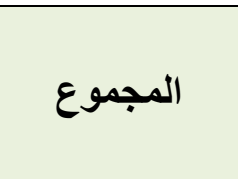 } & \multicolumn{2}{|c|}{ المؤسسات } & \multicolumn{2}{|c|}{ تفطية المؤسسات } & \multirow[t]{2}{*}{ الفئات } \\
\hline مستوى الدلالة & ق قيمة كاץ & $\%$ & 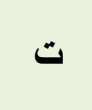 & $\%$ & $ت$ & $\%$ & ت & \\
\hline$\because .1$ & $r \xi 1.1$ & $1 \ldots \%$ & $r \leqslant \varepsilon$ & ᄉ. $1 \%$ & TA & $91.9 \%$ & T17 & نمط التغطية المحايدة \\
\hline$\because .1$ & rq.r & $1 \ldots \%$ & 19 & Y). r\% & 19 & $\vee \wedge . \vee \%$ & $v$. & نمط التغطية المتحيزة \\
\hline$\because \cdot 1$ & $\sum Y . r$ & $1 \cdots \%$ & 0. & $\varepsilon . \%$ & r & $97 . \%$ & $\varepsilon \wedge$ & اتجاه التغطية السلبي \\
\hline$\because \cdot 1$ & 1ヘr. $\varepsilon$ & $1 \cdots \%$ & MI & $11 . \wedge \%$ & $r V$ & $\wedge \Lambda . \curlyvee \%$ & TVV & اتجاه التغطية الايجابي \\
\hline$\because \cdot 1$ & $\varepsilon \cdot . V$ & $1 \cdots \%$ & 79 & $11.7 \%$ & $\wedge$ & $\wedge \wedge . £ \%$ & 71 & اتجاه التغطية غير المحدد \\
\hline$\because \cdot 1$ & Tr.O & $1 \cdots \%$ & $r$ & $7.0 \%$ & r & $94.0 \%$ & rq & نبرة التغطية الهجومية \\
\hline$\because \cdot 1$ & $\leqslant 0$. & $1 \cdots \%$ & $\leqslant 0$ & $\because \%$ & - & $1 \cdots \%$ & $\varepsilon 0$ & نبرة التغطية الدفاعية \\
\hline$\because \cdot 1$ & 199.8 & $1 \cdots \%$ & TOV & $1 Y . T \%$ & $\leqslant 0$ & $\wedge \vee . \leqslant \%$ & TIT & نبرة التغطية غير محددة \\
\hline
\end{tabular}

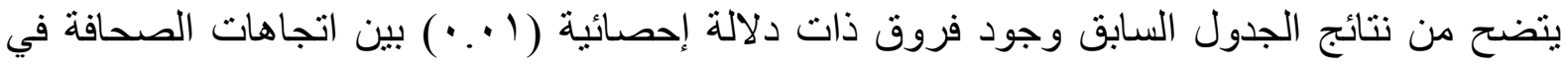

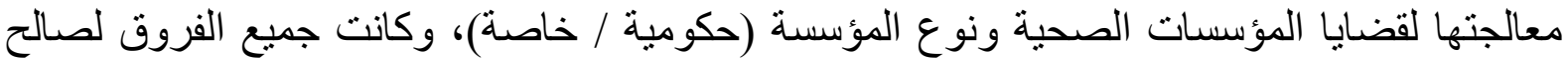
معالجة قضايا المؤسسات الصحية الحكومية.

الفرض الثاني: توجد علاقة ارتباطية دالة إحصائيًا بين أطر معالجة الصحافة البحرينية لقضايا

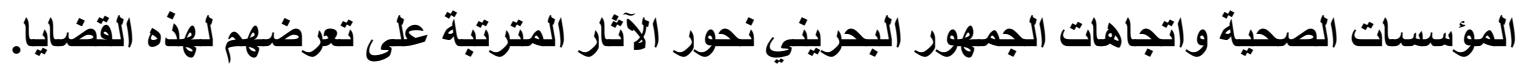
تم التحقق من صحة الفرض من خلال معامل ارتباط بيرسون، كما هو موضح في الجدول الآتي: جدول (0) يوضح دلالة العلاقة الارتباطية بين أطر معالجة الصحافة البحرينية لقضايا المؤسسات الصحية واتجاهات

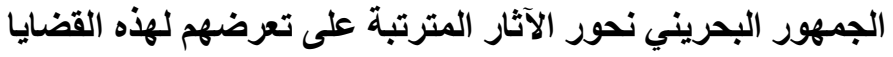

\begin{tabular}{|c|c|c|c|}
\hline الآثار السلوكية & الآثار الوجدانية & الآثار المعرفية & الآثار \\
\hline • Y\१(**) & • $Y \leqslant(* *)$ & $\because \Upsilon \wedge r(* *)$ & إطار الاهتمامات الإنسانية \\
\hline$\because 17$ & $\because T \varepsilon$ &.- .0 & إطار الصراع \\
\hline$\because 119(* *)$ & $\because Y Y V(* *)$ & $\because \cdot r Y$ & إطار المبادئ الأخلاقية \\
\hline$\because .9 \mu(*)$ & $.107(* *)$ & $\because Y Y(* *)$ & إطار المسؤولية \\
\hline$-\cdot .9 r(*)$ & $-\bullet .1 Y 7(* *)$ & $-\cdot \cdot Y I$ & إطار النتائج الاقتصـادية \\
\hline
\end{tabular}




$$
\text { ( ** الارتباط دال إحصائيا عند (1) ( • • ( ). }
$$

يتبين من الجدول السابق وجود علاقة ارتباطية موجبة ودالة إحصائياً (1 + . ) بين استخدام الصحافة

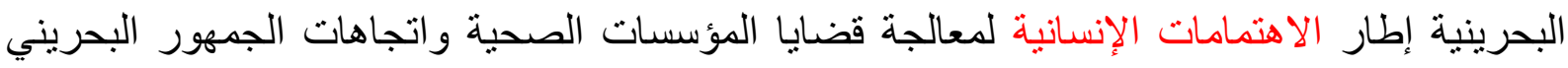

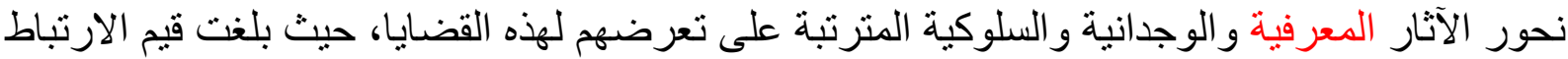

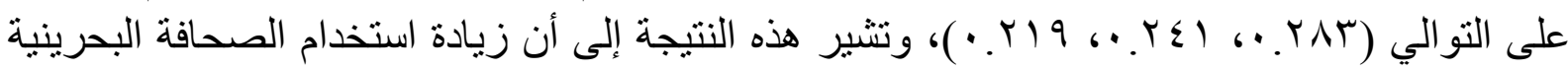
إطار الاهتمامات الإنسانية لمعالجة قضايا المؤسسات الصحية يؤدي إلى زئى زيادة اتجاهات الجمهور البحريني الإيجابية نحور الآثار المعرفية والوجدانية والسلوكية المترتبة على تعرضهم لهذه القضاية القائا.

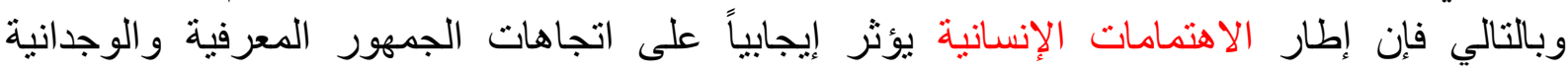
و السلوكية.

ويتبين من الجدول السابق وجود علاقة ارتباطية موجبة ودالة إحصائياً (1 •. •) بين استخدام الصحافة البحرينية إطار المبادئ الأخلاقية لمعالجة قضايا المؤسسات الصحية و واتجاهات الجمهور البحريني نحور الآثار الوجدانية و السلوكية المترتبة على تعرضهم لهذه القضايا، حيث بلغت قيم الارتباط

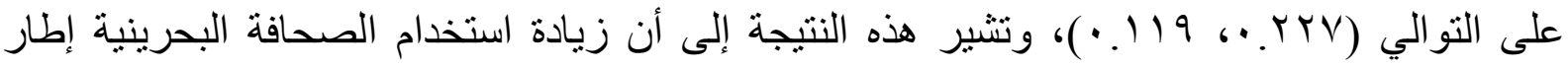
المبادئ الأخلاقية لمعالجة قضايا المؤسسات الصحية يؤدي إلى زيادة اتجاهات الجمهور البهات البحريني الإيجابية نحور الآثار الوجدانية والسلوكية المترتبة على تعرضهم لهذه القضايا. وبالتالي فإن إطار المبادئ الأخلاقية يؤثر إيجابياً على اتجاهات الجمهور نحور الآثار الوجدانية ولية السلوكية.

كما يتبين من الجدول السابق وجود علاقة ارتباطية موجبة ودالة إحصائياً (0 . • ) بين استخدام

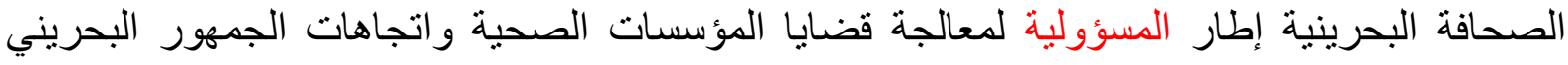

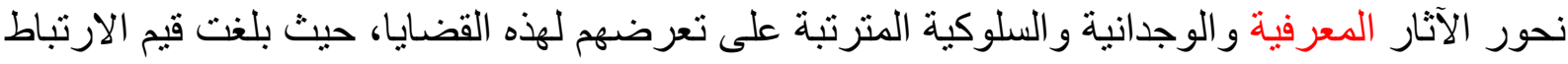

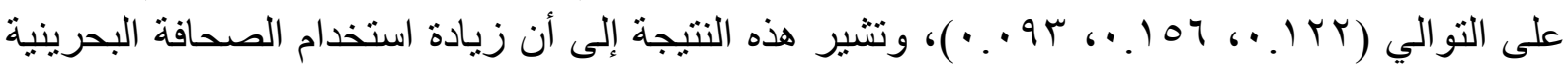
إطار المسؤولية لمعالجة قضايا المؤسسات الصحية يؤدي إلى زيادة اتجاهات الجمهور البحريني الإيجابية

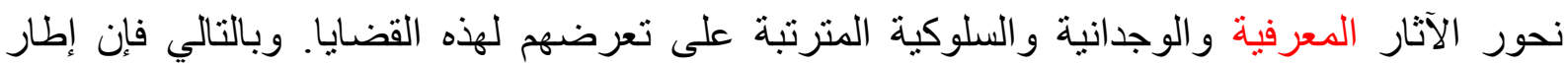

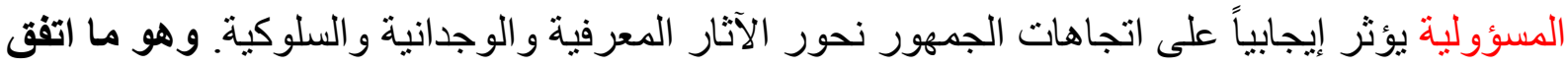

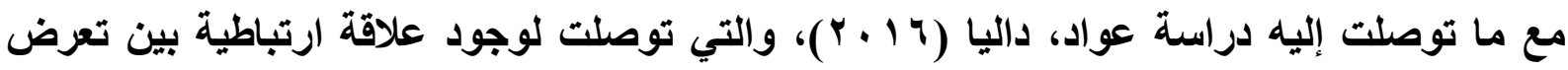

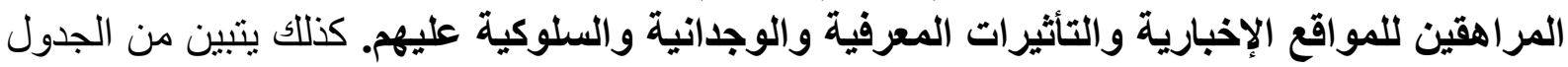

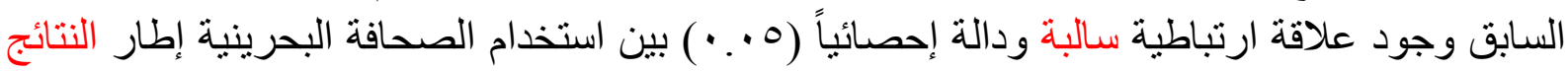

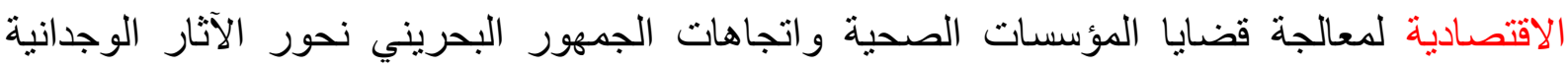

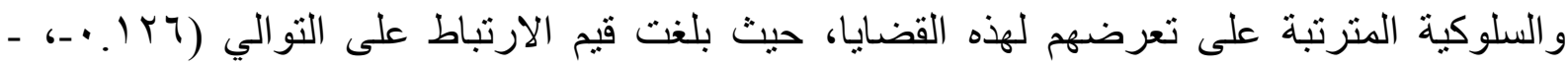

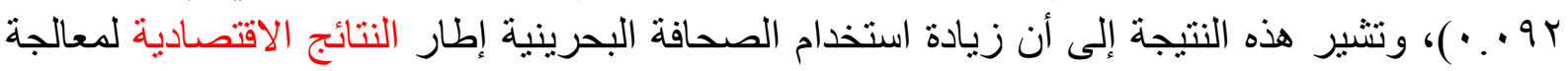

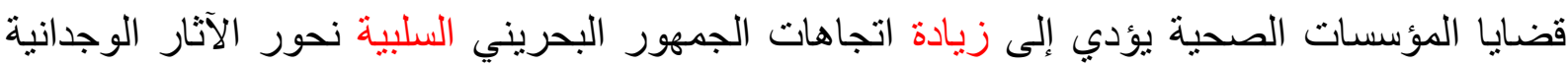

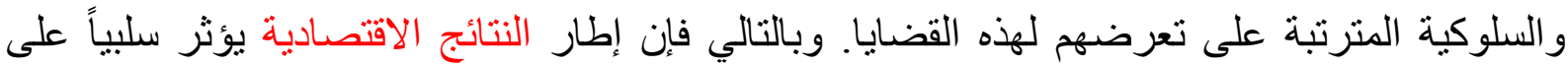

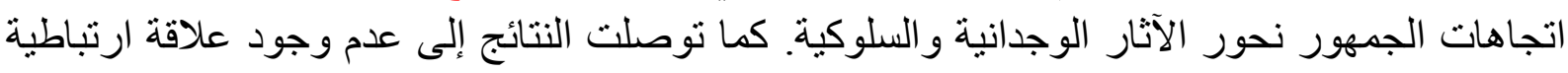


دالة إحصائياً بين استخدام الصحافة البحرينية إطار الصر اع لمعالجة قضايا المؤسسات الصحية و اتجاهات

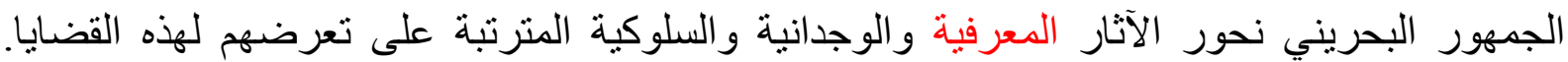

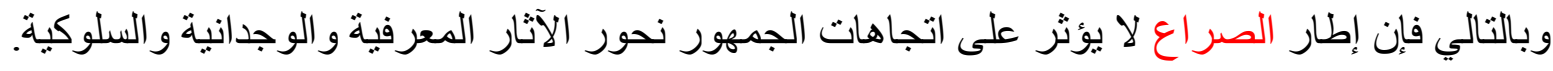

الفرض الثالث: توجد فروق ذات دلالـة إحصـائية في اتجاهـات الجمهور نحو أطر معالجـة الصحافة

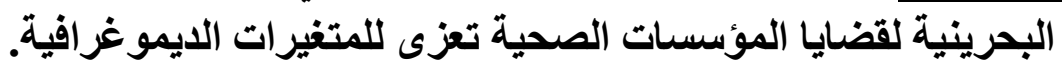

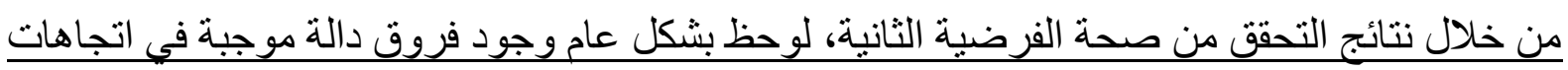

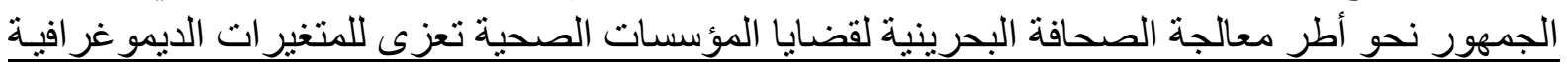

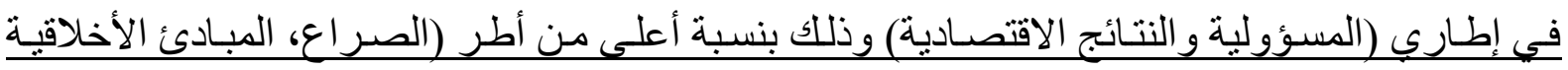

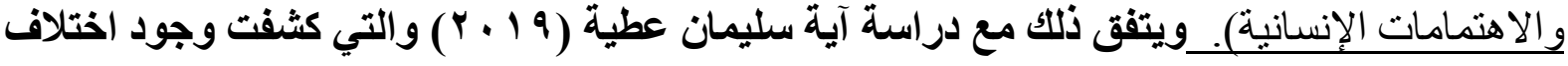

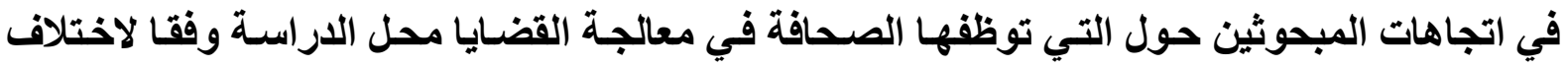
خصائصهم الديمغرافية. ويمكننا تفصيل ذلك كالآتي:

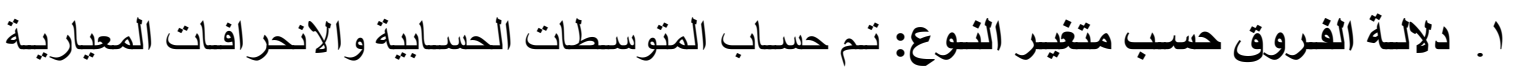

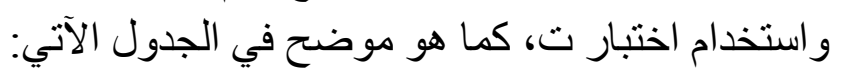

جدول (؟ Y) يوضح دلالة الفروق في اتجاهات الجمهور نحو أطر معالجة الصحافة البحرينية لقضايا المؤسسات الصحية

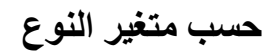

\begin{tabular}{|c|c|c|c|c|c|c|}
\hline مستوى الدلالة & الدرجية & قيمة ت & الالمعرافات & الحسوابية & النوع & الأطر \\
\hline \multirow[t]{2}{*}{$\because \wedge 9 \leqslant$} & \multirow[t]{2}{*}{$\varepsilon 91$} & \multirow[t]{2}{*}{$-\cdot .1 \mu r$} &.$\leqslant 70$ & r. $\varepsilon 01$ & ذكر & \multirow{2}{*}{ إطار الاهتمامات الإنسانية } \\
\hline & & & 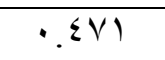 & r. $\{\pi \xi$ & أنثى & \\
\hline \multirow[t]{2}{*}{$\cdot .1 / 7$} & \multirow[t]{2}{*}{$\sum 9 \wedge$} & \multirow[t]{2}{*}{$-1 . Y T \Lambda$} & $\cdot r \wedge \Lambda$ & $\overline{r . Y Y \Lambda}$ & ذكر & \multirow{2}{*}{ إطار الصراع } \\
\hline & & & . 479 & Y.rY. & أنثىى & \\
\hline \multirow[t]{2}{*}{$\cdot r \cdot r$} & \multirow[t]{2}{*}{$\sum 91$} & \multirow[t]{2}{*}{-1.40} & .011 & r.191 & ذكر & \multirow{2}{*}{ إطار المبادئ الأخلاقية } \\
\hline & & &.$\leqslant 09$ & T.YMT & أنثى & \\
\hline \multirow[t]{2}{*}{$\because \cdot A r$} & \multirow[t]{2}{*}{$\sum 9 \lambda$} & \multirow[t]{2}{*}{$-1 . V \leqslant \varepsilon$} & धथार & r.rul & ذكر & \multirow{2}{*}{ إطار المسؤولية } \\
\hline & & & $\therefore \leqslant 01$ & r.rVq & أنثى & \\
\hline \multirow[t]{2}{*}{$.9 \leqslant 7$} & \multirow[t]{2}{*}{$\sum 9 \wedge$} & \multirow[t]{2}{*}{$\because \cdot 71$} & $\cdot . \varepsilon \vee 7$ & 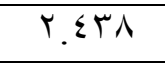 & ذكر & \multirow{2}{*}{ إطار النتائج الاقتصادية } \\
\hline & & & $\cdot . \sum \mathrm{VT}$ & T.乏To & أنثى & \\
\hline
\end{tabular}

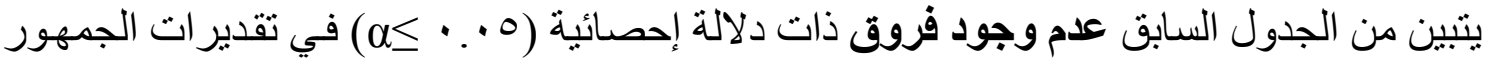

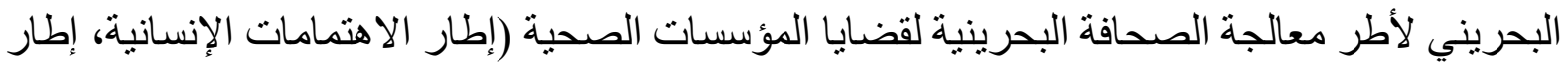

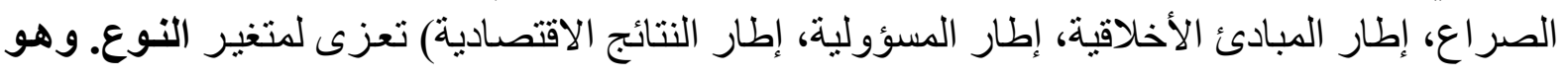




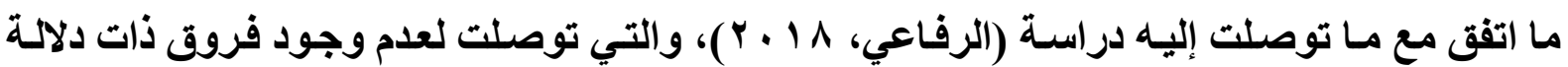

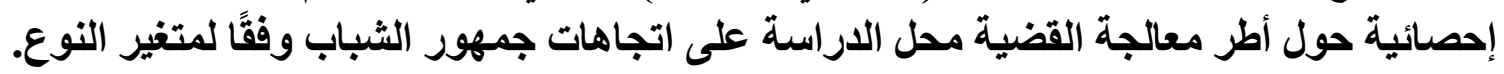

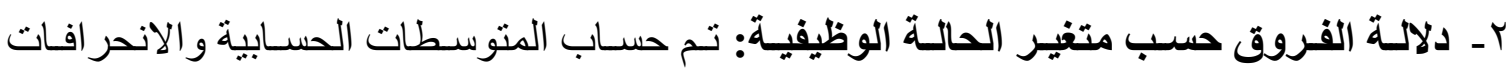

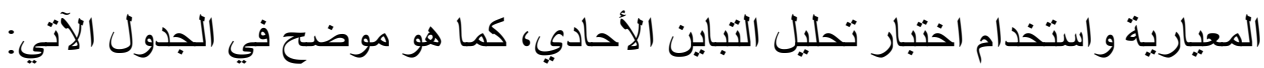

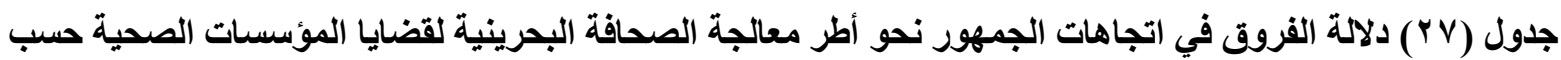
متغير الحالة الوظيفية

\begin{tabular}{|c|c|c|c|c|c|c|}
\hline مستوى الدلالة & الحرية & قيمة ف & الالحرافات & المستوسطاتية & الحالة الوظيفية & الأطر \\
\hline \multirow[t]{4}{*}{ •.Ar. } & \multirow[t]{4}{*}{$r$} & \multirow[t]{4}{*}{$\cdot r \cdot v$} & $\therefore \leqslant 0$. & T. $\leqslant 7 \leqslant$ & موظف & \multirow{4}{*}{ إطار الاهتمامات } \\
\hline & & &. $.0 Y \Lambda$ & Y. $\varepsilon . q$ & عمل حر & \\
\hline & & & $\because \leqslant 0 \leqslant$ & r. $\leqslant 01$ & متقاعد & \\
\hline & & & $\cdot \varepsilon \wedge \lambda$ & Y. $\leqslant \wedge r$ & لا يعمل & \\
\hline \multirow[t]{4}{*}{$\because 99$} & \multirow[t]{4}{*}{$r$} & \multirow[t]{4}{*}{ Y.10V } & $\cdot r q$ & T.rTT & موظف & \multirow{4}{*}{ إطار الصراع } \\
\hline & & & $\cdot \varepsilon \wedge \varepsilon$ & Y.199 & عمل حر & \\
\hline & & & $\cdot r r \mid$ & r.r. & متقاعد & \\
\hline & & & $\cdot . r 99$ & Y.YTT & لا يعطل & \\
\hline \multirow[t]{4}{*}{$\because \cdot 11$} & \multirow[t]{4}{*}{$r$} & \multirow[t]{4}{*}{ T.q. } & $\because \leqslant 0 \mathrm{~V}$ & Y.YAV & موظف & \multirow{4}{*}{ إطار المبادئ الأخلاقية } \\
\hline & & & $\because \leqslant 99$ & $r . \Delta r$ & عمل حر & \\
\hline & & & .01 & T.YTI & 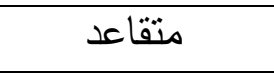 & \\
\hline & & & $\cdot \varepsilon \wedge 19$ & $r .1 \leq \Lambda$ & لا يعمل & \\
\hline \multirow[t]{4}{*}{$\because \cdots$} & \multirow[t]{4}{*}{$\mu$} & \multirow[t]{4}{*}{$1.1 Y q$} & $\cdot r V V$ & Y.Y৭V & موظف & \multirow{4}{*}{ إطار المسؤولية } \\
\hline & & & $\cdot \varepsilon V$. & 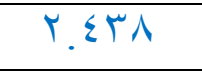 & عمل حر & \\
\hline & & & $\cdot .201$ & T.YOY & متقاعد & \\
\hline & & & 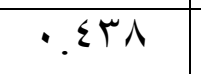 & r.111 & لا يعمل & \\
\hline \multirow[t]{4}{*}{$\because \cdots$} & \multirow[t]{4}{*}{$r$} & \multirow[t]{4}{*}{ N.10r } & 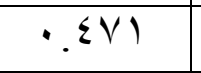 & $r . \varepsilon r V$ & موظف & \multirow{4}{*}{ إطار النتائج الاقتصادية } \\
\hline & & & $\because \sum V Y$ & r.OAT & عمل حر & \\
\hline & & & $\because \varepsilon r \Lambda$ & Y.0 & متقاعد & \\
\hline & & & $\because \varepsilon \vee \leqslant$ & T.YQT & لا يعمل & \\
\hline
\end{tabular}

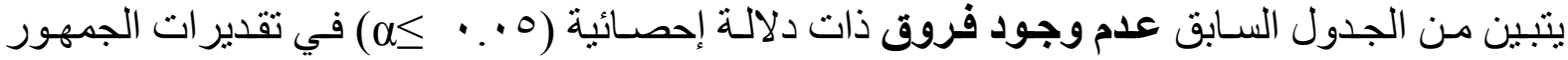

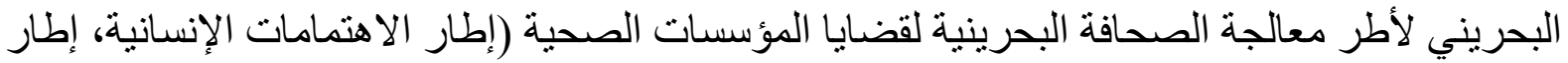

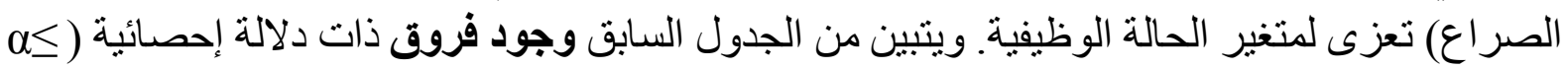


ه . . ) في تقدير ات الجمهور البحرينـي لاستخدام الصـحافة البحرينيـة إطـار المبـادئ الأخلاقيـة لمعالجـة

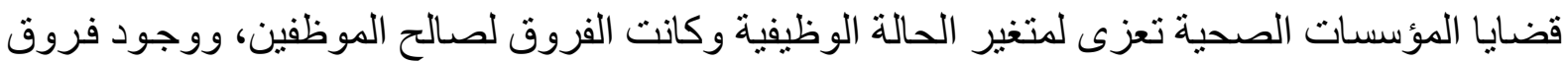

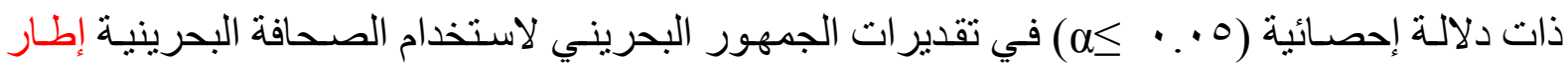

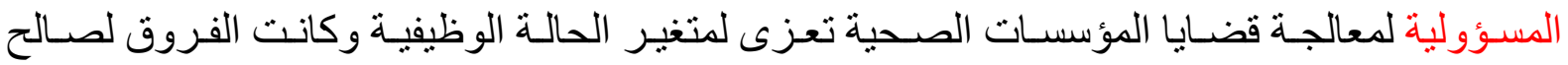
الموظفين، ووجود فروق ذات دلالـة إحصـائية (0. . • ع م) في تقدير ات الجمهور البحريني لاستخدام

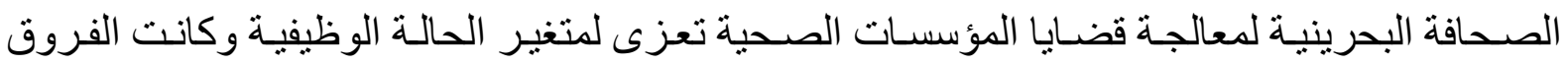

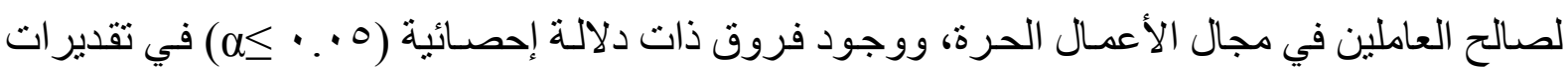

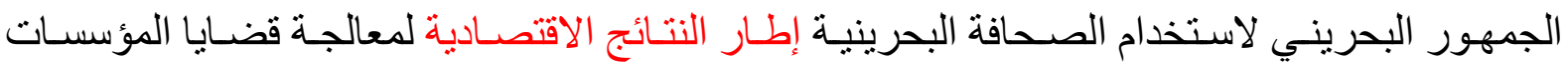
الصحية تعزى لمتغير الحالة الوظيفية وكانت الفروق لصالح العاملين في مجال الأعمال الحرة. rـ دلالة الفروق حسب متغير الفئة العمرية: نم حساب المتوسطات الحسابية و الانحر افات المعيارية

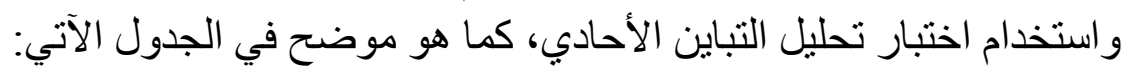

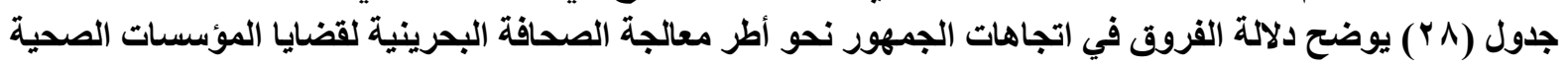
حسب متغير الفئة العمرية الجية الجية المئية

\begin{tabular}{|c|c|c|c|c|c|c|}
\hline مستوى & الحرية & قيمة ف & الانحر افات & المتوسطات الحسابية & الفئة العمرية & 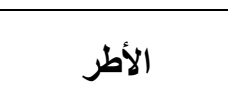 \\
\hline \multirow[t]{4}{*}{ •ru. } & \multirow[t]{4}{*}{$r$} & \multirow[t]{4}{*}{$1.1 \leq 7$} &.$\leqslant 90$ & Y.rq纟 & 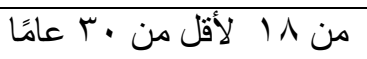 & \multirow{4}{*}{ 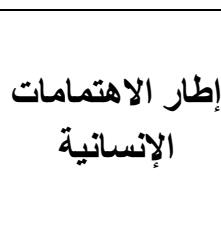 } \\
\hline & & & 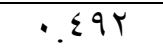 & Y. $\leqslant 0$. & من ·r لأقل من 0؛ عامًا & \\
\hline & & &.$\leqslant 11$ & Y.011 & من 0؛ لأقل من · ج عامًا & \\
\hline & & & $\cdot \varepsilon V \leqslant$ & T. $\leq 7 \leq$ & أكثر من • 7 عامًا & \\
\hline \multirow{4}{*}{$\because \cdots$} & \multirow[t]{4}{*}{$r$} & \multirow{4}{*}{ ย.Y^T } & . & r.r. & 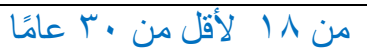 & \multirow{4}{*}{ إطار الصراع } \\
\hline & & & $\cdot r \vee O$ & T.YA & من ·ץ لأقلّل من 0؛ عامًا & \\
\hline & & &. ros & t.rTV & من 0 ؛ لأقل من • T عامًا & \\
\hline & & & $\ddots \leqslant \leqslant 7$ & Y.I 11 & أكثر من • ، عامًا & \\
\hline \multirow[t]{4}{*}{$\because 1 \wedge r$} & \multirow[t]{4}{*}{$r$} & \multirow[t]{4}{*}{$1.7 \times 9$} & $\because$ Or. & Y.107 & 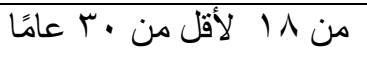 & \multirow{4}{*}{ إلأخلاقية المبادئ } \\
\hline & & & $\cdot . \leqslant \leqslant \wedge$ & $r . r \leqslant q$ & من ·r لأقل من 0؛ عامًا & \\
\hline & & & .010 & T.YT. & من 0؛ لأقل من • 7 عامًا & \\
\hline & & & .011 & Y.1.1 & أكثر من • 7 عامًا & \\
\hline \multirow[t]{4}{*}{$\cdot r \cdot 0$} & \multirow[t]{4}{*}{$\mu$} & \multirow[t]{4}{*}{1.045} & $\because \leqslant \vee \leqslant$ & 9.179 & من ^| لأقل من ·ץ عامًا & \multirow{4}{*}{ إطار المسؤولية } \\
\hline & & & $\cdot r \wedge \tau$ & $r . r \leqslant q$ & من · ب لأقل من 0؛ عامًا & \\
\hline & & & $\because \leqslant 00$ & T.YOA & من 0 ؛ لأقل من •ج عامًا & \\
\hline & & & $\because 0.1$ & t.rTV & أكثر من • ، عامًا & \\
\hline \multirow[t]{4}{*}{$\cdot r \mu$} & \multirow[t]{4}{*}{$r$} & \multirow[t]{4}{*}{$1.1 \leq 7$} & $\because \leqslant \vee 7$ & T.E.r & من \/ لأقل من ·ץ عامًا & \multirow{4}{*}{ إطار النتائج } \\
\hline & & & $\because \leqslant \wedge$. & r.sाr & من · ب لأقل من 0 ؛ عامًا & \\
\hline & & &..$\leqslant 7$ & Y.\{7) & من 0؛ لأقل من • ج عامًا & \\
\hline & & & $\because \leqslant \vee q$ & r.ort & أكثر من • ج عامًا & \\
\hline
\end{tabular}




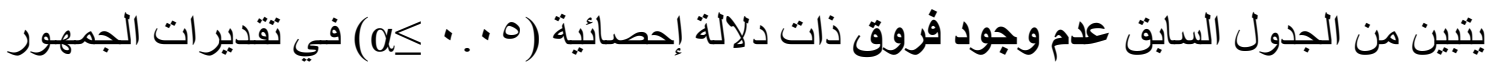

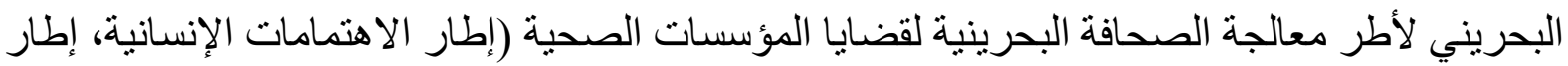

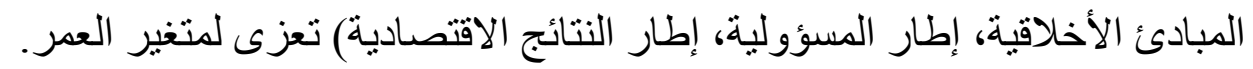

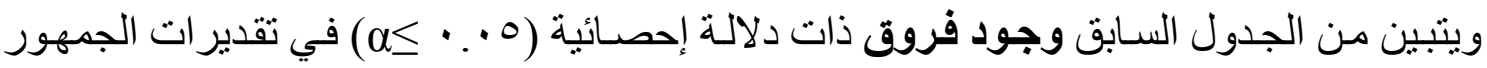

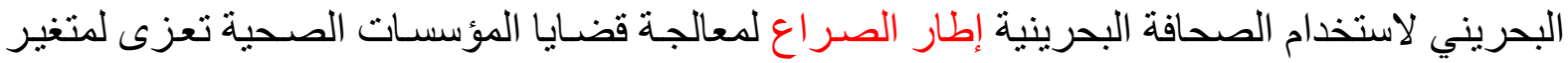

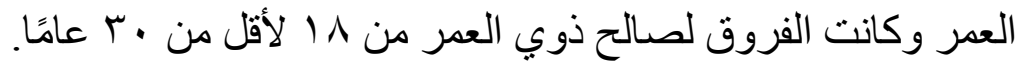

ع - دلالة الفروق حسب متغير المستوى التعليمي: تم حساب المتوسطات الحسـابية والانحر افات

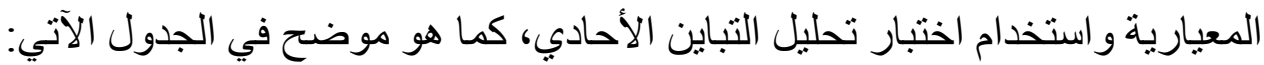

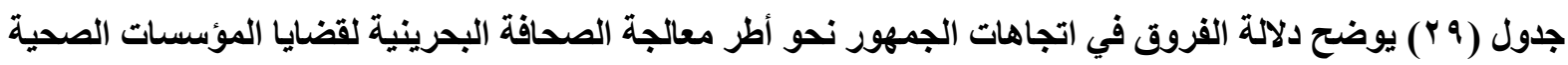
حسب متغير المستوى التطليمي التحري

\begin{tabular}{|c|c|c|c|c|c|c|}
\hline الالالة & الحرية & قيمة ف & الانحر افات المعيارية & المتوسطات الحسابية & المستوى التعليمي & الأطر \\
\hline \multirow[t]{4}{*}{ 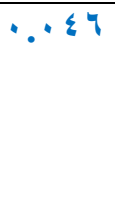 } & \multirow[t]{4}{*}{$\mu$} & \multirow[t]{4}{*}{$Y .7 \wedge \varepsilon$} & $\because \leqslant r q$ & $r .0 \leq 1$ & ثانو ياة عامة فأقلّل & \multirow{4}{*}{ إطار الاهتمامات } \\
\hline & & & $\because \leqslant \vee 7$ & T. $\leqslant 00$ & دبلوم - & \\
\hline & & & $\because \leqslant \vee q$ & T. $\leqslant$ r. & بكالوريوس & \\
\hline & & & $\because \varepsilon \wedge r$ & T.rVq & در اسات عليا & \\
\hline \multirow[t]{4}{*}{.rYq } & \multirow[t]{4}{*}{$r$} & \multirow[t]{4}{*}{$1.1 \leqslant 1$} &.$r q V$ & T.YOY & ثانوية عامة فأقل & \multirow{4}{*}{ إطار الصراع } \\
\hline & & & $\cdot . r 09$ & TYTO & دبلوم - & \\
\hline & & & $\cdot$. MTY & TMIT & بكالوريوس & \\
\hline & & & $\cdot \varepsilon \cdot \varepsilon$ & TMT & در اسات عليا & \\
\hline \multirow[t]{4}{*}{$\because 1 \wedge \varepsilon$} & \multirow[t]{4}{*}{$r$} & \multirow[t]{4}{*}{1.711} & $.0 \leqslant 1$ & T.101 & ثانوية عامة فأقل & \multirow{4}{*}{ إلأخلاقية المبادئ } \\
\hline & & & $.0 Y 9$ & $Y .197$ & 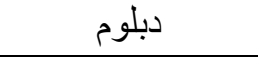 & \\
\hline & & & $\cdot \varepsilon r_{0}$ & Y.YTV & بكالوريوس & \\
\hline & & &.$\leqslant r q$ & T.YTV & در اسات عليا & \\
\hline \multirow[t]{4}{*}{$\because \cdots 9$} & \multirow[t]{4}{*}{$\mu$} & \multirow[t]{4}{*}{$r . \wedge 9 r$} & $\because \leqslant 9 \leqslant$ & Y.IV & ثنانوية عامة فأقلّ & \multirow{4}{*}{ إطار المسؤولية } \\
\hline & & & $\cdot r V T$ & Y.YIE & 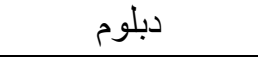 & \\
\hline & & & $\cdot . \varepsilon \cdot r$ & T.TVT & بكالوريوس & \\
\hline & & & $\cdot . \leqslant \varepsilon$ & T.MVT & در اسات عليا & \\
\hline \multirow[t]{4}{*}{$\because \cdots 9$} & \multirow[t]{4}{*}{$\mu$} & \multirow[t]{4}{*}{ r.A } & $.07 \pi$ & r.r.q & ثانوية عامة فأقلّ & \multirow{4}{*}{ إطار النتائج } \\
\hline & & & $\because \varepsilon \cdot \Lambda$ & Y. $\{9 \varepsilon$ & 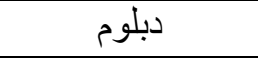 & \\
\hline & & & $\ddots \Sigma \Gamma \wedge$ & T. $\leqslant 0 \leqslant$ & بكالوريوس & \\
\hline & & & $\because \varepsilon Y V$ & Y.0YI & در اسات عليا & \\
\hline
\end{tabular}




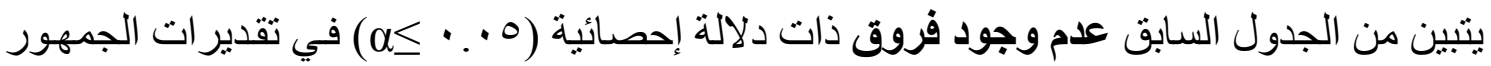

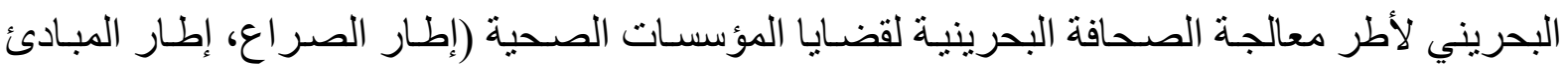
الأخلاقية) تعزى لمتغير المستوى التعليمي. ويتبين من الجدول السـابق وجود فروق ذات دلالة إحصـائية (0 . . كـم) في تقدير ات الجمهور

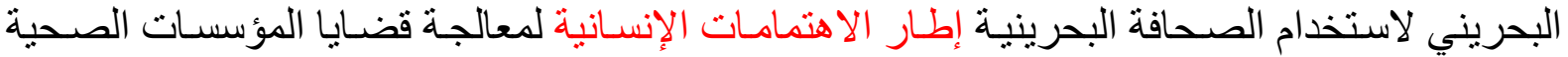

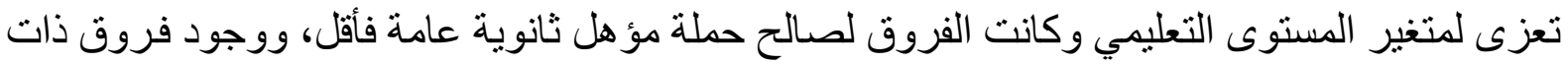

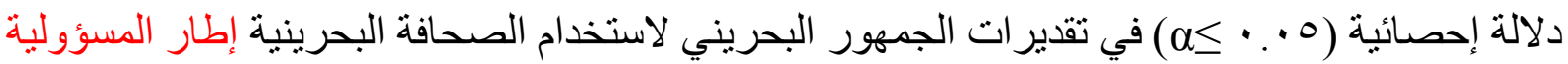

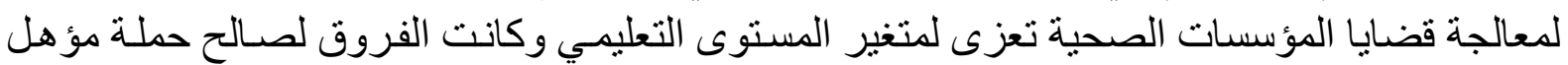

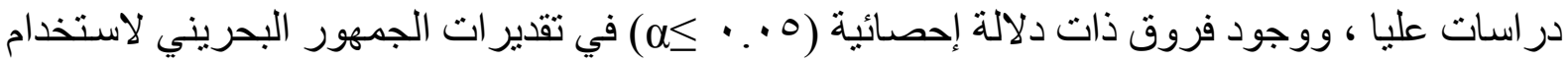

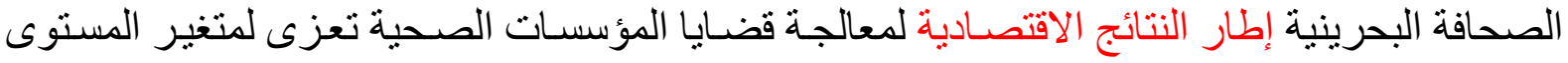

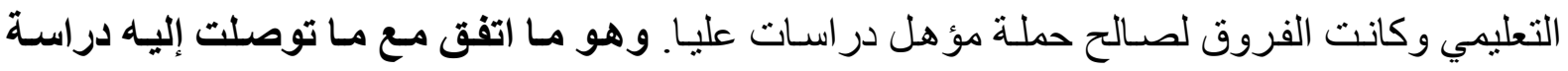

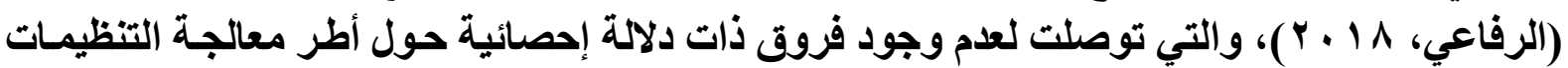

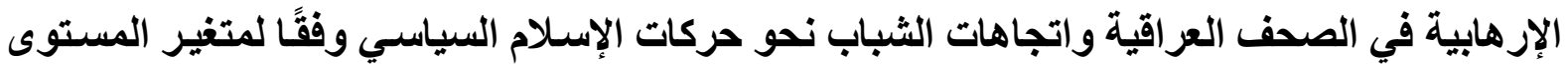

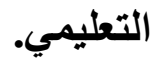

\section{• و وتمثلت أبرز توصيات الدراسة في الآتى:}

بناء على ما تقدم من استنتاجات ومناقثة نتائج البحث، فإن الدراسة توصي بمجمو عة من الأفكار وهي كالآتي:

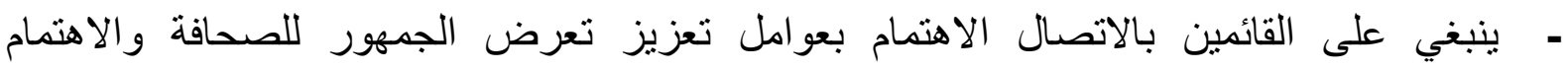
بالمضامين المتعلقة بقضايا المؤسسات الصحية ومتابعتها باستمرار و المراجعة لما تعرضين العرضه من

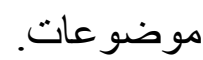
- ضرورة التتوع في أسلوب المعالجة الصحفية لقضايا المؤسسات الصحية، واستخدام الأثكال الصحفية الأخرى غير الخبر الصحفي كالتحقيق الصحفي و التقارير. ـ رورة الموازنة في الاتجاهات السلبية والايجابية في طرح قضايا المؤسسات الصحية (الحكومية و الخاصة). - الموضوعية في طرح قضايا المؤسسات الصحية وتسليط الضوء على المبلى النواحي الإيجابية في المؤسسات الصحية دون المبالغة في التركيز على الايجابيات الطيات أو السلبيات وحدها.

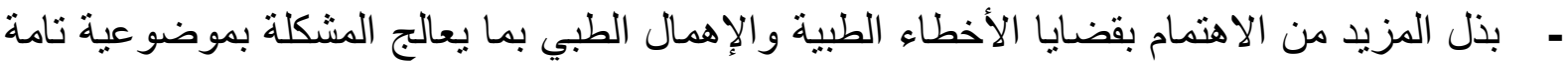

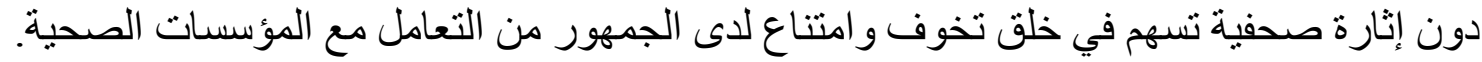

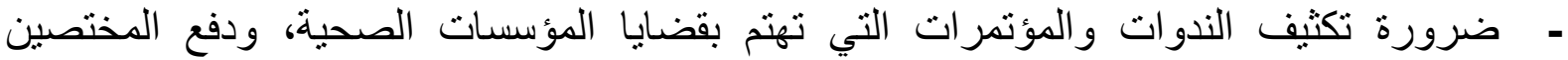

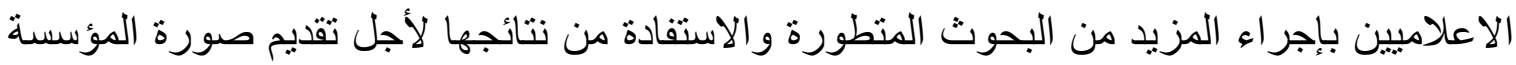
الصحية بما يتناسب مع الو اقع الفعلي لأداء المؤسسات الصنورة الصحية. 


\section{• مقترحات لبحوث مستقبلية:}

أثثارت الدراسة الحالية بعض الموضوعات التي يمكن إجراؤها مستقبلًا في إطار الاراسات المهتمة

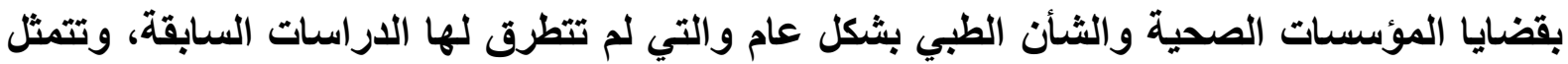

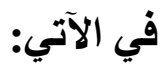

- إجر اء دراسات وبحوث تتناول موضو عات بعينها متعلقة بقضايا المؤسسات الصحية، مثل: حوادث

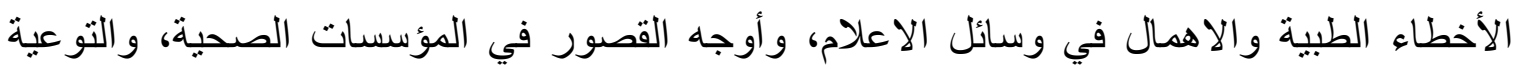

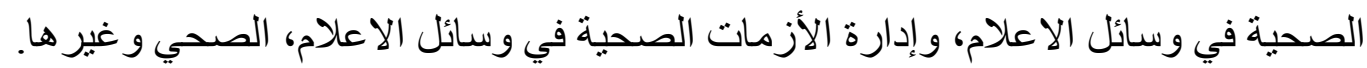

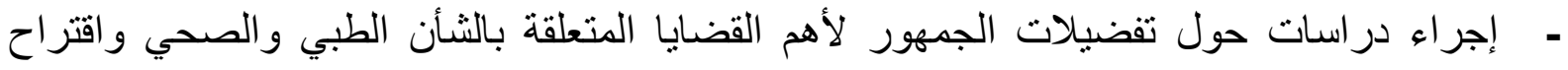

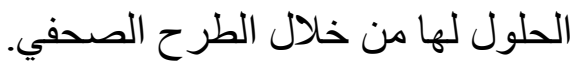

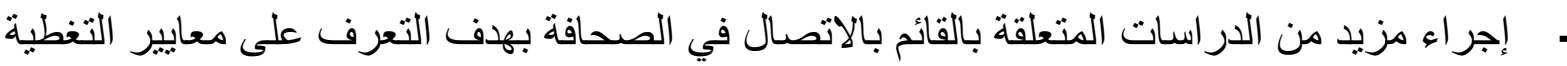

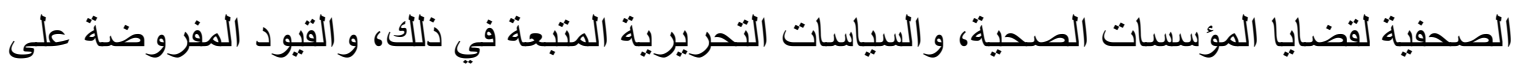
أخبار المؤسسات الصحية وقضاياها المختلفة.

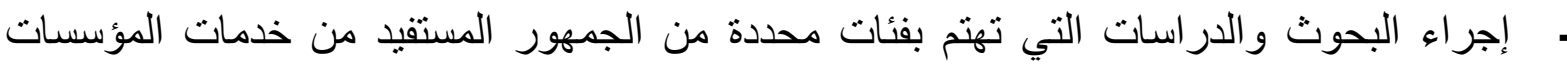

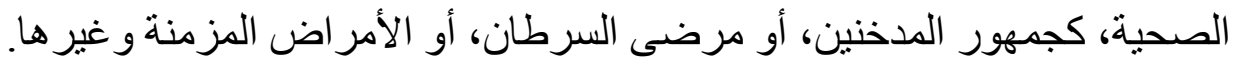

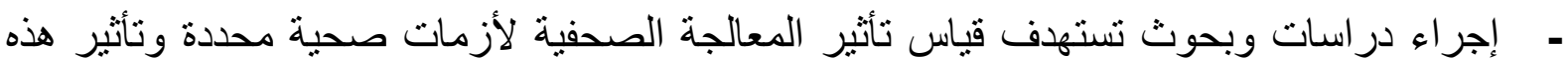
المعالجة على اتجاهات الر أب العام. تُبن

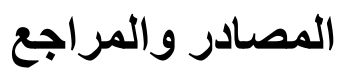

أولاً: المراجع العربية الكتب العربية:

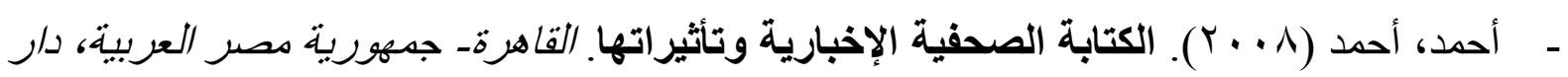

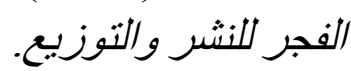

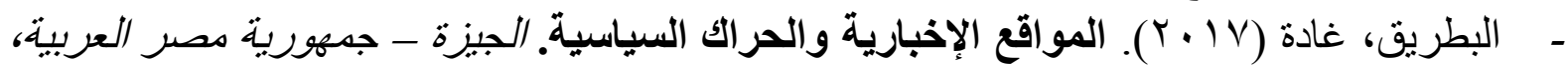

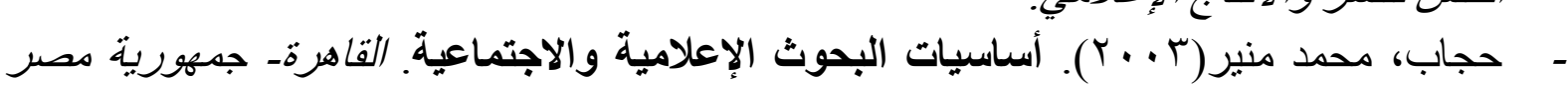

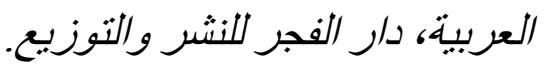
- حسين، سمير محمد(9V7 (1) ). بحوث الاعلام، الأسس والمبادئ. القاهرة - جمهورية مصر العربية، دار النشر للجامعات. 


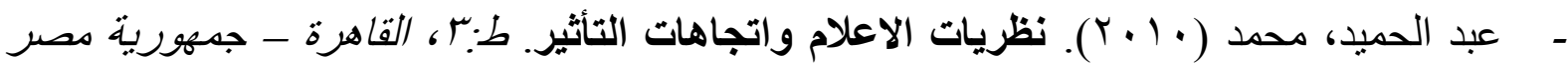

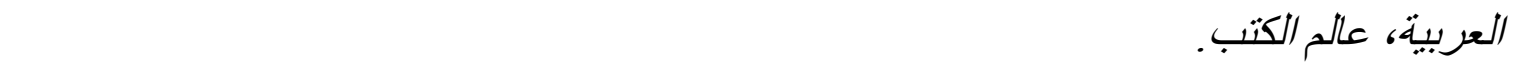

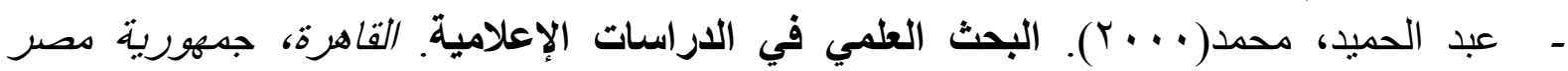
العربي، عالم الكتب.

- مكاوي، حسن/ و السيد، ليلى (r ( • r). الاتصال ونظرياته المعاصرة، طا ـ القاهرة- جمهورية مصر العربية، الدار الدصرية اللبنانية.

- Ahmed, Ahmad ( $\uparrow \cdots \wedge)$. News Journalism Writing and Its Effects. Cairo - Egypt, Dar AlFajr for Publishing and Distribution.

- AlBetrique, Ghada ( $r$ • $\vee$ ). News sites and political movement. Giza - Egypt, Atlas Publishing and Media Production.

- Hijab, Muhammad Mounir ( $r \ldots r)$. Fundamentals of Media and Social Research. Cairo Egypt, Dar Al-Fajr for Publishing and Distribution.

- Hussein, Samir Muhammad ( $19 \vee$ ४). Media research, foundations and principles. Cairo Egypt, Publishing Center of Universities.

- Abdul Hamid, Muhammad ( $\uparrow \cdot \cdot \cdot)$. Media theories and influence trends. $r$ rd Edition, Cairo - Egypt, The World of Books.

- Abdul Hamid, Muhammad ( ....). Scientific research in media studies. Cairo, Egypt, The World of Books.

- Makkawy, Hassan / and Al-Sayed, Leila ( $r+1 r)$. Communication and its contemporary theories, ' st Edition, Cairo - Egypt, The Egyptian Lebanese Publishing Centre.

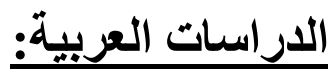

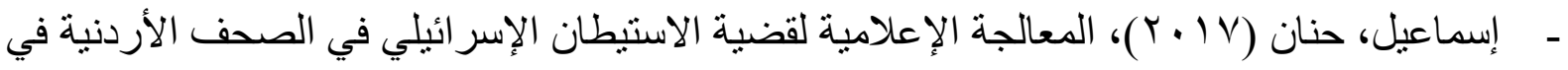

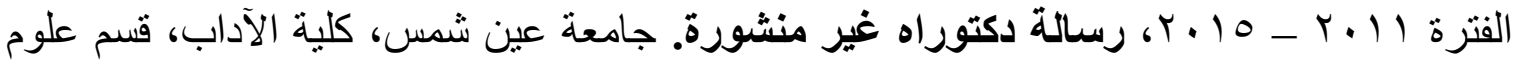

$$
\text { الاتصال والإعلام، جمهورية مصر العربية. }
$$

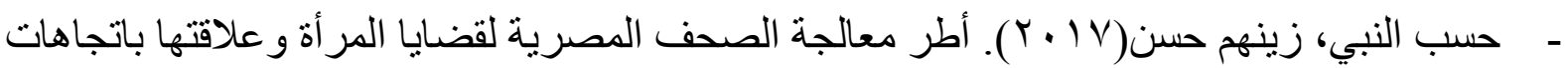
الثباب الجامعي نحو قضية التحرش الجنسي، رسالة دكتوراه غير منشورة. جامعة المنيا، كلية

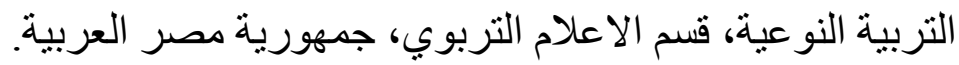

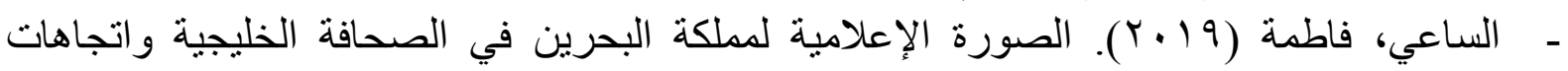
الصحفيين الخليجيين نحوها، رسالة ماجستير، جامعة البحرين، كلية الآداب، قسم الإعلام و السياحة و الفنون، مملكة البحرين.

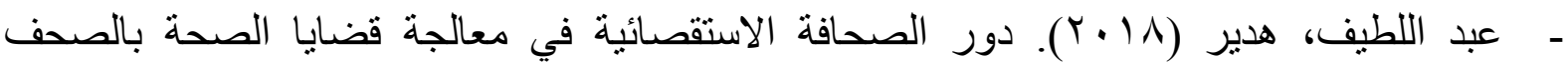
المصرية، رسالة ماجستير، جامعة القاهرة، كلية الاعلام، قسم الصحافة، جمهورية مصر العربية. 


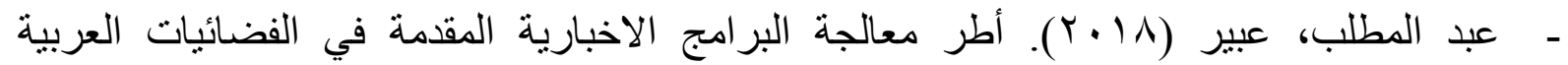

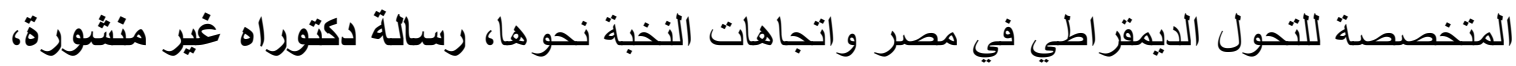
جامعة عين شمس، كلية الآداب، قسم علوم الاتصال والاعلام، جمهورية مصر العات العربية.

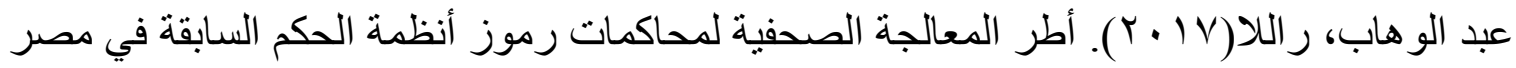
و علاقتها بتقييم الجمهور للأداء السياسي، رسالة دكتوراه غير منشورة، جامعة عين شمس، كلية الآداب، قسم علوم الاتصال و الاعلام، جمهورية مصرية لجهر العربية.

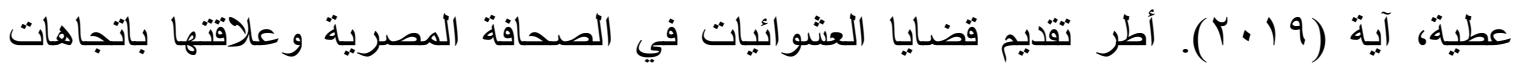
الجمهور نحو هذه القضايا، رسالة ماجستير، جامعة القاهرة، كلية الاعلام، قسم الصحافة، جمهورية مصر العربية.

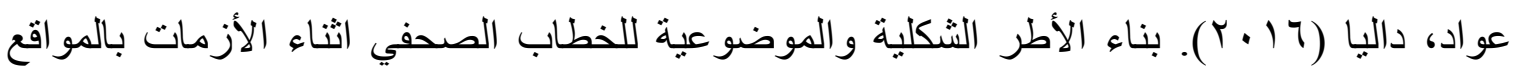

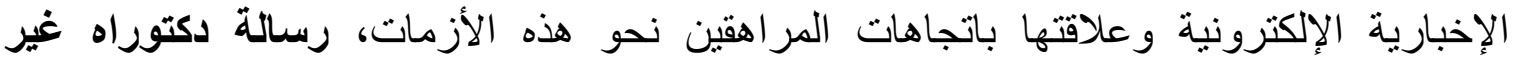

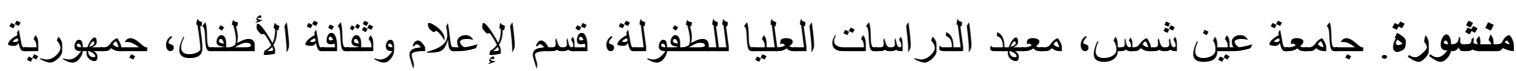

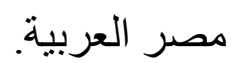
عوض، فدوى محمود (Y IV (Y). معالجة الصحافة الغربية الإلكترونية للقضايا المصرية واتجاهات

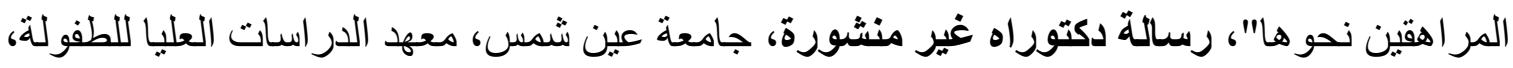

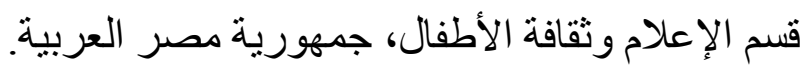
العوضي، منال محمد(Y V • Y ). أثر شبكات التو اصل الاجتماعي في تعامل الشباب مع وسائل الإعلام

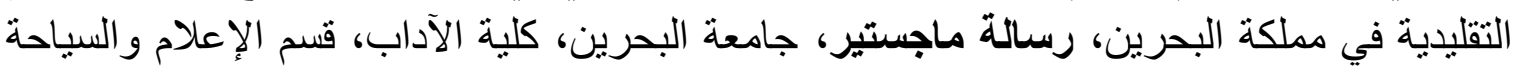
و الفنون، مملكة البحرين. محمد، غادة عطية (Y. V V). أطر معالجة المواقع الإخبارية والصحف الإلكثرونية للثائعات

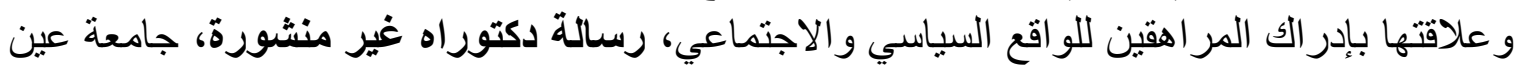

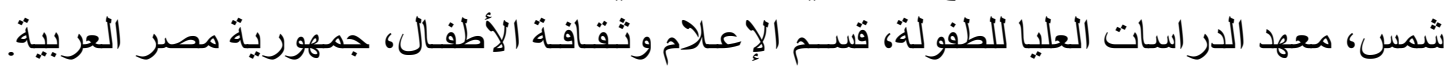

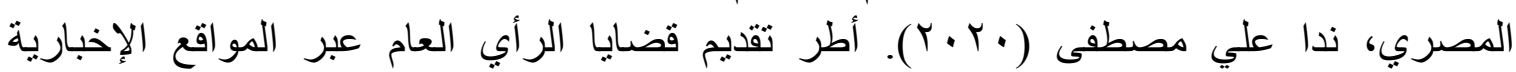

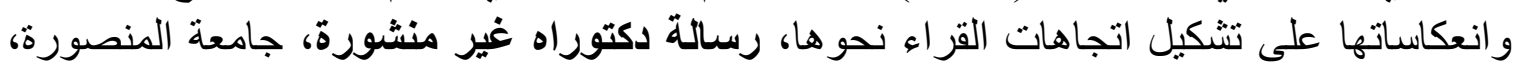
كلية الآداب، قسم الإعلام، جمهورية علئه مصر التهات العربية. المطيري، عادل حمدي (9 ( ب ( ). أطر المعالجة الإعلامية للقضايا السياسية المحلية في الصحافة الكويتية الإلكترونية واتجاهات الجمهور الكويتي نحوها، رسالة الكالة ماجستير، جامعة عين شمس، كلية

الآداب، جمهورية مصر العربية.

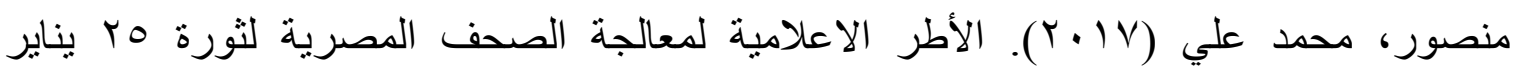
و عـلاقتها باتجاهات الجمهور نحو ها، رسالة دكتوراه غير منشورة، جامعة عين شمس، كلية التربية النوعية، قسم الاعلام، جمهورية مصر العربية.

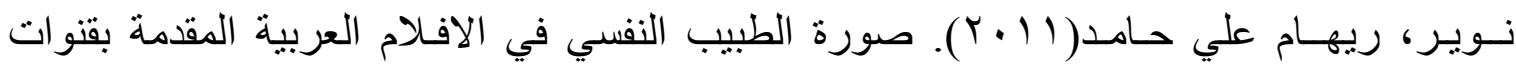
الأفلام و علاقتها بالصورة الذهنية، رسالة ماجستير، جامعة عين شمس، معهد الدراسات فلات العليا

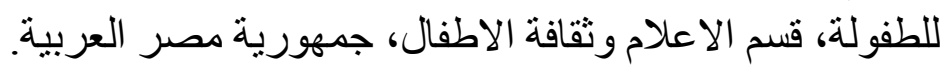


- Ismail, Hanan $(Y \cdot \mid \vee)$, Addressing The Israeli settlement issue in Jordanian newspapers r. 1 - $r \cdot 10$, unpublished PhD thesis. Ain Shams University, Faculty of Arts, Department of Communication and Information Sciences, Egypt.

- Hasab Elnabi, Zainhum ( $r \cdot$ \V), Frameworks of addressing Women Issues in Egyptian Newspapers' and their Relationship with Graduated Youth Attitudes Toward Sexual Harassment issue, Unpublished PhD Thesis. Minia University, Faculty of Specific Education, Department of Educational Media, Egypt.

- Al-Saiee, Fatima ( $(\cdot 19)$. The Media Image of the Kingdom of Bahrain in the Gulf Journalism and the Attitudes of Gulf Journalists Toward it, Master Thesis, University of Bahrain, College of Arts, Department of Media, Tourism and Arts, Bahrain.

- Abdul Latif, Hadeer $(\uparrow \cdot \mid \wedge)$, The Role of Investigative Journalism in Addressing Health Issues in Egyptian Newspapers, MA Thesis, Cairo University, Faculty of Information, Department of Journalism, Arab Republic of Egypt.

- Abdulmutallib, Abeer $(\uparrow \cdot \mid \wedge)$. Framing the democratic transition in Egypt in news programs presented in Arab specialized satellite channels and Elite attitudes towards it, unpublished $\mathrm{PhD}$ thesis, Ain Shams University, Faculty of Arts, Department of Communication and Media Sciences, Egypt

- Abdel Wahab, Ralla ( $(\cdot \mid \vee)$. Framing the trials of former Egyptian political leaders in Egypt and their relationship to the audience evaluation of political performance, unpublished $\mathrm{PhD}$ thesis, Ain Shams University, Faculty of Arts, Department of Communication and Media Sciences, Egypt.

- Attia, Aya $\left(r_{+} 9\right.$ ). Frameworks for presenting slums issues in the Egyptian press and their relationship to public attitudes towards these issues, MA thesis, Cairo University, College of Information, Department of Journalism, Egypt.

- Awad, Dalia ( $Y \cdot 17$ ). Building formal and objective frameworks for journalistic discourse during crises on electronic news sites and its relationship to adolescents' attitudes towards these crises, unpublished $\mathrm{PhD}$ thesis. Ain Shams University, Institute of Graduate Studies for Childhood, Department of Information and Children's Culture, Egypt.

- Awaad, Fadwa Mahmoud ( $(\cdot \mid \vee)$. tackling Addressing Egyptian issues in Western Electronic Journals and adolescents 'attitudes towards them," unpublished $\mathrm{PhD}$ thesis, Ain Shams University, Institute of Higher Studies for Childhood, Department of Media and Children's Culture, Egypt.

- Al-Awadi, Manal Muhammad ( $(\cdot \mid \vee)$. The Impact of Social Networking on Young People's Interactions with Traditional Media in the Kingdom of Bahrain, Master Thesis, University of Bahrain, College of Arts, Department of Media, Tourism and Arts, Bahrain.

- Mohamed, Ghada Attia ( $r \cdot$ I $\vee$ ). Frameworks of news websites and electronic newspapers of Rumors and their relationship to adolescents' perception of political and social reality, 
unpublished PhD thesis, Ain Shams University, Institute of Higher Studies for Childhood, Department of Information and Children's Culture, Egypt.

- Al-Masry, Nada Ali Mustafa $(Y \cdot Y \cdot)$. Frameworks of presenting public opinion issues through news websites and their implications on shaping readers 'attitudes towards them, unpublished PhD thesis, Mansoura University, College of Arts, Department of Media, Egypt.

- Al-Mutairi, Adel Hamdy ( $(\cdot 19)$. Frameworks domestic political issues in Kuwaiti electronic journalism and the attitudes of the Kuwaiti Public towards it, Master Thesis, Ain Shams University, Faculty of Arts, Egypt.

- Mansour, Muhammad Ali ( $Y \cdot \mid \vee)$. Media frameworks of Egyptian newspapers' for The January ro revolution and its relationship to public attitudes towards it, unpublished $\mathrm{PhD}$ thesis, Ain Shams University, Faculty of Specific Education, Department of Media, Egypt.

- Nwair, Reham Ali Hamed ( $r \cdot 11)$. The image of the psychiatrist in the Arab films presented in the film channels and its relationship to the mental image, a master's thesis, Ain Shams University, Institute of Higher Studies for Childhood, Department of Media and Children's Culture, Egypt.

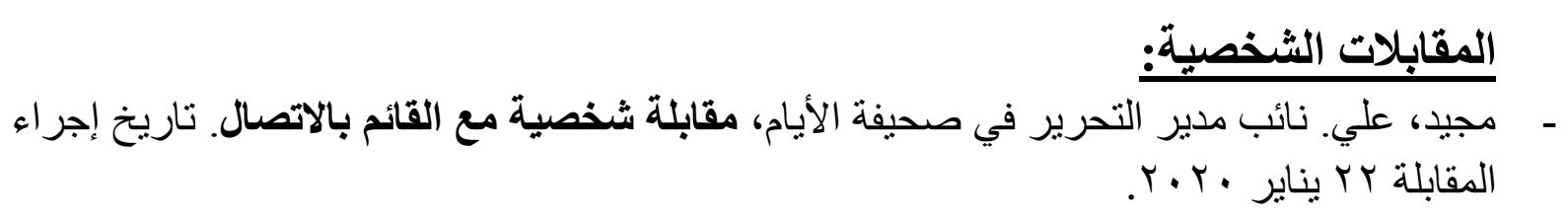

- Majeed, Ali. Deputy Editing Manager in Al-Ayyam Newspaper, Personal Interview with The Communicator. Interview date was on January $r$, $r \cdot r \cdot$.

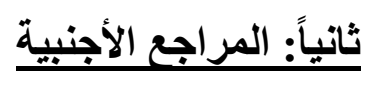

\section{$\underline{\text { References }}$}

- Akintola, Olagoke, and Others $\left(r \cdot{ }^{0}\right)$. Print media coverage of primary healthcare and related research evidence in South Africa. USA: The Open Access Publisher, BioMed Central.

- Chiang, Jonathan and Others $(Y \cdot Y \cdot)$. Geographic and Longitudinal Trends in Media Framing of Obesity in the United States. Washington: Obesity Research Journal.

- De Hoog, and Others ( $r / 9)$ : Is the news making us unhappy? The influence of daily news exposure on emotional states. (UK: British Journal of Psychology).

- Fredriksson, Mio and Others $(r, 1 \varepsilon)$. Regional media coverage influences the public's negative attitudes to policy implementation success in Sweden. UK: Health Expectation/ 
an international journal of public participation health care and health policy, John Wiley \& Sons Ltd.

- Isik, Oguz ( $(\cdot 17)$. Reflection of medical error highlighted on media in Turkey: A retrospective study. Pakistan: Pakistan Journal of Medical Sciences.

- Littlejohn, Stephen W. and Foss, Karen A. ( ${ }^{*}$. 9 ). Encyclopedia of Communication Theory. California: SAGE Publication, Inc,).

- Rachul, Christen and Caulfield, Timothy $\left.\left(r_{+}\right)^{0}\right)$. The media and access issues: content analysis of Canadian newspaper coverage of health policy decisions. USA: The Open Access Publisher, OJRD (Orphanet Journal Of Rare Disease, BioMed Central.

- Sun, Shaojing and Others $(Y \cdot 19)$. Chinese media coverage of eating disorders: Disorder representations and patient profiles. (Wiley Online Library, International Journal of Eating Disorder.

\title{
Bahraini Press Frameworks of Health Organizations Issues and it's Reflections on Publics Trends.
}

Fatema Khalil Aseeri

\author{
Media and Communication Sciences Department, Faculty of Arts, Ain \\ Shams University, Egypt
}

\begin{abstract}
The written Newspapers is one of the most important media upon which public people relies to obtain reliable information, which may affect their opinions toward the issues at hand, and the issues of Health Organizations are one of the most important issues raised in the press, as Health Organizations provide services directly related to humans life.

Therefore, the study problem can be articulated in the following question: What are the media frameworks of topics and issues related to Health Organizations in the Bahraini Press? In addition, what are their implications on Publics Trends?

To answer the previous question, the study relied on the media survey method, and used the content analysis tool to analyze the content of (Akhbar Al Khaleej) and (Alayam) Bahraini Newspapers, with a sample of $r$ r . Newspapers, and the questionnaire tool was used on a random sample of 0. individuals, the category of adults residing in the Kingdom of Bahrain.

The most important results concluded by the analytical study were that there is no apparent difference between the two Newspapers in terms of addressing Health Organizations Issues. As all Bahraini daily Newspapers follow the state's policy and has the same policy and that the trend of negative coverage of Health Organizations Issues is applied on (Public /
\end{abstract}


Governmental Health Organizations) only. While representing a completely positive image of (Private Health Organizations), the study has revealed that the most framework used in covering Health Organizations Issues is (The Liability Framework), while least concerned issues are (Medical Errors and Medical Negligence).

The most important results concluded from the field study were that the Bahraini public's exposed to the Bahraini Daily Newspapers is relatively low. However, the cognitive, emotional, and behavioral effects caused by exposure to health Organizations' issues through the Newspapers are high, and the news framework that was adopted the most by the survey's subjects was these in the (Human Interests framework). It was also proven that there were differences of statistical significance in the public's reviews towards frameworks of the Bahraini Newspapers' of Health Organizations Issues, due to demographic variables.

As it turns out that the Bahraini Public believes that the Bahraini Newspapers has contributed to enhancing its information and health behaviors, yet almost half of the public has some concerns about receiving treatment in some Health Organizations as a result of being exposed to the issues of Health Organizations issues shown in the Newspapers. It has also been proven that nearly a third of the public in the Kingdom of Bahrain is refraining from going to some Health Organizations due to their exposure to Health Organizations Issues through the Newspapers. The most prominent recommendations of the study were the necessity of balancing the negative and positive trends in discussing the issues of health institutions (public and private). Therefore exerting more attention towards the issues of medical errors and medical negligence in a way that addresses the problem completely and objectively without journalistic sensationalism that contributes to generate fear and stop the public from seeking treatment in Health Organizations.

Keywords: Press, Frameworks, Health Organizations, issues, Publics Trends 